(10) (a)

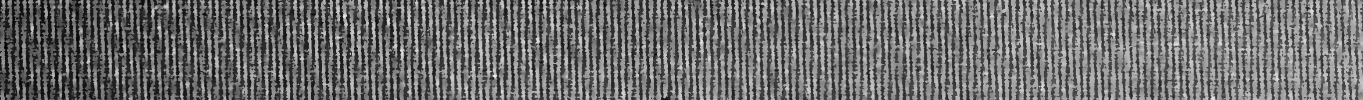
Wham

(I)
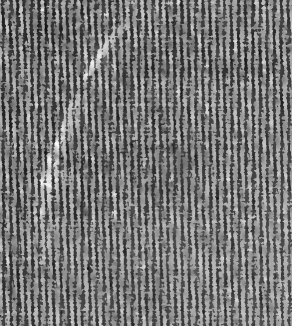

(I)

(1)

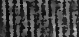

(I)

(1)

(3)

(1)

Halm

(1)
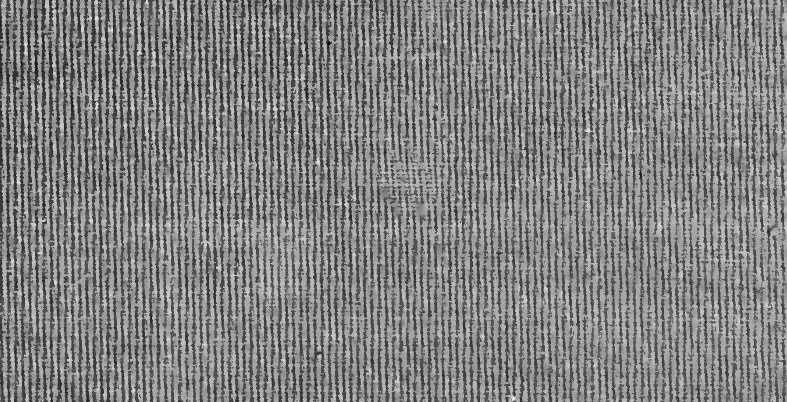

Wm

What

(I)

m) 

From the collection of the

$$
\begin{aligned}
& \text { - Prefinger }{ }^{2} \underbrace{\mathrm{m}}_{\text {ibrary }} \\
& \text { t } \\
& \text { p }
\end{aligned}
$$

San Francisco, California

2006 
$$
\text { . }
$$ 


\section{HOW TO USE THE EDUCATIONAL SOUND FILM}


THE UNIVERSITY OF CHICAGO PRESS, CHICAGO THE BAKER \& TAYLOR COMPANY, NEW YORK; THE CAMBRIDGE UNIVERSITY PRESS, LONDON; THE MARUZEN-KABUSHIKI-KAISHA, TOKYO, OSAKA, KYOTO, FUKUOKA, SENDAI; THE COMMERCIAL PRESS, LIMITED, SHANGHAI 


\title{
HOW TO USE THE EDUCATIONAL SOUND FILM
}

\author{
BY \\ M. R. BRUNSTETTER, Ph.D.
}

Director, Bureau of Publications, Teachers College, Columbia

University; formerly Research Associate, Erpi

Picture Consultants, Inc.

THE UNIVERSITY OF CHICAGO PRESS CHICAGO - ILLINOIS 
COPYRIGHT 1937 BY THE UNIVERSITY OF CHICAGO. ALL RIGHTS RESERVED. PUBLISHED JANUARY 1937. COMPOSED AND PRINTED BY THE UNIVERSITY OF CHICAGO PRESS, CHICAGO, ILLINOIS, U.S.A. 


\section{FOREWORD}

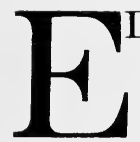

DUCATION is no longer the relatively simple and leisurely process of a century ago. The amount of human knowledge has increased beyond the learning capacity of any one person. No individual lifetime can span more than a small part of the accumulated wisdom of the world. To complicate the situation further, our funded knowledge is almost unlimited in its ramifications and implications and no one human mind has the necessary versatility to comprehend it all.

In the face of these conditions, the words "curriculum" and "method" become exceedingly significant and the educator must be constantly on the alert for more efficient teaching processes and more effective learning implements. With so much to be learned, time becomes of the essence. With the pattern of the modern world becoming increasingly complex and with the human mind constantly battering away at the ramparts of the infinite, the learner cannot spend his time muddling with details when he should be dealing with the overview, nor can he expect to comprehend the pattern of life unless he can trace its warp and woof, infinitely fine though they may be.

So it is that the schools must ever be devising better ways of teaching and learning, better instruments for translating vicarious experience as nearly as possible into reality. Sometimes the educator creates his own devices. Again, he adopts and adapts the discoveries and inventions of others. So it was with printing, with the radio, and with the talking picture.

The processes of education and the implementation of these processes usually develop slowly through evolution. That is, they are the result of the trial-and-error procedure 
rather than of careful experimentation and scientific study. It is heartening to know that the development of the utilization in the schools of this potent device, the educational talking picture, is not to be haphazard, but is to be accomplished through painstaking research in adapting the instrument to the objectives to be attained.

This book presents the story of an interesting attempt to avoid the utilization of the educational talking picture, some of the mistakes school administrators and teachers have made with other instructional devices in the past. It stresses the importance of the careful integration of the instrument with the curriculum. It shows the part that proper administrative procedures must play in the program of use. But the book will be especially helpful to the teachers who must use the device. It discusses the philosophy of the talking picture and the techniques of using the pictures and fitting them into a daily routine. It emphasizes the necessity of adapting the use of the talking picture to the different phases of the teaching process, such as presentation, drill, or review. Even more valuable, however, is the fact that the author has not presented a book of theory, but rather has described the results of actual experimentation and the conclusions formulated as a result of extensive utilization of educational talking pictures in a large number of actual classroom situations.

Ever since the dawn of civilization man has been attempting to discover or devise more effective means and methods of acquiring and transmitting knowledge and skills. But always there have been limitations of one kind or another. The struggle has been the conquest of these limitations. The coming of the educational talking picture represents one of the greatest forward steps. It expands enormously the possibilities of the words "teach" and "learn." It is one problem to provide the right kind of educational talking pictures. It is another problem, and one which is equally important, to provide for their proper utilization in the educational process. 
This book ought to go a long way toward preventing many years of wasteful floundering in an attempt to integrate the use of the talking picture with the school program. If it does so, it will rank as a major contribution to our educational literature.

Alexander J. Stoddard

Superintendent of Schools, Providence, R.I. 


\section{PREFACE}

HIS volume discusses the utilization of a new type of instructional material-the educational sound film. It lists and illustrates techniques for placing the film into effective service in the classroom. The whole emphasis is upon the problem of how to use the sound film, a problem which hitherto has largely been neglected.

Any program for the use of materials of instruction involves administration, supervision, and the teaching process itself. This book, therefore, is addressed to teachers, principals, supervisors, and superintendents of schools as a practical guide to the initiation and development of a local program of audio-visual instruction. Administrators will be especially concerned with the chapters describing the organization of audio-visual aids, while teachers will find the chapters illustrating methods of instruction with sound films of particular interest.

The procedures suggested here are based upon extended experience in studying teachers' use of sound films and in helping to organize programs of audio-visual instruction in school systems. An important source of material was a study of sound-film use conducted by the author in 1935. A group of different sizes and types of schools and school systems, so selected as to furnish a cross-section of the educational field, participated in an extended experimental program set up to discover effective teaching and administrative procedures. Certain programs adopted by local school systems organizing the use of audio-visual aids have been utilized as another source of reference.

The recommendations and suggestions given here are not to be regarded as final or all-conclusive. The efficient use of the sound film in education, as with the expansion and re- 
vision of the curriculum, must necessarily be a process of experimentation and evolution. It is hoped, however, that the procedures described will be helpful in obviating certain administrative difficulties and in stimulating creative teaching.

To some readers, the analysis of film-teaching techniques and administrative functions may seem unduly complex and burdensome. This conclusion is particularly apt to be reached by those who hitherto have been accustomed to think of the motion picture as an incidental or extraneous feature of teaching. But the whole art of teaching is in itself complexnot to be mastered without detailed study, creative thought, and practice. The writer believes that those who take the trouble to analyze the place of the film in the learning process and to devise procedures for adapting the sound film to their problems of instruction will be amply repaid.

M. R. Brunstetter 


\section{ACKNOWLEDGMENTS}

7 THE many teachers of the experimental study whose work with educational sound films is presented here

1 the author desires to express his gratitude. The following individuals gave generously of their time and effort in directing and reporting the film programs developed in their schools: E. Winifred Crawford, director of visual education, Montclair, New Jersey; S. J. Smith, assistant superintendent of schools, and Dr. Elsie F. Neuner, supervisor of elementary science, New Rochelle, New York; Dr. W. D. Kuhlmann, principal, and F. M. Worrell, director of visual education, Englewood Junior High School, Englewood, New Jersey; Mortimer L. Simpson, principal, and Mary S. Casey, assistant principal, Public School 170, New York City; John C. Parker, director of curriculum, Forth Worth, Texas; W. W. Evans, county superintendent of schools, Bloomsburg, Pennsylvania; Vernon G. Smith, superintendent of schools, and Roberta Oliphant, teacher in the Greenacres School, Scarsdale, New York; John G. Cornwall, dean of Dickinson Junior College, Williamsport, Pennsylvania; George A. Walton, principal of George School, George School, Pennsylvania; Professor J. H. Brownback, Ursinus College, Collegeville, Pennsylvania; G. V. Bruce, instructor in science, New Jersey State Normal School, Newark, New Jersey; and Dr. L. H. Westfall, supervising principal, South Glens Falls, New York.

The co-operation of the Victor Animatograph Corporation and the Bell and Howell Company, who supplied the soundfilm projectors used in the various study centers, is gratefully acknowledged. The films for each school library were provided by Erpi Picture Consultants, Incorporated. 
The author wishes to express his appreciation to Frederick L. Devereux, vice-president of Erpi Picture Consultants, Incorporated, who made possible the experimentation of which this book is an outgrowth. For critical reading of the manuscript and valuable suggestions the writer is indebted to Dr. N. L. Engelhardt and Dr. Paul R. Mort of Teachers College, Columbia University, and to Dr. V. C. Arnspiger, director of research and production, Erpi Picture Consultants, Incorporated.

Special thanks are due to Dr. Melvin Brodshaug for permission to include the material presented in Appendix II, and to Dr. Laura K. Eads for assistance in field supervision. 


\section{CONTENTS}

CHAPTER PAGE

I. Sound-Film Materials of Instruction ․ . . . . . $\quad 1$

II. Teaching Purposes for Which the Sound Film May Be UsED . . . . . . . . . . . . . . . . . 11

III. Techniques of Teaching with Sound Films . . . . . 42

IV. Organizing an Audio-visual Instruction Program . . $\quad 73$

V. How 'To 'Train 'Teachers in the Use of Sound Films 96

VI. Mechanical and Routine Aspects of Sound-Film Use . $\quad 114$

APPENDIXES

I. Outline of a Typical Unit Taught with a Sound Film . 142

II. The Integration of Sound Films with Elementary-School

Science. By Melvin Brodshaug, Ph.D. . . . . . . 151

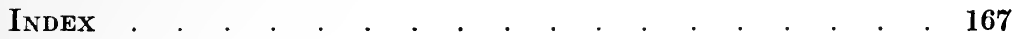





\section{CHAP'TER I \\ SOUND-FILM MATERIALS OF INSTRUCTION}

$\eta$ HE modern dynamic conception of learning has forced the instructor to relinquish the rôle of one who merely teacher, and listening and reading by the student, no longer suffice as the sole means of acquiring information. The use of the classroom as a laboratory of learning, in which the student participates in a wealth of interesting, fruitful experiences, illustrates the trend toward capitalizing the learner's initiative. In the classroom laboratory, materials of instruction are destined to play an increasingly important part, since they facilitate pupil experiencing and provide sources of information which the pupil may tap.

Classroom instruction has traditionally been handicapped by limitations of time, of space, of reality. Consider the difficulties of teaching facts and appreciations about a foreign country, for example. In lieu of an extended tour of the country, one or two weeks are devoted to reading, discussion, writing, collecting and studying pictures, drawing, and like activities. The absence of first-hand contact with the subject matter being studied, the shortness of the time available for the project, offer serious obstacles to accurate perception. If the child is to develop a real understanding of the country the working tools of the classroom-textbooks, maps, charts, globes, models, motion pictures, the radio, the phonographmust be analyzed for their contribution to the topic, carefully selected, and skilfully utilized in creating a stimulating, realistic learning situation. It is particularly important to plan for the development of those concepts and appreciations 
which cannot be adequately expressed in words, either spoken or written.

The importance of the selection and use of instructional materials has been recognized in the recent studies of educational groups. In the Eighth Yearbook of the Department of Supervisors and Directors of Instruction, a committee reporting on this challenging problem orients the relationship of materials of instruction to education by stating:

The program of the school is conceived as made up of those experiences of children which are shaped, guided, utilized, or afforded by the school, and materials of instruction are defined as those means to such experiencing which children and teacher together employ. ${ }^{1}$

The chairman of the reporting committee suggests a broad classification for aids to learning:

1. Materials used in arriving at knowledge or understanding

a) Materials involved in or contributing to first-hand experience

b) Materials for indirect, second-hand, or vicarious experiencing

2. Materials for appropriation or utilization of the cultural heritage of the past

3. Materials for the expression of ideas, interests, feelings, or purposes

4. Materials employed in developing skills of communication

The wealth of material available to the modern teacher is illustrated by the variety of devices and aids discussed in the report: experiences, environmental materials and resources; visual aids, such as pictures (still pictures, slides, silent films, and sound films), specimens, models, and field trips; textbooks and workbooks; bulletins, pamphlets, catalogues, magazines, papers, posters, maps, charts, prints, and pictures; tapestries and wall hangings; exhibits, properties, and costumes; programs, reviews of plays, and biographical sketches; mimeographed units of work and teacher-andpupil-made helps; annotated bibliographies of source materials and of available illustrative materials. ${ }^{2}$

${ }^{1}$ Eighth Yearbook of the Department of Supervisors and Directors of Instruction of the National Education Association: Materials of Instruction. (New York: Bureau of Publications, Teachers College, Columbia University, 1935), p. 1.

${ }^{2}$ See also the Thirteenth Yearbook of the Department of Elementary School Principals: Aids to Teaching in the Elementary School (Washington, D.C., 1934). 
The educational sound film has taken its place among modern materials of instruction. Researches ${ }^{3}$ have clearly established its potential effectiveness as an aid to learning. But the school's adoption of the sound film should be accompanied by the realization that this device, like any other tool, functions best under proper working conditions and in the hands of a skilful user. The contribution of the older visual aids in many cases has been minimized by the failure to understand and to organize their use. The study of the sound film as material of instruction involves understanding the character of the film medium, the function it may assume in the learning process, and the responsibilities of the teacher and the administrator in developing its use in the local school system.

\section{THE NATURE OF THE EDUCATIONAL SOUND FILM}

The sound film is a device for presenting objects, incidents, events, or ideas in a simultaneous appeal to sight and hearing. The unity of the impression received through these two senses results in a close approximation of reality, a significant asset for the teaching process. The sound film goes beyond the earlier visual aids in combining depicted motion with its accompanying sound, although inanimate objects, ideas, and subjects not in themselves involving sound may also be presented to advantage.

Another important characteristic of the sound-film medium is continuity of thought. Scenes and sequences are linked together for the orderly exposition of ideas or the chronological development of narration. This means that the edu-

${ }^{3}$ The following monographs report experiments evaluating the educational sound film:

V. C. Arnspiger, Measuring the Effectiveness of Sound Pictures as Teaching Aids (New York: Bureau of Publications, Teachers College, Columbia University, 1933).

Phillip J. Rulon, Sound Motion Picture in Science Teaching (Cambridge, Mass.: Harvard University Press, 1933).

L. H. Westfall, A Study of Verbal Accompaniments to Educational Motion Pictures (New York: Bureau of Publications, Teachers College, Columbia University, 1934). 
cational sound film may be prepared to present a carefully controlled experience, an experience which the teacher may adapt to the immediate needs and interests of the students.

The apparent simplicity of a sound film hides from the observer the variety and complexity of the cinematographic techniques which entered into its production. In addition to natural photography there is time-lapse photography, which depicts in a few seconds action ordinarily taking place in hours, days, weeks, or months. Slow-motion photography serves the reverse purpose, presenting action normally too rapid for detailed study. Microcinematography reveals otherwise hidden activity.

Animated drawings and diagrams-skeleton outlines in motion-explain obscure processes. Double exposure, composites, and parallel pictures on a divided screen are useful for comparison and contrast. The mobility of the camera takes the observer to advantageous positions for study, through long shots, close-ups, unusual angles, panning shots, and the like. 'Titles, word labels, and moving arrows may be employed to focus attention upon specific details. The sound component of the film is equally versatile: natural sound, representation of important sound only, sound effects, dynamic interpretations. All of these facilities make it possible to bring to the classroom materials which otherwise could not be presented by the teacher as effectively, as quickly, or as inexpensively.

Apart from these general characteristics of the sound-film medium, what educational qualities are embodied in a good teaching film? It is not pertinent to describe here the process of producing an educational sound film. ${ }^{4}$ However, those using sound films should have some idea of the educational foundation upon which the classroom film should be built. In the first place, a film which is worth while for instructional

${ }^{4}$ An interesting account of the production of instructional sound films is given by Frederick L. Devereux, and others, The Educational Talking Picture, chaps. ii and iii (Chicago: University of Chicago Press, 1935). 


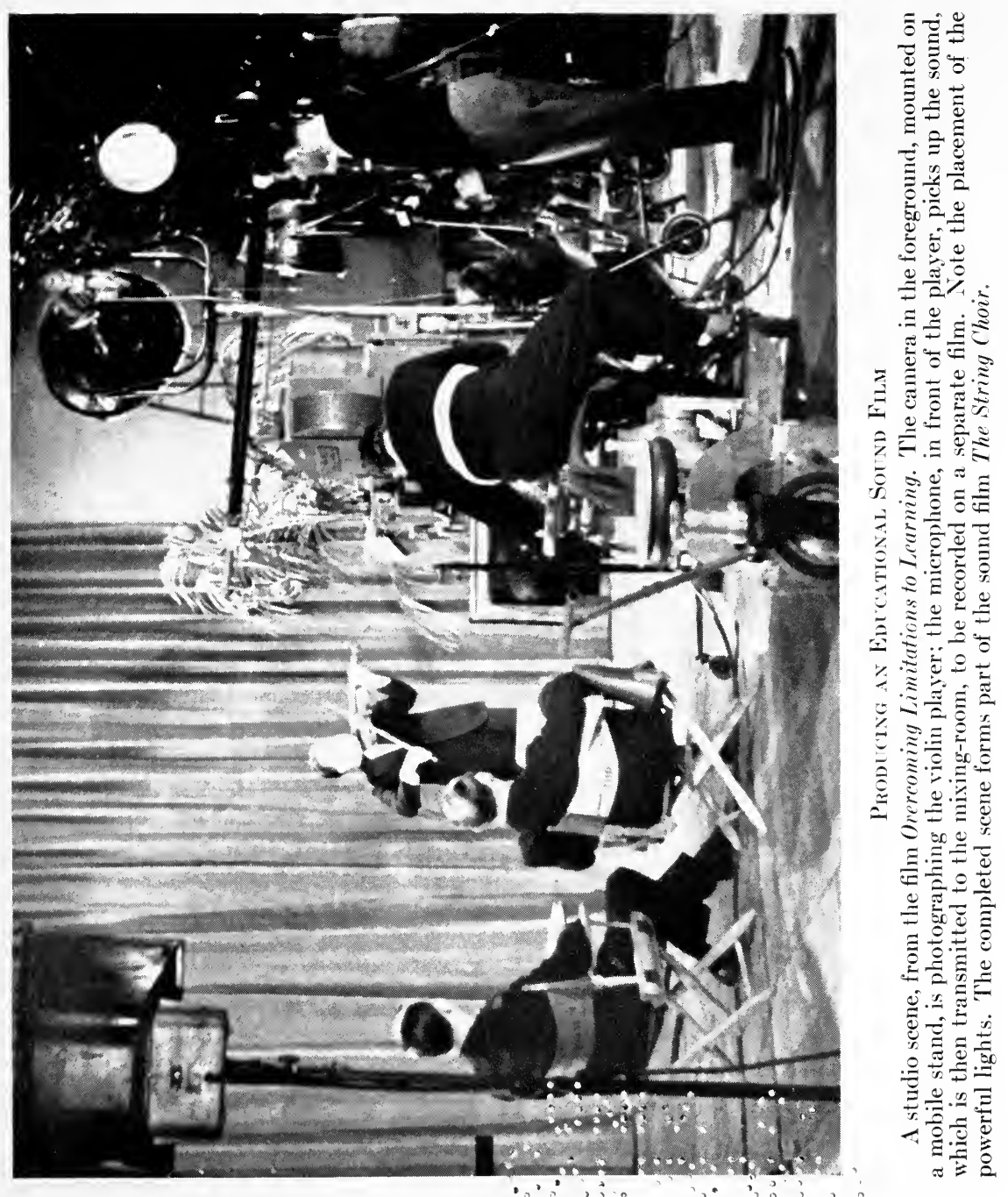




$$
\begin{gathered}
2 . \\
\cdots, \cdots \\
\cdots
\end{gathered}
$$


purposes must be directly integrated with the curriculum. Just as the textbook is expected to be basic in the course for which it is intended, so a school film should be immediately applicable to the important concepts and objectives of courses of study. This does not deny the usefulness of films which highlight related areas, such as films which show the application of the principles of chemistry and physics in modern industry, or those feature pictures which have an authentic historical background.

In the second place, a superior school film will exhibit the application of valid educational methods in its construction. ${ }^{5}$ For example, picture elements will be logically organized in terms of desirable objectives; the language, length of scene, and style of treatment will be suited to the interest and understanding of particular grade levels; there will be adequate repetition and summarization; non-essential or extraneous elements will be avoided. The sound film should be limited to those elements of subject matter which it is best qualified to present. Its value is enhanced when it is accompanied by printed supplementary material in the form of a unit of instruction or study guide. Adherence to such standards in the production of a film makes possible its effective utilization by the teacher.

THE FUNCTION OF THE SOUND FILM IN THE

\section{LEARNING PROCESS}

The art of teaching with the sound film involves also an understanding of the part which the film showing plays in the learning process. What can it contribute? What can it not contribute? How does it assist the pupil in his learning? Does its use obviate that of other materials of instruction?

The major function of the educational sound film is that of presenting information. But merely observing a film does not constitute or provide the entire learning which is to be ex-

${ }^{5}$ Devereux discusses standards governing educational sound films, and includes a check list for evaluating films. See Devereux, op. cit., pp. 39-57, 204-10. 
pected. The most frequent source of error in the use-or rather, misuse- of films has been occasioned by the failure to recognize this fact. From the film showing the student receives a host of impressions, gains some understandings, is stimulated to learn more. But the extension and completion of his learning comes about as he thinks over, discusses, tests, verifies, and explores that which the film has presented. This means that not only should the showing of the film be introduced from a challenging angle, but that subsequent learning activities tied up with the film should be initiated. It is precisely this most important step-that of placing the film in a dynamic learning situation-that has so often been overlooked.

Let us suppose that a student is about to observe for the first time a sound film which deals with some of the principles of physics - the phenomena of magnetism, for example. The instructor has paved the way for the showing by recalling familiar examples of magnetic forces and by suggesting leading questions which focus attention upon particular sequences or ideas in the picture. As the student observes the film his mind is busy in a number of ways - recognizing that which his previous experience and the teacher's introduction have made familiar, interpreting it in its new context, confronting new problems, seizing upon details which challenge his interest, getting partial understandings of new concepts, perhaps even complete understanding of some new idea. His observation of the film at this stage is very largely a process of enriching and extending knowledge previously acquired, of partial interpretation of new concepts, and of orienting the study he is about to undertake.

After the initial showing of the film he engages in discussions, reading, experiments, and demonstrations. In subsequent showings of the film his mental activity becomes more and more that of complete integration of the concepts which he has been studying. By reason of the first showing, and the intervening study activities, the student gets more out of the 
repeated showing, consolidating his learning and gaining new appreciations of the pictured material.

This discussion may be summarized in the statement that the use of the sound film should be one link in a chain of learning activities. The sound film's functions are to present information, to mold attitudes and appreciations, to stimulate interest. It is not a mechanized substitute for the assimilation of ideas and the formulation of new concepts which take place in the mind of the learner.

The use of the sound film as part of the total learning experience suggests its relation to other materials of instruction. The sound film is complementary to, and not exclusive of, other materials and activities of instruction. Each type of instructional material or activity has its own contribution to make to the pupil's learning, and the skilful teacher knows when and how to utilize each. If detailed study of some concept is required, it may be advantageous to refer to a textbook, a map, or a chart. If clarification is needed for some idea which cannot be vividly and concisely expressed in words or in still pictures, then the film should be utilized.

Another aspect of sound-film use merits attention in this connection-the need for training students in the techniques of learning from the sound-film medium. Simply because this new device presents objects and events in natural sight and sound-an approximation of reality which does not require the intermediate stages of recognizing printed symbols and interpreting the mental images they call forth-it cannot be taken for granted that every learner will absorb the subject matter of the film quickly, accurately, and with the proper organization. It is, of course, obvious that almost anyone can get a great deal from a talking-picture presentation, particularly if the material depicted is so chosen and arranged as to fall at least partially within the range of his experience. But not to train the child in understanding the language of the sound film would be to limit the ultimate possibilities for rapidity, accuracy, and richness of learning. 
What factors are involved in learning from sound films? The student should, of course, be familiar with the use made of such devices as time-lapse photography, slow-motion photography, and microphotography. An important learning skill to be developed is the ability to study the picture from a predetermined perspective. For example, a teacher using the film The Development of Transportation may stress the territorial expansion of the United States and the part which transportation devices have played in the various stages of our country's growth. Or he may point out the various barriers to travel, as a means of enriching the class study of the local environment and transportation facilities. Again, he may be using the talking picture as a means of stimulating improvement in oral composition, calling attention to the language and inflection of the speaker in describing the synchronized picture. In each case the student is to concentrate upon the aspect of the film, throughout the whole picture, which is pertinent to the purposes of the day's lesson.

Another technique in learning from talking pictures is that of observation. Anyone who has asked several individuals to describe the contents of a store window, the appearance of a stranger, or an exciting episode, has been struck by the common failure to notice many important details. The student must learn to follow and retain the pictured continuity of thought. This same requirement applies to the recorded sound of the film, whether it be natural sound or a synchronized interpretation.

THE TEACHER AND THE SOUND FILM

One of the best definitions of teaching is that it consists of placing the student in situations out of which the desired learning grows. In creating this learning environment the teacher has to consider the child, the objectives, the subject matter, and the devices which will constitute the learning activities.

It is frequently assumed that because the sound film is a 


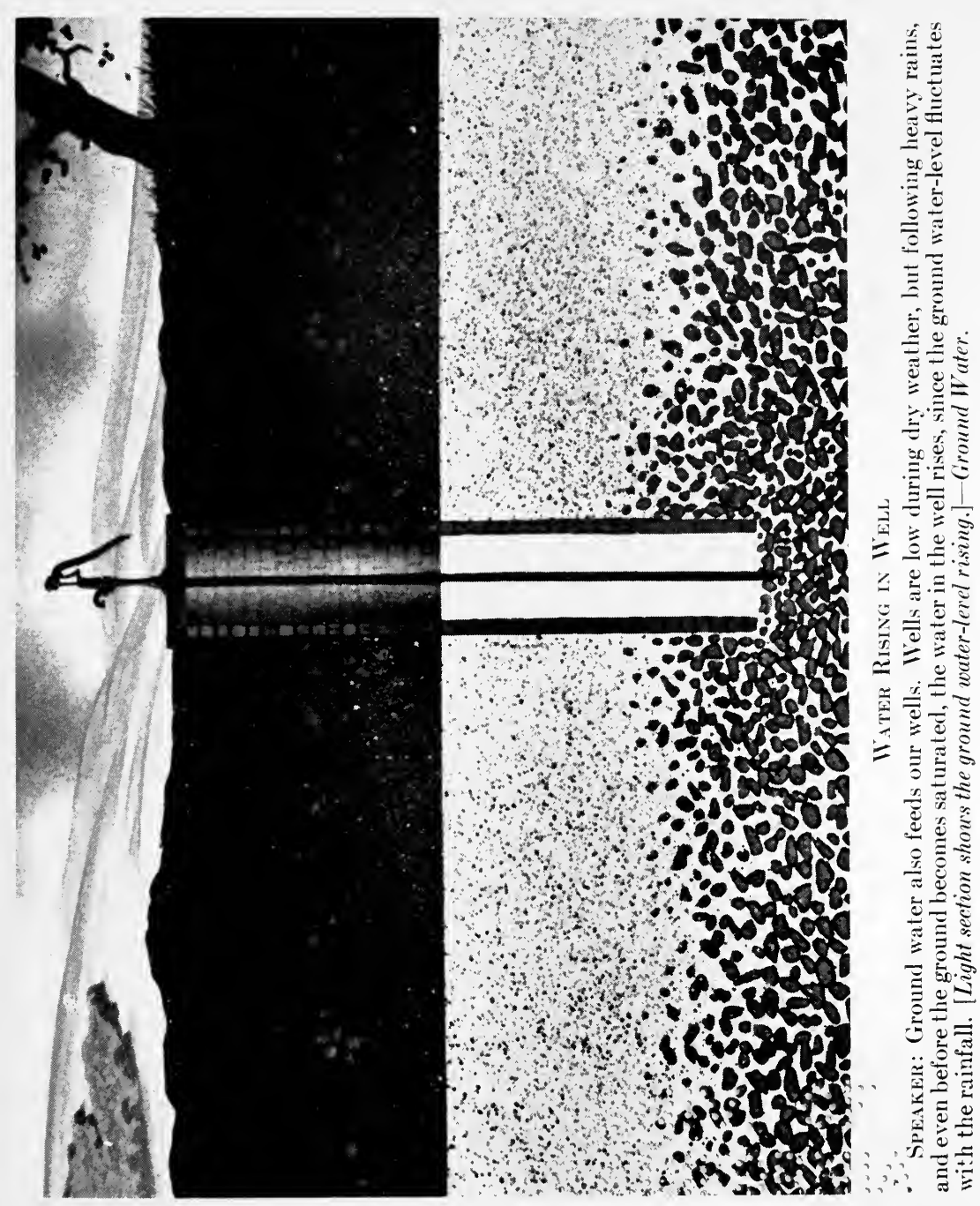




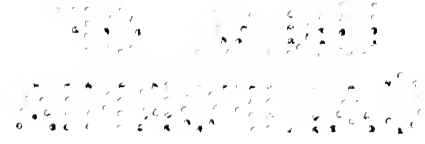


clear and stimulating medium for presenting information, no particular techniques are needed for its use. Nothing could be farther from the truth, or could so surely minimize the potential usefulness of the film. It is not enough simply to see that the film is threaded, the classroom darkened, and the projector motor started. The use of the educational sound film can be merely an interesting experience limited to a few minutes and then forgotten, or it may be made the point of departure for exploring an enlarging area of subject matter. There is an urgent need for teachers to study carefully the means of utilizing the sound film to the best advantage in their classroom procedure.

How can the teacher become skilful in the use of the sound film? The first essential is to study the sound film as a medium of instruction. The second step is to learn the basic principles of film teaching - the different instructional purposes which the film may legitimately serve and the techniques for achieving those purposes. The third step is that of experimentation-devising and testing different methods and new applications. Professional growth along these lines will result in skill which takes full advantage of the sound film's possibilities.

The discussion has made clearly evident the fact that the film medium needs the teacher quite as much as the teacher needs the film. It is the teacher who makes the adjustment between the sound and screen representation of subject matter and the learning needs and interests of the students. It is the teacher who individualizes each use of an otherwise standardized device.

THE SCHOOL ADMINISTRATOR AND THE SOUND FILM

The administrator's concern with the use of audio-visual materials of instruction in the schools is that of establishing favorable conditions for their application. Perhaps the best way of describing his problem is to say that the use of sound films and other devices for teaching should be planned at the 


\section{HOW TO USE THE EDUCATIONAL SOUND FILM}

outset as a program. The various elements which enter into audio-visual instruction should be studied in terms of local needs and facilities, and organized so as to insure the greatest educational values.

A program for the use of sound films involves analysis of the local courses of study to discover the topics and objectives with which available film materials are integrated. Standards must be set up to govern the selection and purchase of suitable films, so that funds will not be wasted upon film subjects which will be used once and then shelved. Teachers must be trained in skilful teaching techniques. In addition, the school system which approaches seriously the problem of securing the most effective use of the sound film will perfect an administrative routine which places selected films in the classroom at the desired time, with a minimum of interruption to the teacher and the class. This aspect of the administration of a program of audio-visual instruction entails the selection of suitable projection equipment, the adaptation of certain classrooms and auditoriums for the showing of sound films, the training of operators, and the proper distribution, storage, and care of equipment and films.

The planned approach to the use of audio-visual materials of instruction is significant in several respects: first, it is a program, outlined in attainable steps to reach certain goals; second, it studies the use of these devices from a professional point of view, that of furthering educational opportunities; third, it enlists the participation of all members of the local staff rather than of a few teachers who happen to be interested in film instruction; fourth, the comprehensive attack upon all phases of the problem insures the maximum educational return from the investment in instructional materials. 


\section{CHAPTER II}

\section{TEACHING PURPOSES FOR WHICH THE SOUND FILM MAY BE USED}

\section{T}

HE fundamental consideration in judging a program of talking-picture use is how well the films are made to function in the classroom. Administrative procedures, such as the routine of film distribution or the training of operators, are simply preliminary service arrangements to place at the teacher's disposal the motive power of the film. The techniques which the teacher employs in integrating the use of the sound film with the other instructional activities of the classroom determine to a large extent how much the students are going to get out of the film experience. On the one hand is a vivid contact with life, wrapped up in a few hundred feet of celluloid; on the other hand is the student, brimming with curiosities awaiting release. Between them stands the teacher, whose daily living with the group has equipped him to create a unique learning situation with the film, a situation stimulating to every individual in the class. Teaching with films is not a matter of showing a picture to thirty or forty passive young observers and hoping that it has done its work; teaching with films is dynamic, interpretative, exploratory.

The sound film invites the best efforts of the teacher who is not content with routine methods, who is constantly seeking new and better ways of meeting teaching problems. The challenge to the creative teacher appears not only in the sound film's clear and vivid presentation but in its flexibility of use which permits the accompanying learning activities of the group to be guided in almost any direction. Conspicuous evidence of this fact has been revealed in the variety of ap- 
proaches and activities originated by different teachers in the same grade using the same film.

It must not be supposed that the educational talking picture is a labor-saving device for the teacher. One principal has remarked:

It cannot be said that the talking picture will make the teacher's task less strenuous. To present the facts in Nature, in Geography, in Science and in Music, she has to work harder because she has to preview, organize material, prepare her questions, get ready for her summary. It is more difficult than teaching from the book. By the time she has prepared a lesson like "The Work of Running Water" she has learned so many facts from both the picture and the sound that she has to have outlined a very definite plan of attack for the unit. All this we think makes for better teaching. ....

\section{PLANNING THE USE OF THE FILM}

A teacher who has studied and experimented with audiovisual materials of instruction will undoubtedly have acquired certain fundamental attitudes toward the way in which these devices may be brought to bear upon his teaching problems. Most important of all is the idea that the film is a tool rather than a toy, and this means that the teacher will be concerned with planning for its proper use in the particular lesson or series of lessons in which it is to assist. Many untrained teachers mistake the educational talking picture for an entertainment experience, a diversion to be scheduled as a pleasant interlude in the familiar routine. This attitude has probably carried over from film theatergoing habits. Another common failing is that of relying upon the picture to do all the teaching; the film is shown but nothing is done about it, either before or afterward. There is a familiar analogy here in the traditional attitude of the teacher who saw his only function as that of giving text assignments and quizzing. Lack of teaching skill with the printed word has found its counterpart in the misuse of the motion picture in the classroom.

The preparation which the skilful teacher makes for the use of the film involves some careful thinking. "What are 


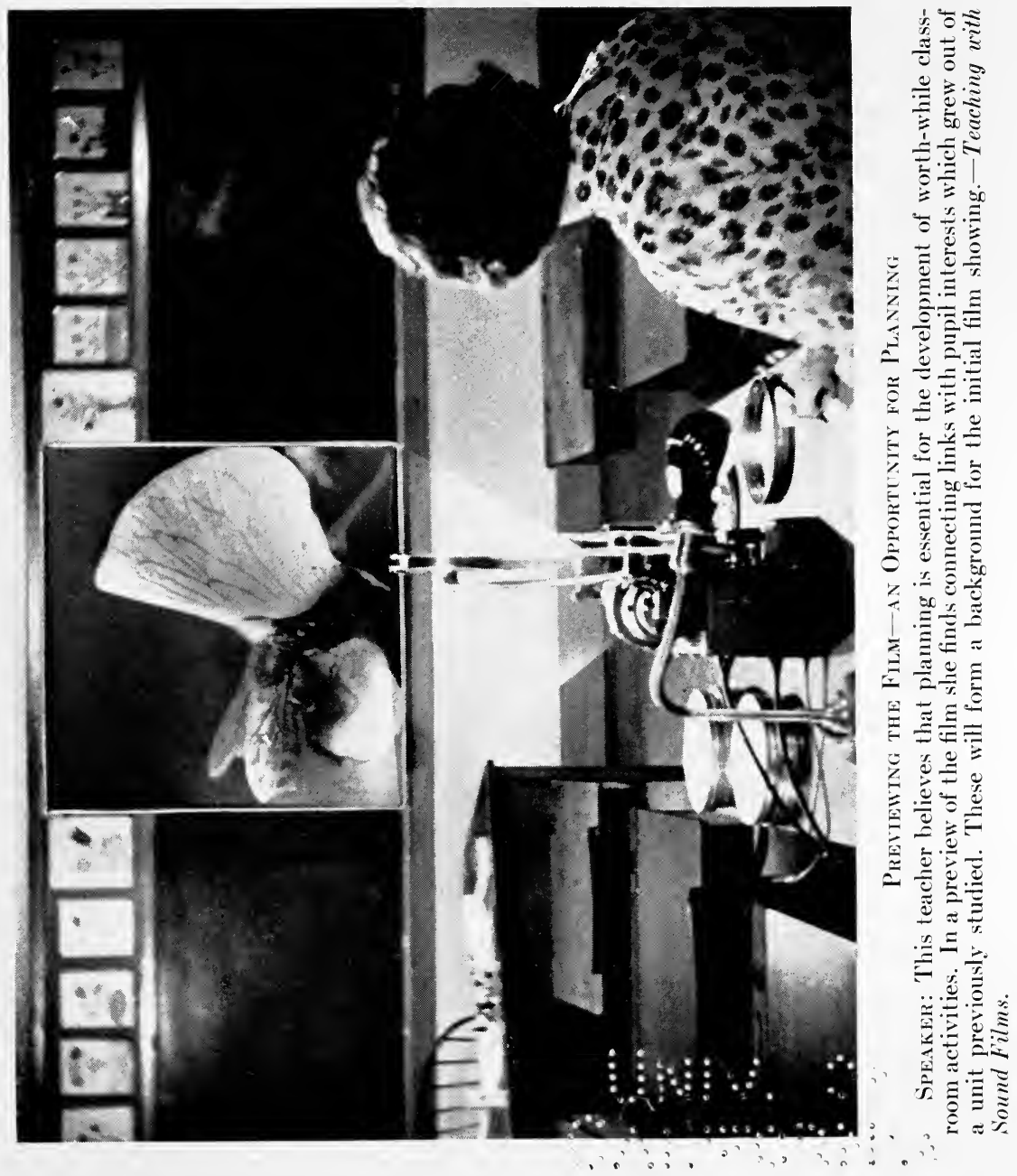




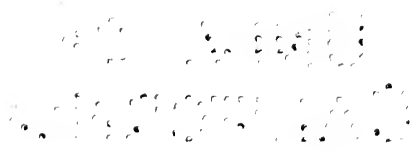


the objectives of the unit?" "Which sound film will be most helpful in achieving these purposes?" "How well do I know this particular film?" "What supplementary printed materials are available to help me in its use?" "At what point in the unit shall I introduce the film?" "What do I expect it to accomplish at that point?" "What activities and projects might be started as an outgrowth of the first showing?" "How many times shall I use the film, and for what purposes?" These are some of the questions which guide the teacher's preparation. Of course, considerable leeway must be allowed for changes dictated by shifts of interest-opportunities which the alert teacher is always quick to capitalize.

Day-by-day planning, as well as the long-range, preliminary outlining of the approach, is also an essential if the unit is to proceed steadily toward its objectives. Note the careful preparation and teacher planning which took place for the daily sessions of this auditorium class:

With one teacher in charge of a group ranging from one hundred and fifty to two hundred and twenty-five pupils, the program for each period must proceed without pause or interruption or the attention of the pupils is distracted and problems of discipline result. For this reason, far more planning was required than for the usual class period.

In preparing for the Tuesday and Thursday periods, this procedure was usually followed:

1. A preview was given the preceding day (for teachers only), at which time the important facts illustrated were noted.

2. Any demonstrations or home-made slides needed to supplement the film were prepared.

3. A plan of presentation was then worked out in detail, and the time required for each part accurately noted to insure the full utilization of the period.

4. A lighting schedule was made out for the pupils controlling the house and stage lights, and a similar one for the pupil operating the projector.

5. When the blackboard or some stage setting was required, the work was done in the morning, before the class met. To allow for this, the classes were scheduled for the third and fourth periods. ${ }^{1}$

${ }^{1}$ Described by F. M. Worrell in The Educational Screen (February, 1936), pp. 43-45.

The illustrations presented in this and the following chapters are taken from reports submitted in a study of educational sound-film use conducted by the author. 
In planning a lesson, unit, or project it must be recognized that teaching involves more than the establishment of purposes and the devising of an array of procedures. The student of method must consider the unit or lesson as an entity in itself, as an integrated experience which is greater than, and different from, the sum total of the various activities which take place. In other words, what the child gets out of the unit is not just so many pages read, discussions held, reports made, and art activities pursued. What he has received is a reorganization of the background of his experience; the materials he has assimilated not only make for a mastery of certain facts and skills, but inevitably widen his outlook. And from the teacher's point of view this total experience represented by the unit cannot be laid out in exact detail in the advance planning; it must grow and develop with the child.

A workman building the brick walls of a house uses the plumb line and the level as guides, and the completed wall turns out exactly as planned in the blueprints. The creative teacher, on the other hand, is guided only by the general specifications indicated by the educational goals of the local program; he can build just one part of the structure which will represent the child's education. He plans the small section to be furnished by the particular lesson or unit; as the section is erected, he selects, adapts, and modifies the building stones or learning activities which seem most useful. Thus the completed wall, although it may differ from the original plan, is strong and built solidly into the sections constructed through earlier experiences and units.

What part does the sound film play in this broader conception of the lesson or unit? Although the educational talking picture is in itself a self-contained experience, it has roots branching out into many other areas fertile for investigation by the learner. From the standpoint of teaching method, this means that the use of the sound film throughout a unit must be adaptive-that is, continuously shaped to the changing 
pattern of the individual and group curiosities and achievements.

PURPOSES FOR WHICH THE SOUND FILM MAY BE USED

In discussing film teaching methods it is necessary first to define the term "method." "Method" has come to refer indiscriminately to anything from highly specific procedures to whole systems of organized teaching. It will be helpful, therefore, to make a clear-cut distinction between the teaching purposes for which a film may be used and the techniques by which the film is made to achieve those purposes.

The instructional purposes for which teachers are using the educational sound film cover a remarkably wide range. Where units of instruction have been planned, the film has been used to stimulate interest and so lead into the unit; to present the major concepts of the unit, as a direct teaching aid; to enrich or extend a unit by highlighting certain related topics in which interest has developed; to provide a rapid survey or general background; and to summarize or review the unit. ${ }^{2}$ Teachers following the traditional organization of classroom work use the sound film to present subject matter currently studied. Outside of the classroom, the sound film is being utilized to enrich club activities, assembly programs, and parent-teacher meetings.

A suggestion of the varied objectives which may be sought through the aid of the sound film appears in this report of a first-grade unit on animals. The teacher used the film Animals of the Zoo for the following purposes:

a) To provide a basis for reading material

Charts were made, stories of which were dictated by the children

b) To aid in spelling and language work

Children wrote letters to absent pupils telling them about the picture

Original stories were written about "the movie we had seen"

c) To stimulate art work

The results were some really fine pictures of the lion, bear, zebra, buffalo, and other animals

${ }^{2}$ See the classroom demonstrations of these uses in the film Teaching with Sound Films. New York: Erpi Picture Consultants, Inc. 


\section{HOW TO USE THE EDUCATIONAL SOUND FILM}

d) To add to our "store of information"; for example:

Why the giraffe has a long neck

Why the buffalo has its head close to the ground

Why the eyes of the hippopotamus are raised

e) To stimulate group feeling and co-operation

Children brought books from home, also pictures, for all in the group to use and enjoy

f) To develop further the reference habit

Where difficulty in drawing arose, and consultation for help from group did not successfully give form or size, etc., we referred to these books and pictures

g) To serve as a basis for arithmetic

The spoken words "pounds," "tons," etc., gave the concept of these terms in a definite, interesting situation

The purposes of the film presentation govern the teacher's techniques. It may clarify the discussion, therefore, to anticipate the next chapter by classifying typical film teaching procedures. A convenient grouping is as follows:

1. Adapting the particular film to the capacities and current interests of the class

2. Introducing the use of the film in the day's lesson-not only for the first showing but for any subsequent showings

3. Manipulating the film showing - presenting all or only part of the film, interrupting projection, and the like

4. Following up the showing of the film-correcting mistaken ideas, singling out concepts for study, initiating special projects or learning activities, and reviewing

Specific illustrations of these techniques will be described in the next chapter.

\section{A. THE USE OF THE SOUND FILM TO INITIATE A UNIT OF INSTRUCTION}

The following example illustrates one approach to the use of the sound film for this purpose. The classroom project started from the informal presentation of the film as an appreciational activity:

An elementary group saw the film Spiders during an assembly period, the purpose of the showing being for enjoyment and information. The classes had discussed the film before they attended the assembly. One fifth-grade group became so interested in spiders that a study of spiders 


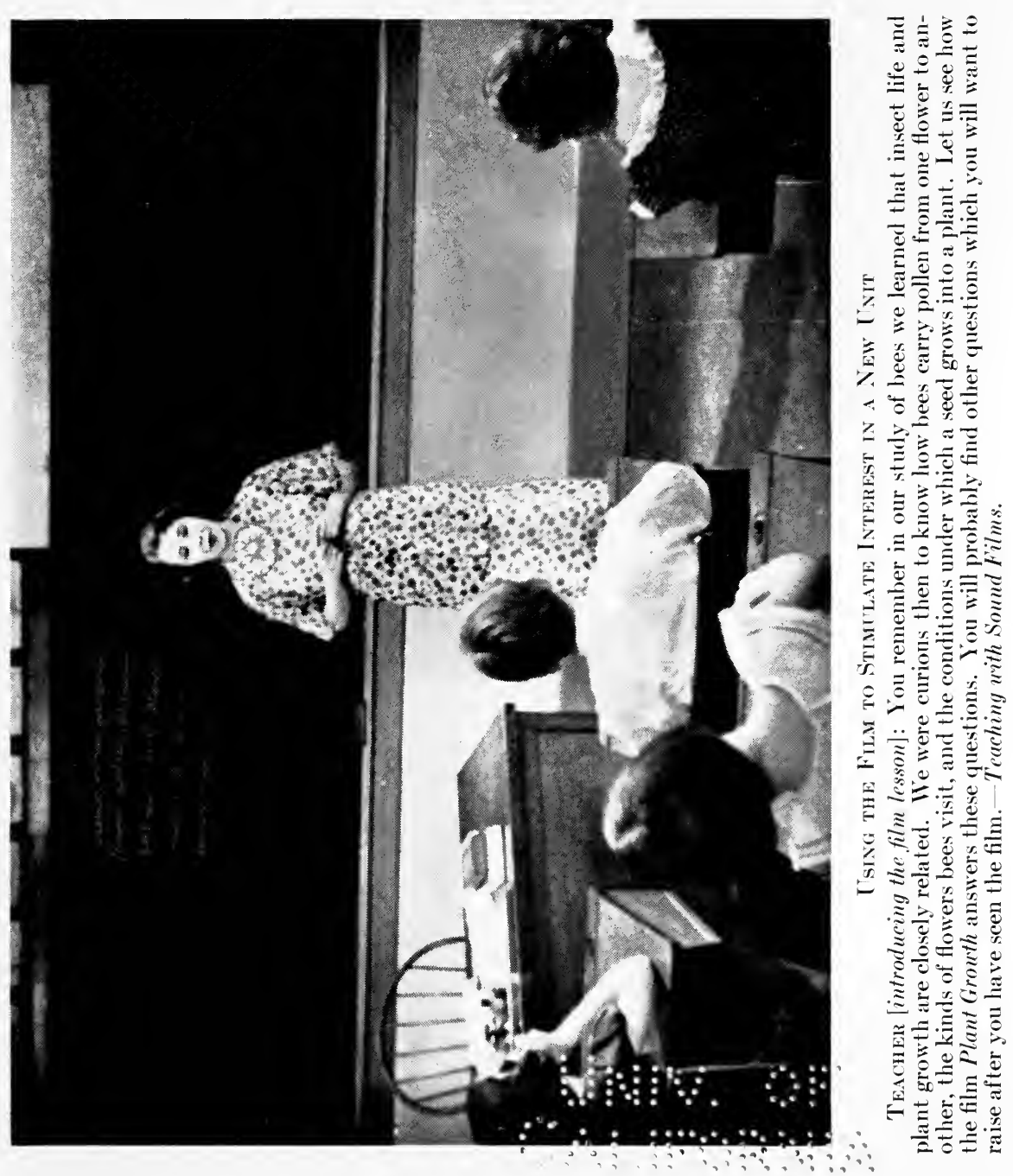




$$
\begin{gathered}
0 \\
\vdots \\
\vdots \\
\vdots \\
\vdots
\end{gathered}
$$


was begun with the children exchanging their experiences about spiders on their way from the assembly to the classroom. The unit that developed included a study of different kinds of spiders, their habits and their value to mankind. The children made a collection of spiders from the vicinity so that they might observe their habits. The spiders were brought to school in fruit jars and great interest was taken in watching the weaving of the webs. During a trip to the Museum of Natural History in New York one child discovered a tarantula in an exhibition; this led to a discussion regarding poisonous spiders. The children read many science books and brought their own story books, which contained pictures and stories of spiders, to share with the class.

These pupils had seen the film the first time merely with the thought of enjoying it, but when their interest led them into a detailed study of the subject they desired to see the film again. The second showing sent them back to their collections and books for more interesting study.

From a large group class in a junior high school comes another example of the manner in which an educational talking picture was used to motivate and provide perspective for the pupils' attack upon a new unit. In this description note the manner in which devices such as the demonstration and slide were used to sharpen the focus of attention throughout the period.

A preview of the sound film Electrostatics revealed that as this film was comparatively general in its scope, illustrating such things as the electroscope, static machine, generating of static electricity, cause of lightning, etc., it could be used as an introduction to the unit. A blackboard explanation of proton and electron electricity was also planned as the first step in studying the problem "What Is Electricity?"

The teacher's purpose was twofold - to arouse interest in the new subject and to give the pupils a working knowledge of the term "Electricity." The pupils' purpose was to learn the electrical subdivisions of an atom and the nature of each.

The following program was arranged:

a) Short talk by the teacher on the importance of electricity in our daily lives; an outline of the key problems to be solved in the unit.

b) Several of these problems were flashed on the screen, and the attention of the pupils was called to the fact that these could be answered from the film which was to follow. (This means of focusing the attention on specific facts was frequently used.)

c) The film was then shown. 


\section{HOW TO USE THE EDUCATIONAL SOUND FILM}

d) At the end of the first showing the pupils were requested to write for the next day the answers they had found in the picture.

e) Following such an activity the question "What Is Electricity?" naturally arose. This was then explained by the teacher in a blackboard demonstration.

The following day a short test was given at the beginning of the period on the work covered the preceding day. The questions asked on the slide were discussed by the group, and if there was a decided difference of opinion, the picture was shown over again.

The problem introduced in the large gathering, namely "What Is Electricity?" was then covered more thoroughly in the supervised study period which followed.

A junior college instructor used the sound film The Frog as an introduction to a unit of work in the biology laboratory:

In this case the film was shown first, without any introduction to the topic. The students knew that they were to begin work on the frog on that date, but no advance discussions were held. The film itself thus became the introduction, and a good one in so far as general responses and external features were concerned. For a college group, however, what would have been most needed would have been an introduction to the internal anatomy, as most of the laboratory hours were spent on such dissections. The introduction not covered by the film was given in the usual method by the laboratory instructor.

In the biological films I believe the greatest value from an instructional standpoint is their use as introductions to new units of work. The sound film certainly has the ability of capturing the students' interest and this stimulation should lead to a more extensive and more careful study of lecture notes and textbook assignments.

A science instructor in a teachers college reported an initial use of a film apparently with the deliberate purpose of challenging the students by a host of unsolved questions:

The next unit taken up was the "Molecular Theory of Matter." The film An Introduction to the Molecular Theory of Matter was shown twice before the study of the unit. The first showing left the class, except a few who had studied physics, in a state of complete confusion as to its meaning. The second showing did not help much. The following two weeks was devoted to an intensive study of molecular phenomena. The study involved heavy instructor-demonstration activity. All through the unit the film served an effective overview or orientation function. It was possible to refer back to scenes in the film at numerous points with meaning. It prob- 
ably would have been helpful to reproduce these scenes during the various stages of instruction. The complete film was shown at the close of the study and seemed entirely meaningful this time.

\section{B. THE USE OF THE SOUND FILM TO PRESENT THE FACTS AND CONCEPTS OF A UNIT OF INSTRUCTION}

Here the sound film becomes a medium of direct instruction, through its presentation of the major ideas embodied in the unit the class is studying.

A sixth-grade class studying the uses of plants saw Plant Growth, Fungus Plants, Flowers at Work, Roots of Plants, and Seed Dispersal. Individual studies were made and reports were read and discussed. After each film had been shown, plans for study and for gaining new information were made to be carried out before showing the films again. In this case further study took the form of observation of plants brought into the classroom and the planting of seeds in window boxes so that answers from nature itself might be found to questions raised by the films.

An interesting use of the film as a direct teaching tool was made with a junior high school class in general science. The instructor limited his entire treatment of sound to the showing of the film Sound Waves and Their Sources. No use was made of textbooks. After the initial presentation of "sound" by the film, the class discussed the subject and asked questions, which led to a second showing of the picture. Notes were then written up directly from the film. The teacher reported:

The students in this group were impressed by the fact that in the film they could actually see such phenomena as sound waves, a thing which the printed page could never adequately describe.

When the film is an integral part of the unit, the teacher can make full use of it as a direct instructional aid. A group of sixth-grade classes meeting periodically in the auditorium of a platoon school was studying the erosional effect of running water, using the film The Work of Running Water. The lesson $^{3}$ described here was the second in the development of

${ }^{3}$ The complete outline of the five lessons is reproduced in Appendix A. 
the unit; the film had been shown the previous period to introduce the whole topic. Because of the large size of the class the teacher had made very careful preparation, building the lesson around the information presented by the picture. In this case only the first half of the film was shown.

The teacher in this lesson sought to re-establish the facts taught in the previous lesson, correcting any erroneous impression which the children might have formed. As a new feature, unusual land formations were to be discussed, specifically the work of boulders in forming potholes, and mushroom forms such as the Garden of the Gods.

Drill cards containing questions on the previous lesson were given to volunteers. These pupils came to the platform, read the questions, and asked for answers from other pupils in the group. The pupils were advised that if they were at all doubtful of answers, they should watch carefully the next showing of the film.

On the blackboard was written the word "pothole" and pupils were told to watch for these in the picture and be able to explain their formation, also to watch for odd-shaped rocks where soft rock had worn away and left the hard rock standing. They were to be able to name these and to tell where some are found.

After this introductory teaching, the first part only of the film was presented, so that the pupils would have the opportunity of studying in detail the topic of the day. The machine was turned off just before the topic "Stream Deposits" appeared. Following the showing the questions which had been given in preparation were asked and discussed.

At this point the teacher recapitulated the information which had been presented in the film: the three stages in the life of a river-youth, maturity, and old age-with the characteristics of each stage. She drew special attention to the characteristics of river formation which had been illustrated in the day's showing, and suggested questions leading to the next lesson, dealing with erosion on flood plains. The pupils 


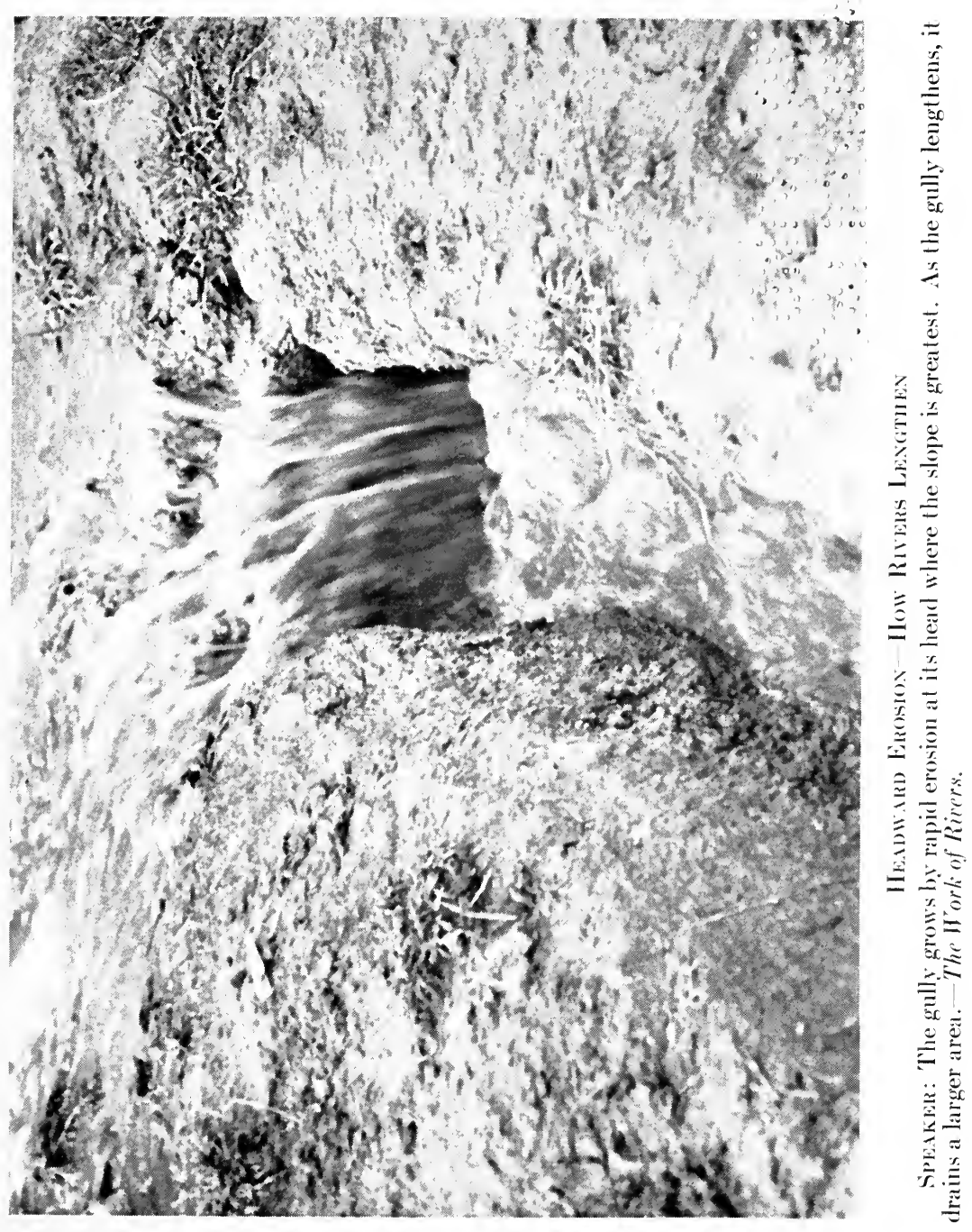




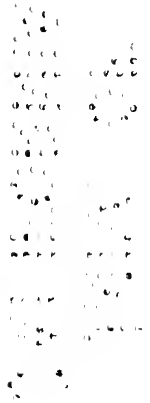


began work on models of a canyon as illustrated by the film, and continued their collection of pictures related to the scenes in the film.

A unit on wild animals was undertaken by a group of third- and fourth-grade classes in a platoon school. Lessons involving the use of the talking picture Animals of the Zoo were presented to the entire group by the teacher in general charge of the unit. Other activities, such as reading, discussion, drill, and art projects, were carried on in the individual classrooms. A description of the unit is given here in outline form.

Unit.-Animals of the Zoo.

\section{LESSON 1}

Aim.-To direct observation of children toward various types of animalsfood eaten-and special adaptability for mode of life.

Preparation.-Contest between teacher and child audience to determine how much each sees and hears. Listening for names of fruits, vegetables, and other foods relished by various animals. Also listening and watching for characteristics.

Presentation.-Showing of the film Animals of the Zoo-"an imaginary visit to the zoo to see many animals we have read about."

Organization.-Teacher saw two animals which enjoyed a fruit that is very good for children. Children's answers are printed in italics in brackets. [Bears and monkeys eat oranges]

Teacher heard word to describe a hungry tiger. ("Snarly" was wanted but was indistinct on film.)

Teacher mentioned a "Soldier boy" animal because of horn on nose and skin put on in armor fashion. [Rhinoceros]

Nature seems to have forgotten to give one animal feet. Why did she not give him feet and what was provided? [Sea lion lives in water mostly and needs fins more than feet]

One animal was so shy. She liked vegetables, especially lettucecarried her babies in a queer way. How were the babies carried? What was her name? [Lemur] (A surprising answer because of the rareness of animal in experience of child. The child who answered had seen it in a book or movie previously.)

This type of organization continued until all animals were mentioned in some way or other.

Teacher then called for favorite animal viewed in film. Children came to platform representing the mentioned animal. Representative 


\section{HOW TO USE THE EDUCATIONAL SOUND FILM}

then made up riddle about himself and called on child in audience to guess who he was-for instance: "I have a long mane on my back, I like to eat raw meat. What am I?" [Lion]

"I am very big. I have a long trunk. I eat many pounds of hay each day." [Elephant]

"I have a small face. I look like a human being. I like cough medicine for dessert." [Monkey]

"I am all white. I like to jump in the water and on ice. I like cooked meat." [Polar bear]

"I am black. I have no feet. I like to stay in the water most of the time and catch fish." [Sea lion]

Application.-This was undertaken in the individual classrooms. Compositions, poems, and drawings of these animals were encouraged.

Unit.-Animals of the Zoo.

\section{LESSON 2}

Aim.-To know more intimately the larger land animals.

Preparation.-Children suggest from memory large animals in order of size-elephant, hippopotamus, rhinoceros. "We plan to revisit the zoo and know the animals better."

Presentation.-Film shown after the foregoing introduction. Names of animals on blackboard. Size and weight of each told. Size indicated by height, length, and width in auditorium-i.e., elephant is eleven feet high (standing on the platform of auditorium it would reach the ceiling); similar sizes indicated with others. Food and natural protection of each discussed.

Organization.-Pictures of these animals shown and poems about each read. Poems were work of $3 \mathrm{~A}$ grade.

"The next time we will visit and learn more intimately the habits of the flesh eaters: lion, tiger, wolf dog, and their prey, the buffalo."

Unit.-Animals of the Zoo.

\section{LESSON 3}

Aim.-To know more thoroughly the habits of the flesh-eating animalsthe lion and the tiger-and the animals upon which they prey.

Preparation.-Review of the large vegetable-eating animals-elephant, hippopotamus, and rhinoceros. "Today we're visiting flesh eaters."

Presentation.-Children watched for flesh-eating animals as the film was shown. Dramatic narration of lion's prowling at night-his method of walking; protective coloring; sense of smell; colored claws; pouncing on prey; tearing victim for eating. (Display picture.) Buffalo and zebra easy prey for tigers and lions. (Display these pictures.) 
The same method was followed for description of tiger-a member of our household pet family, the familiar cat.

Method of catching the lion and tiger told by children. (The information was acquired through movies outside school and adventures of Frank Buck in daily papers.)

Organization.-Child narrated dramatically the approach of a lion and tiger in search of food. All pictures of animals displayed. Recitation of class poems made about characteristics of each animal:

The lion roars,

He eats raw meat.

He has a mane on his head.

And sharp claws on his feet.

The tiger's stripes are orange and black,

He also eats meat raw.

He walks along on big soft feet-

The biggest cat you ever saw!

Poems of the same type were made about the buffalo, zebra, elephant, hippopotamus, and rhinoceros.

It should be noted that the sound film, in presenting the essential facts and concepts of the unit, also gives information useful in conducting related classroom activities. For example, teachers report drawing upon the film to get suggestions for costuming, to provide patterns for modeling and painting, to show children planning a field trip what to look for and where to find it, and to stimulate the making of science collections in the summer.

In an activity-type elementary school the same film, Animals of the Zoo, was employed to provide information as a basis for the circus project of the class. The pictures in the film led the children to make a frieze for the blackboard, drawings, and a picture book entitled At the Zoo. The teacher provided a book on Circus Fun which was so much enjoyed by the children that they made up a game about the animals of the film similar to the game about the animals in the book. Dramatization also came out of the film experience. 
C. THE USE OF THE SOUND FILM TO ENRICH OR EXTEND A UNIT

The previous discussion of methods and purposes has been concerned largely with the use of films which are basic to the unit of instruction which is being studied. However, sometimes there may be no basic film available, and a film dealing with only one section of the unit, or with ideas related to one section, may be employed. Again, the teacher may wish to extend the contribution of the basic film by utilizing another talking picture which goes beyond the content outlined for the unit. The teacher sensitive to evolving interests can make good use of films which highlight areas tangent to the unit as originally planned. This use of the sound film is especially significant in meeting the needs of pupils of superior ability who can quickly master the essentials of the unit and thus have time to pursue their special interests. Still another possibility explored by teachers is that of employing a specific subject-matter film in a different course, for motivation or illustration.

An interesting example of this varied use of the sound film is presented by music teachers' showing of the film Sound Waves and Their Sources, designed primarily for physics classes. In one high school the music teacher employed this film to present the concepts of sound and tone, and to give pupils a clear idea of the construction of the human throat. The fact that the sequences in the film which served these two purposes constituted only a small part of the total footage presented no difficulty as long as the pupils understood the specific purpose of the showing and had had their attention called to the materials they were to study in the film.

One of the most frequent applications of the film to a different subject-matter course is that in which a science film is used in an English class as motivation for oral and written composition. In a rural school in which special stress was being laid upon written composition, the films were used to stimulate this type of activity: 
The pupils of the third and fourth grades were doing poor work in English composition, so we decided to try writing assignments based on film showings. Several films which children of this age would probably like and generally comprehend, were selected and shown at intervals of several days. The children were not told to watch the picture for the purpose of writing about it, but instead were told that they might use the content of the picture for their story if they preferred it to anything else. The resulting compositions were almost entirely on the subject of the film shown, with marked improvement both in the content and in the quality of construction. There was also a greater willingness to write. Thus the motion picture furnished subject matter and increased interest for writing. This plan might not, however, be as successful in a less remote community where children's experiences are richer and more numerous.

Sometimes the injudicious selection of a film defeats the possible contribution. A fourth-grade group had been studying the life-history of frogs, toads, and newts as a result of interest developed through seeing them in gardens, pools, and brooks. Toads', newts', and frogs' eggs had been brought to the classroom. The film Tiny Water Animals ${ }^{4}$ was introduced to broaden the unit but proved not as interesting to the class as a whole as the teacher had hoped. The children kept looking for the water animals they knew. Had the film The Frog been shown it would have fitted exactly into the pupils' experiences and would thus have suggested further points for study. As it was, the pupils did not have the background to appreciate and study the content of the film selected.

A much better example of the enrichment of a unit of activity appears in the following account. Note the fact that the sound film here was employed to broaden an unusual activity which chance had brought to the classroom.

A nest of bees had swarmed in the park across the street from the school. The principal had gathered the swarm and brought it into a six-grade classroom, placing a bee-hive rack and the swarm in a cage until the queen bee entered the hive. Then the hive was installed at the window, with the entrance so arranged that the bees could come and go as they wished. The fact that the principal himself had gathered the bees interested the children in this addition to their classroom, but seeing the ways the bee gathered

${ }^{4}$ This talking picture deals with microscopic pond life. 
nectar from the flowers in the sound film, Flowers at Work, gave an added incentive to study. The film led the children to have a keen interest in watching the bees visit the different-shaped flowers.

Typical of many classroom situations in which the use of the sound film is integrated with other audio and visual devices, is the following report. In this instance the sound film was utilized to enrich and clarify concepts already developed through previous study and the use of other devices.

Many of our classes that were listening to the Damrosch radio concerts as part of the regular music work, saw the film Brass Choir of the Symphony Orchestra. One sixth-grade group that was studying the instruments of the orchestra in groups as developed in these radio concerts had studied pictures of the instruments, and had heard victrola records which gave the tone and range of each instrument. The film was then projected as a means of bringing out points that the other devices could not show: how the player holds the instrument, how he fingers the keys, the quality of tone possible from each, the blending of the parts and the type of music which brass instruments can best portray. Many pupils had thought of the breath as the whole means of producing the tone, and were much interested in the finger-work. The selection played by the whole choir gave a new meaning to martial music. The part showing knights marching, with banners flying, was particularly interesting to some and resulted in attempts at original art composition. The children had a greater interest in tuning in on the radio to hear the band or orchestral music.

The sound film is a convenient and effective device for explaining quickly ideas related to the topics being studied. In a junior high school science class the teacher brought in the sound film Molecular Theory of Matter to clarify some of the incidental questions arising from the study of heat and electricity. This film was also utilized in a high-school physics class at the beginning, middle, and end of a unit on heat, to explain the relationship of heat in the molecular activity of matter in its three states.

In a normal school certain films were used to illustrate, not subject matter as such, but a method of organizing subject matter for presentation to elementary-school pupils. The films Plant Growth, How Nature Protects Animals, and 


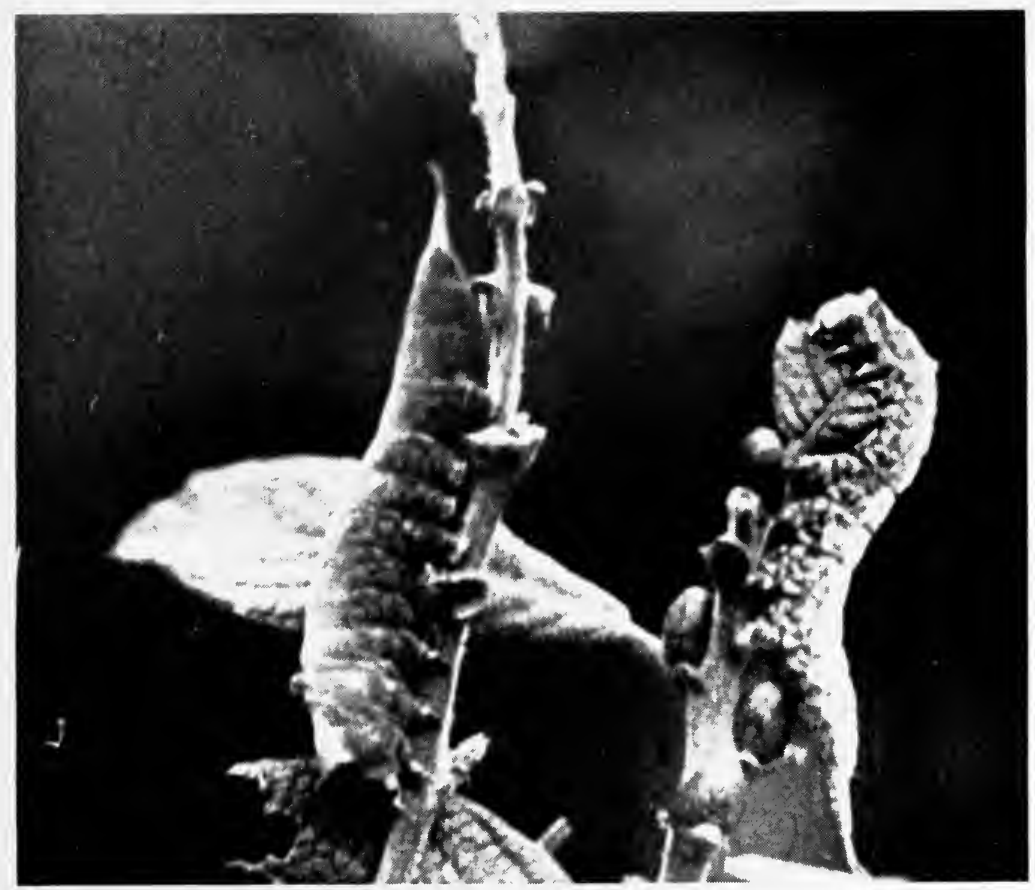

\section{Disconering Insect Camouflage}

SPEAKER: This caterpillar has no other way of defending himself against his enemies, so nature has given him the appearance of a curled leaf. Thus he is able to escape the notice of hungry birds and stronger insects.-IIow Nature Protects Animals. 


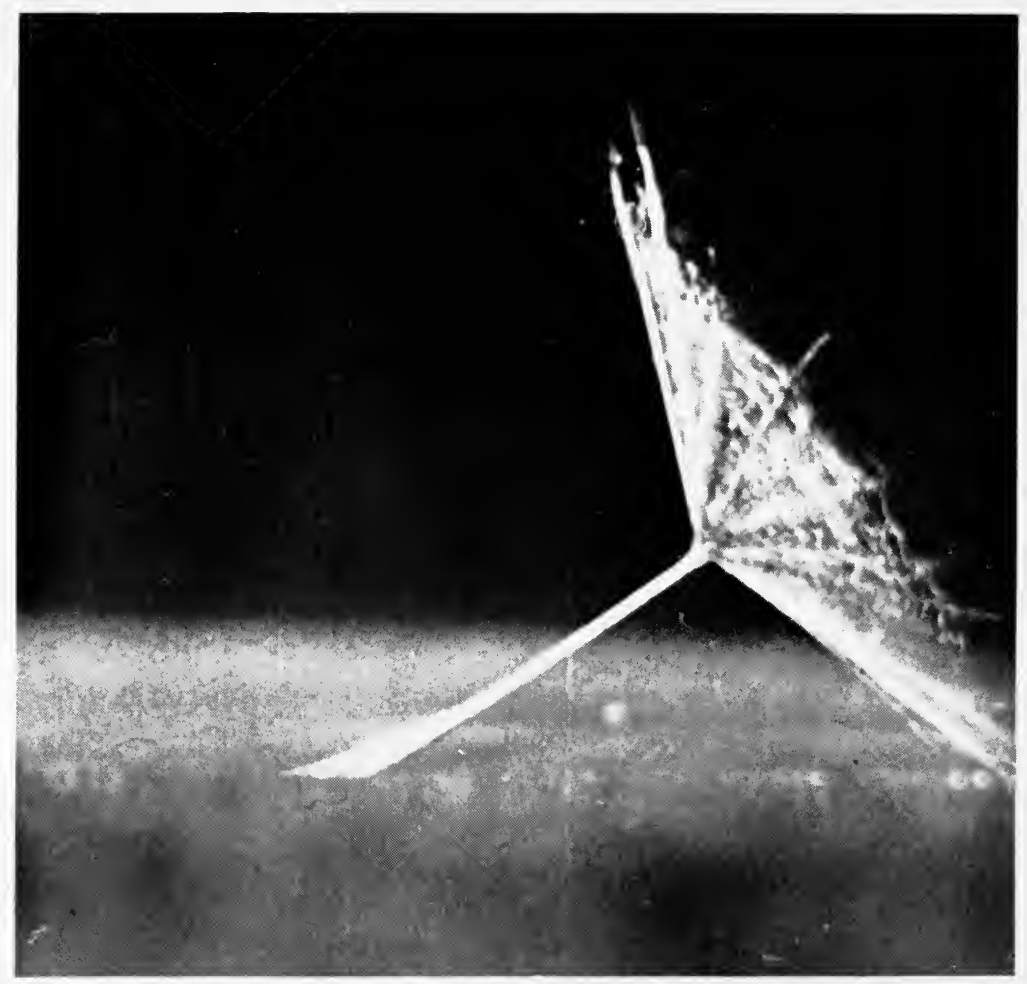

A Parachete he the Plant World

SpeAker: This seed has a parachute, which opens if the air is dry and begins to close when it becomes damp. After the seed has dropped to the ground, the parachute may open and close repeatedly and thus push the seed toward a better location.- -Seed Dispersal. 
Seed Dispersal were studied for this purpose by the classes in science teaching methods. The instructor stated:

I consider this an excellent device to illustrate concretely the meaning of a unit organization directed toward the understanding of fundamental functions in the plant and animal world, as opposed to the usual procedure in nature work of naming and identifying as an end. The films met this point clearly and forcefully.

In a sixth-grade science class, a unit on the balance in nature was being studied. The teacher, at the suggestion of the science supervisor, brought in the film Pond Insects as a special feature, to enable the students to study the interrelations between different forms of insect life. An interesting sidelight upon teacher preparation appears in this teacher's reaction to the use of the film. After the lesson, the teacher suggested to the supervisor that it would have worked out better for the class if she had previewed the picture, noting the film points especially pertinent to the unit. This teacher in some way had missed the film when it was previewed and had neglected to become thoroughly familiar with its content. She, as well as her students, decided upon a second showing of the film for the purpose of rounding out the information they had received.

Another elementary-school class was studying the Tennessee Valley Administration Project. From this unit a special interest developed in the earth's changing surface. The teacher secured the manuals and films on The Work of Running Water, The Wearing Away of the Land, and The Earth's Rocky Crust. These three films, shown twice, were used as part of the research work of the children and in some instances opened up lines of interest which otherwise would not have been disclosed.

\section{THE USE OF SOUND FILMS FOR A RAPID SURVEY OR GENERAL BACKGROUND}

The increasing tendency in curriculum construction to provide survey courses for general education, orientation, or integration emphasizes the need for instructional materials 


\section{HOW TO USE THE EDUCATIONAL SOUND FILM}

which enable the teacher rapidly to present broad concepts and their interrelationships. Typical of this trend are the courses in certain areas of the junior high school and the general introductory courses of the college Freshman year.

A private school developing a non-college-preparatory curriculum utilized films as an integrating device:

Our school introduced this year a three-year sequence for the study of contemporary society, as a preparation for citizenship. It is intended for boys and girls who look forward to entering business or some vocation, either immediately after graduation or after a short period of preparation in non-collegiate technical or business courses, and is designed to afford them the opportunity for thorough and interesting work closely connected with the practical aspects of life and suited to preparation for business, home life, and citizenship.

The work of this group is planned especially to allow for correlation of the various fields of study taken up. Teachers meet every two weeks and plan together for content and procedure which will relate the work of all their classes and fit it to the needs and interests of individual students. The curriculum included for this year (tenth-grade) work in English, social studies, mathematics, and science. The biology teacher in charge of the science work used a number of the films in this connection. The work was closely integrated with English, reports being written on the pictures for presentation in the English class and science notebooks being reviewed by the English teacher.

A college instructor used sound films in a science survey course, to cover the broad field laid out in a new syllabus. He summarized the contribution of the films for this purpose as follows:

In the survey course there were eighty-eight students-a heterogeneous group since the course is offered only to first-year students and many of them have had no great amount of science.

The films reinforced what I gave in lecture form. It is very difficult to indicate action, movement, activity, and in this the films were of considerable assistance. Moreover, with specimens, slides, and lectures, it is hard to impress the first-year students with the proper relation to time and place; the motion picture creates a definite impression for them.

With the introduction of films, we have been able to cover material much more rapidly and fully. 
A high-school biology teacher used the sound film The Frog as general background material throughout his course:

Our biology course does not deal with the frog as a separate unit of work. The frog is studied in all of the units of work along with other organisms, both plant and animal; therefore, the film did not help us in studying the frog as a unit of work in itself. This, however, does not mean that where a sequence of relationships comprises the course, this film of the frog will find little or no use. On the contrary, the very contents of this film aid in emphasizing the idea of a sequence of relationships, such as reproduction, metamorphosis, and adaptation to environment.

E. THE USE OF SOUND FILMS TO SUMMARIZE OR REVIEW

Summarization and reviewing are essential phases of good teaching. An effective review device or method helps the student to organize definitely the information he has acquired, emphasizing important ideas and subordinating minor points. It suggests a new perspective both for what has been learned and for what is to be learned next, setting the ideas of the unit in the pattern of still larger concepts. It recalls rapidly to the student's mind the essential ideas. It has the possibility of frequent repetition for testing purposes. It makes clear immediately to the student the things he has missed. Above all, it possesses a high degree of interest.

A high-school biology teacher commented as follows upon his use of the sound film The Frog at the end of the school year:

The film works in exceptionally well in the latter part of the year as a review of the outstanding principles of the course and even as a summary of a number of the topics which are given in the state examinations. Although all students had a knowledge of the frog from laboratory and textbook, those who had seen the film made a higher average in the tests.

Typical of the sound film's adaptability for summarization is the case in which the film The Development of Transportation was utilized to bring to a focus the concept of transportation which had appeared recurrently in the year's history work in a small rural high school. Throughout the year transportation as an underlying factor in the development of modern industry and life had been emphasized. The sound 
film was presented to give the pupils an idea of modern transportation devices, to let them see the intricate transportation system ramifying throughout the country, and to show them the influence of these developments upon modern life. Although the pupils had been studying this topic over a long period, had done extensive notebook work on transportation, and had read widely, the teacher noticed from the discussion after the film showing that their ideas had been considerably enriched. She cited as an example the question of one student, "City streets aren't ever that crowded, are they?"

A general-science teacher made good use of the sound film for reviewing. A method he utilized often was to show a number of films previously used in teaching and then have the pupils make a summary outline, composed for the most part of the content of the films. In place of an outline, essays were sometimes written about each film. The latter method seemed very successful at the end of the term when work on the contracts had been completed.

In another general-science class the film Electrostatics was employed to summarize a unit of work on the subject of static electricity. About eight periods of study, experimentation, and testing had preceded the showing of the film. Both teachers and pupils commented on the fact that the use of the picture had been quite profitable in providing an interesting outline of the subject as well as giving a fuller understanding of the topic.

A fourth-grade class studying fungus plants saw the film Fungus Plants as a review exercise. One pupil had brought in a tree fungus; this started the project. Discussions precipitated the need for further reading and research to identify the specimens of fungi brought in by the various pupils. A number of jars with bread-mold spores forming a network were placed in the room. Pictures from the library were shown to the class. A microscope belonging to one of the pupils was enjoyed by the entire group. After the study had proceeded for some time an exhibit was made: mushrooms, 


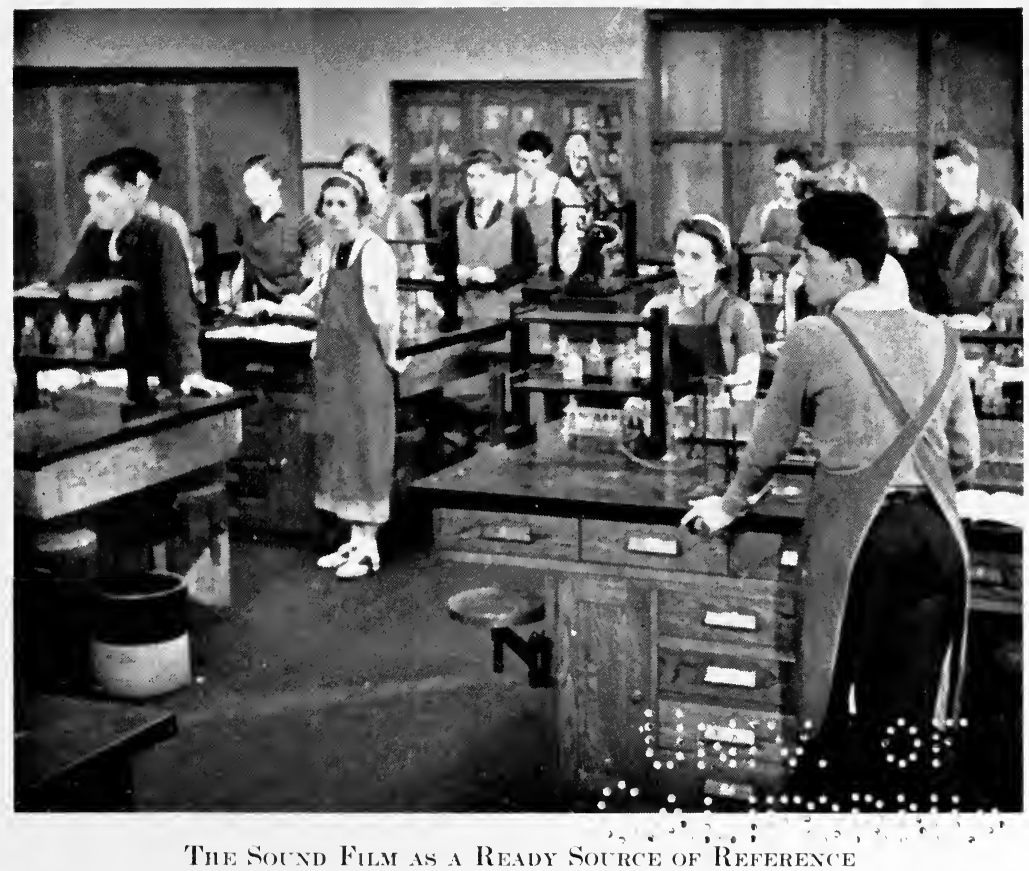

TEAcinen [at front blackboard]: You remember when we studied oxidation and reduction last term, the film explained the chemical action of reducing agents on oxides. This week in our study of metals we plan to investigate the general topic of reducing ores to their metals. Let's review the film again, to make sure we understand the basic principles of reduction. [Teacher pulls doun sereen, the projector is started, and the class sees the blast furnace sequence from "Oxidation and Reduetion."] - Teaching with Sound Film.s. 


$$
\begin{aligned}
& \because \because \quad \therefore \quad: \div \\
& \therefore \ldots+\cdots+\cdots \\
& \text {, , , , . , , }
\end{aligned}
$$


shelf-fungi, puffballs, lichens, molds, rusts, and mildew. Some of the fungus designs were made the basis for art work. Experiments were carried on in the class with molds, rusts, and mildews. When the picture was introduced, it contributed definitely to the students' appreciation of the growth of these plants and helped them to organize their knowledge on the topic.

Another junior high school science class had been studying for three weeks the life-cycle of plants. Experiments, special reports, and class discussions of the topic preceded the presentation of films. The teacher decided that the series Plant Growth, Plant Roots, Flowers at Work, Seed Dispersal, and Fungus Plants could serve as a visual and verbal summary of the topic. He indicated before the presentation of each film certain facts and actions to expect; the class engaged in a discussion of these points after the film showing had been concluded. The instructor commented:

The pupils felt that it gave them an integrated understanding of the processes that would otherwise have been difficult to make clear by isolated experimentation and discussion. They desired that such pictures should be presented at the beginning of the topic as well as at the close of the study.

In a high-school physics class the subject of sound had been studied six weeks before. As a review a few experiments were performed and pupils were asked to watch for those sequences of the film which were related to the experiments and those which were not. The film was presented and then the pupils asked questions concerning the film content and the textbook content. The instructor said that as the film followed exactly the material used in the course of study, it became a vitalized review of the subject matter. This use points to the possibility of repeating films basic to the course of study at intervals throughout the year, so that students not only have the learned subject matter recalled to mind but see the relationship of previous units to those which are being studied at the moment. 
F. THE USE OF THE SOUND FILM IN CLUB PROGRAMS AND SPECIAL PROJECTS

No longer is the classroom the hub of the school universe. The extra-curricular program and the school activities taking place outside the building have given ample evidence of their contribution to the child's education. It is not surprising, therefore, that teachers have discovered the usefulness of sound films for activities quite apart from the usual classroom instruction.

In a junior college music films were made the basis of much direct instruction in the music courses which form an important part of the school curriculum. In addition, the music supervisor encouraged the use of the films at club meetings, for the benefit of students not specializing in music.

Here again the films proved valuable for education as well as for entertainment. They were truly enjoyed by the students, who felt that they were being entertained. Probably if they had realized that they were being educated musically, they would have resented it!

The description of the use of the films in a typical garden club program follows:

In one of the elementary schools there is a garden club which meets Tuesday afternoons from $1: 15$ to $1: 45$. Children from grades three to six are members of the club. The group is responsible for planning the flower garden on the school grounds and for tending the shrubs and flowers about the school.

On rainy or cloudy days the sound films on plant life were shown as part of the group activities. After the film Plant Growth had been shown, the children expressed curiosity about the inside of the flower, which provided a natural motive for the use of the film Flowers at Work. After the showing of the film, the teacher suggested that for the next club meeting each child should bring in a flower so that they could dissect the specimens to see the various parts of the flower.

An important function of clubs and related activities is that of providing an outlet or avenue of expression for individual interests. In a school system which accents this aspect of the child's training, the director of visual instruction reported: 
Through visual and other sensory aids in the curriculum, many pupils find individual interests which lead among other things, to observations, readings, construction, photography, and collections. These interests often take the form of hobbies, some of which are of short duration, while others last for years.

The sound film Plant Growth which was used to summarize and clarify a sixth-grade study of "seeing in terms of vital life-processes," was one contribution in a project that led the girls of the group to form a bird club. This little club spent most of Saturday in a park which stretches for miles along the top of the neighboring mountains.

Some members of a fourth-grade group, after studying injurious insects, experimented with exterminating aphids in their home gardens.

Many children who have not had their own gardens asked for them, and others, who usually have their own plots, became intensely interested in planting, cultivating, and watching flowers and vegetables grow-as a result of seeing the several science films on plants.

A number of schools held hobby shows. In these there were science collections and exhibits which showed interest in many things the children had seen in the films. The individual interests that the films initiated for some pupils will last for years. With the additional leisure that many adults will have, the opportunity for boys and girls to find hobby-developing interests is an important contribution the schools can make.

\section{G. THE USE OF THE SOUND FILM IN ASSEMBLY PROGRAMS}

The school assembly program has been recognized as a center for socializing experiences. ${ }^{5}$ It has been suggested that considerable value may accrue from the assembly presentation of films which, although they may not be classified directly as classroom material, are related to the curriculum and thus serve to broaden the child's understanding and enrich his appreciation of the world about him. Furthermore, there may be a definite place in the assembly for direct instructional films of the type which can be appreciated and assimilated by students in large groups. Music-appreciation films and films which tend to build up desirable health attitudes illustrate apt subjects for auditorium use.

The use of films in the assembly frequently proves to be the

${ }^{5}$ See the Fourteenth Yearbook of the Department of Elementary School Principals, National Education Association: Socializing Experiences in the Elementary School (Washington, D.C.: 1935). 
starting point of activities in the classroom which require the detailed study of the film. Where the use of films has been confined almost entirely to the assembly, there have been requests from teachers to have the films made available for classroom projects. Apparently the assembly use only of classroom films represents a preliminary phase to be outgrown with the development of a more intensive program.

To illustrate the way in which classroom projects sometimes develop from the assembly use of films, the following is quoted from one director's report:

Jack and Jill in Songland was shown to an assembly group of kindergarten and primary children for enjoyment and appreciation. A thirdyear group that had begun the study of formal music was intensely interested in the song and could talk of nothing else when they returned to their room. The following pupil discussion took place as a direct result of thought provoked by the film:

"The story of Jack and Jill is a nursery rhyme. That is a good song [referring to the film song 'The Elf Band']. May we not make a song of our own?"

"Yes, one that has to do with what we are studying."

"We are studying about our town. Let's write a poem and call it 'Our Town.",

"Then we can write the music to fit our words."

The poems found in our many library books and readers were studied to ascertain what appealed to us. After study, each reading group contributed its ideas. Each of the three groups was anxious to have its own poem chosen. The best ideas were pooled and the poem "Our Town" was the result. Before the music was achieved much careful preparation was needed. The two-line melody of the "Elf Band" was adhered to rigidly. A review of the third-grade music work covered earlier in the year was necessary before completing the work. The review included a brief analytical study of our own songs, and a visual study in comparing walking, running, skipping, and slow or waiting notes in particular phases of our regular music work in this grade. Steps up and down, skips, and time were a few of the technical knowledges needed. (All of this took place before the musical phase of the undertaking was attempted.) The completed song "Our Town" represented the combined efforts of the class to produce a short verse that was not a nursery rhyme but was original and set to music of the children's own making. The result was an experience which meant something to them. 


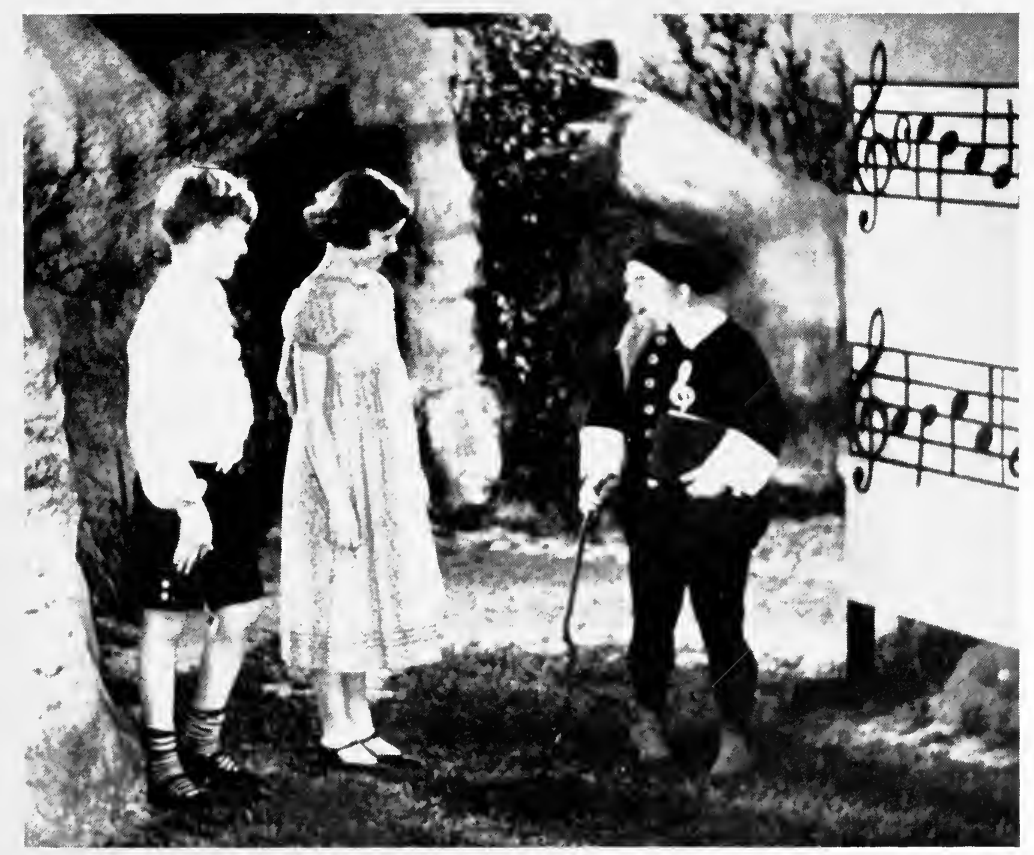

Jark and Jill Leari abot't Notes aNd the Stafa

SoxgMax [entering gaily]: I saved another song, and I have it in my book. ('Hildirex: So did we, and we put the notes on the staff.

Soxcinus: (Oh, so you have! Well, well, that's very good! How would you like me to play it for you?

-Jack and Jill in Songland 

Toward the end of the school term the school decided to hold a parent evening. This class, during a discussion of what to contribute to the evening's program, was unanimous in selecting the song, "Our Town." A discussion of plans resulted in the decision to print the music on a large piece of wrapping paper, twelve by six feet, so that the students could hold it up and explain how they had written the words and music.

\section{Our Town}

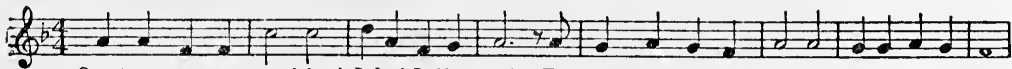

Our town once was wood-land It had Indian trails, The Dutch and English peo-ple set-tled in the vales.

Typical of still another type of use in the school assembly is the following:

Wonder and appreciation-two purposes closely linked together-were in the minds of some teachers for the use of the films. A first-grade teacher took her children to the primary assembly to see Jack and Jill in Songland. These little folks were delighted with the story, and the face of one child who had never seen a motion picture showed joy and wonderment. The children liked the film so much, that as soon as they had seen it, they asked to have it over again. In the classroom the first-grade group sang the song, discussed the staff, notes with stems and without, and the scale. (Topics in formal music are not studied here until the third grade.) The children were interested in how the elf man made the staff and the piano appear, why the elf changed one note and made the stem go up instead of down, elves and all about them, and many other whys and wherefores. The children had seen the film twice on January 9, but their interest kept up so long that in May they wanted to see it again.

A kindergarten group who saw the same film liked the little Brownie man and spoke of his happy face, commented on the fact that Jack did not cry, exclaimed over the beautiful place where Jack and Jill heard the fairy music, and liked the little dance the two did to the fairy orchestra. They talked about how Jack and Jill had to match tones to make the song and then matched tones with the teacher and each other.

Some teachers were quite frank in recognizing that their use of the films in the assembly, though valuable in itself, would have been replaced by the use of the films in classroom study had the program been continued. A sixth-grade teacher when reporting the use of nature study and the transportation films in assembly periods for appreciation and enjoyment, gave as her purpose that of enriching the children's 
lives with information about various kinds of plant and animal life:

Another year we can plan our work with these helps in mind since we are acquainted with the type of picture. Children were much interested in flowers and afterwards described to classmates who had been absent the parts of flowers, even remembering names. Some reading was done on transportation. Only the lack of time prevented more detailed study of the subject. The films are a splendid beginning for work in any of these subjects. The children enjoy them and listen with much interest and are more than anxious to continue along similar lines.

To show the stimulus for further study which even the single showing of films in the assembly provided, the report from a fourth grade teacher in the same school is given here. Her class had seen How Nature Protects Animals and Flowers at Work in the assembly and had promptly developed an interest in spring, animals, and flowers.

The films were shown in assembly to the fourth, fifth, and sixth grades. As preparation for each showing of a film, we had talked over the main points in the manual accompanying the films. Afterwards in the classroom, we made a chart showing the different protections nature has given to animals. We talked about these devices, and some members of the class made copies of the chart and played a game guessing which device suited each animal.

A variation from this type of assembly program-indeed, the exact reverse-is evident in this report:

A junior high school group received so much from the films that they decided to present their work and two of the films they had especially enjoyed to the assembly.

Electrostatics and Fungus Plants were the two films the class selected.

The pupils thought that classes that were not studying definite work of which the films were a part, might not understand all the films. Accordingly a student introduced each film to the assembly and told of some of the significant factors of the film in relation to their own lives.

In another school system additional films were rented to make up assembly programs. The procedure was described as follows:

A definite selection of films was made on the basis of appeal to the children and of appropriateness to the classroom activities in which the 
children were engaged at that particular time of year. As a usual thing, four films were shown on occasions of this kind and were greeted with active interest on the part of teachers and pupils.

An interesting variation of the assembly use was the noonhour program inaugurated in a rural school where most of the students remain in the building for lunch. Remarking that the noon hour in a crowded building constitutes a problem, the supervising principal said:

Motion pictures-recreational, vocational-proved a happy solution for both teachers and pupils on many occasions.

Concerning assemblies, he said:

Pictures provided an always enjoyable and usually profitable assembly program. They had the advantage of always being ready to perform as a substitute for some speaker who failed to arrive or for a group of students who at the last minute had to announce their unpreparedness for the program.

In one junior high school, films have been made to serve a variety of socializing purposes. Assembly programs featured music films which had been secured to vitalize the appreciation of the work of noted composers. Music-appreciation films were also shown in the assembly for the purpose of aiding the sale of concert tickets. Entertainment films were shown once a week in conjunction with student-organization activities. One of the most interesting uses, however, was that in which the film Choosing Your Vocation was presented as a part of the junior high school graduation exercises. The program, organized by the students, was intended to emphasize the importance of orientation and vocational guidance. Along with exhibits and speeches, this film served to show parents some of the techniques which boys and girls should follow in selecting a vocation.

The dean of a private school made use of sound films in the evening social hour:

Our use of the films outside of the classroom was perhaps even more successful than their regular classroom use. Our students are allowed a social period after dinner every evening from $6: 30$ to $7: 15$. Games, con- 
versation, and similar voluntary activities are the order of the day. On several occasions, the talking pictures were shown in the assembly room during this period, accompanied by an illustrative program, with all interested students invited to attend.

Among the films shown in this way were two orchestra selections, The Percussion Group and The String Choir, Transportation, and Tiny Water Animals. The first two were followed by illustrative trio music with appropriate instruments, the last by a talk on microscopy as a hobby. The transportation film was introduced by the head of the Social Studies Department, who pointed out the significance of transportation in the development of civilization. The showing of this film was followed by an exhibition of electric trains by boys in the model railroad hobby group.

\section{H. THE USE OF SOUND FILMS IN TEACHER-TRAINING PROJECTS}

One of the difficulties which has confronted the elementary-school teacher is that of securing a ready command of the numerous subject-matter fields and skills in which she must be prepared to give instruction. This is especially noticeable in the case of elementary science. Many teachers lack the background of knowledge that will permit them to develop worth-while units of instruction in science at this level. Curriculum-makers in elementary science have been keenly aware of this situation as an obstacle to further progress. The sound film assists in developing the teacher's understanding of new subject matter. In one school system which utilized sound films, a course in elementary science had recently been installed. Under the direction of an efficient supervisor, the work had been proceeding with fair success. After six months' use of science films, she remarked that "the films proved particularly useful, not only because they helped with the education of children, but also because they helped the teachers with materials unfamiliar to many of them. They aided materially in making a success of the new course of study."

In this same school system an unusual application of a teacher-training film was reported:

In connection with teacher-training, the film on The Primary Teacher at $W_{o r k}{ }^{6}$ was shown to teachers of the first and second grade and their

${ }^{6}$ The talking picture The Primary Teacher at Worl. presents an outstanding teacher discussing her classroom and its activities. 
pupils, and written reports of teachers' and children's reactions to the film were compiled. It was interesting to note that the children stimulated their teachers to an evaluation of their classroom procedure by asking questions about certain classroom activities observed in this film.

The children were told that the lady was talking to the teachers, that they could watch for things they liked in the pictures and tell their teacher later.

\section{Below are listed some of the pupil comments:}

Mary Elizabeth says "Could we make our plans for 'quiet time' the same as we do for our 'work period'?"

We are working for better posture; those children sat well on their chairs.

The chairs looked comfortable with their high backs.

The flowers looked nice on the table.

The teacher went around and helped children with their work.

She had a bowl of pretty flowers on her desk, also a typewriter.

She gave the children nice things to do.

The teacher had on a pretty dress.

It looked more like a house than a schoolroom-with curtains and things.

They didn't interrupt the teacher.

I'll take our class!

I only saw boys working at the work bench. Girls work here in our school.

Those children had good self-control-better than ours even.

The children's names were on their chairs.

I like the teacher because she has a nice voice.

I like the children because they know how to work.

They have a room committee just like ours but larger. Maybe if we had more names on our room committee the children would be happier.

They have a lot of pictures around their room.

I didn't like the way they all stood up when the girl was showing her book.

I didn't like it when the boy was pounding and the teacher took away the wood. I thought it was sad. But she put it down again.

I liked the teacher who was sitting at the desk.

I wanted to hear the children talking.

I didn't like it because one girl walked in front of the others all the time.

They had a better place for the library than we do.

I want you to let us change our room and move the furniture. 
The teachers apparently welcomed the opportunity to suggest improvements:

The film was very interesting. Providing lockers for each child is an excellent idea. I like this because it makes a much neater looking room, in addition to making the children feel they have a part of the room for their very own. Tables and chairs allow for grouping better than desks. Do you think a progressive program such as the one shown is applicable in most of the schools?

All our pupils appreciated the art and wished for an easel. May we have one?

I find the children's remarks about the film of more value than anything I saw in the picture, because they gave me an insight into a great many of the situations which exist in our room.

I. THE USE OF THE SOUND FILM IN PARENT-TEACHER AND OTHER COMMUNITY GROUP MEETINGS

Principals and superintendents have utilized the educational sound film as a means of bringing the community into closer contact with the work of the school. Administrators have found that this medium enables them to acquaint parents with new materials and methods in modern education, an opportunity which infrequent school visits fail to provide. There is need for experimental adult-education programs, to discover what contribution films can make in general cultural courses for grown-ups and how films may best be utilized with these groups.

The principal in a rural community sent a notice to the parents, inviting them to attend the showing of the films as part of the regular classroom instruction. From this innovation followed the request that these films be shown to various adult groups. As a result evening programs featuring music appreciation were held, at which a nominal fee was charged to pay for the rental of the films. At one session four sound films of famous composers were shown, after which the music instructor led a discussion and described the activities of his department in the school. At an evening meeting, open to the community, sound films showing the four choirs of the symphony orchestra were shown and the music instructor 


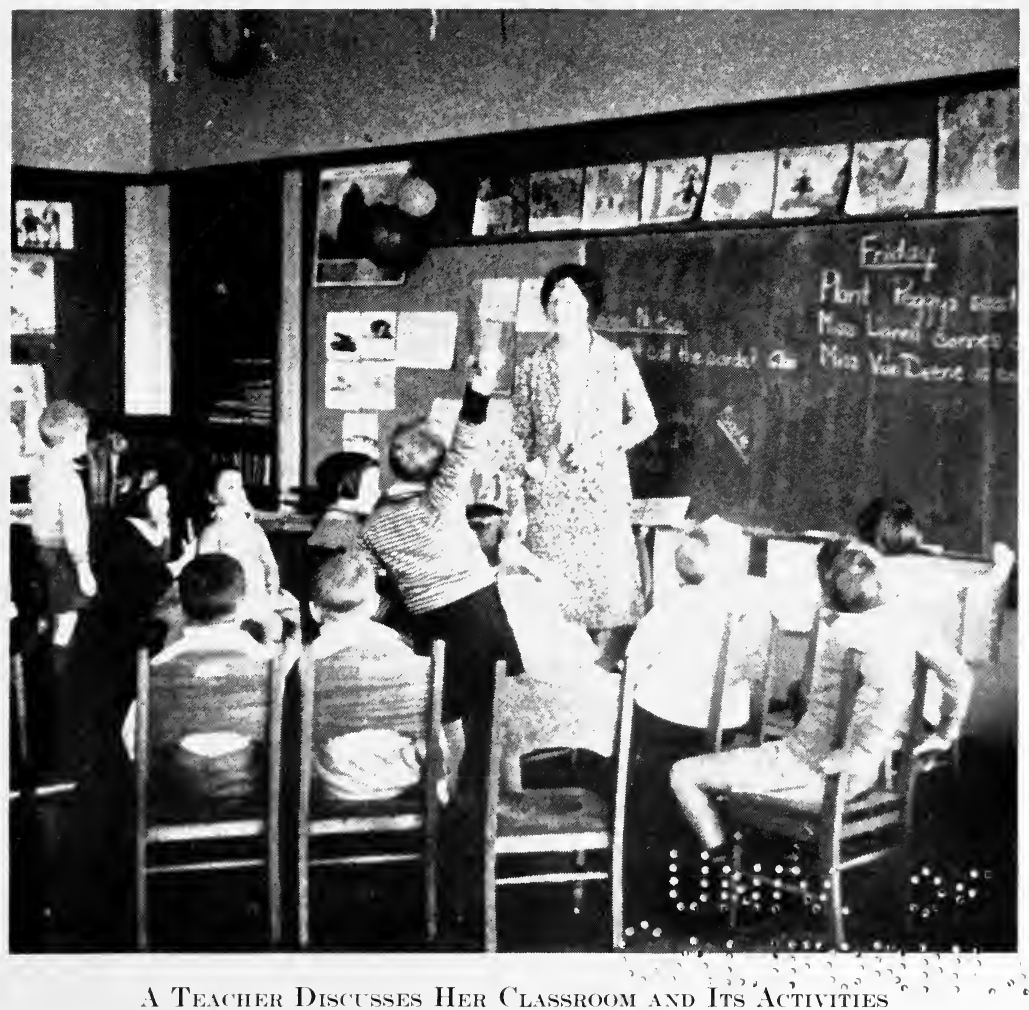

Miss Stone: Now the children are ready to make their plans for the day. The teacher has suggestions to offer too. A definite record of work to be accomplished gives the children an immediate objective and helps them to measure their achievement at the close of the day. The necessary repetition of certain words and phrases establishes a fixed vocabulary.-The Primary Teacher at Work. 

explained his work in developing the school band and orchestra.

At another evening meeting, held for the benefit of the local parent-teacher association, a program demonstrated the sound films used in the regular classroom instruction. This demonstration was very well received. The teacher-training film, The Primary Teacher at Work, was also shown. The supervising principal commented that this film was not well suited to the group and consequently met with little enthusiasm or comment. Incidentally, this convinced him of the need for developing a suitable background of appreciation as a preparatory step before films of this type were presented to groups of parents.

The principal of the junior high school in another school system was asked to appear before a "Better Films" group, to present certain of the films which were being utilized in the schools and to explain the type of work done with this new device.

In another community, the superintendent reported:

From time to time the principals demonstrated the films and equipment before their Parent-Teacher Associations. In this way general information was given to parents concerning the value of films as an aid to instruction.

A program at the Woman's Club in connection with the Annual Community Flower Show, featured films on insects and plant life. A third community use of the films was in connection with a course on gardening given to a group of adults. This course was sponsored by the Parent-Teacher Association Council. 


\section{CHAP'TER III}

\section{TECHNIQUES OF TEACHING WITH SOUND FILMS}

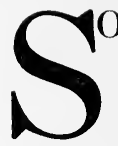

O FAR the discussion of method has been concerned principally with the teacher's purpose in using the film-with the part the film may be made to play in specific learning situations. But of equal importance is the "how" of the film-lesson procedure: how the film may be adjusted to the current interests and the abilities of the class; how it may be introduced in the day's lesson; how the film showing itself may be manipulated as a teaching device; and how the film presentation may be utilized as a springboard for the learning activities which follow. These techniques exhibit the teacher's craftsmanship in building the filmcentered unit, step by step, into an experience yielding the desired outcomes.

A problem of interest to the supervisor and to the teacher intent upon improving his skill in film instruction is that of evaluating the effectiveness of particular techniques used in a film lesson. The general criteria for good teaching apply of course to the film lesson-purposes clearly evident both to teacher and to pupils, a well-organized attack upon the subject matter, activities which engage both individual and group interests, resourcefulness in turning unexpected situations to good account, and the like. But how is the teacher's use of the film, that learning experience in which the student participates both as an individual and as a member of a group, to be judged? For example, was the picture introduced at precisely the right point in the discussion? Had the students acquired a questioning attitude which focused their attention upon salient features of the film? Did they begin to work immediately upon the facts the film had contributed 
and the further questions it had raised? Specific analysis of this type aids the teacher in opening up new possibilities for creative techniques. In general, a rough but usually obvious measure of success is the degree to which the students were stimulated in their attack upon the problems of the day's lesson. The teacher who analyzes his work from this angle is usually left in little doubt as to the effectiveness of the procedures by which the film was made a part of the learning situation.

\section{FREQUENCY OF FILM SHOWING}

It will be noted that some of the procedures described in this chapter apply to the initial showing of a film, while others refer to subsequent showings. This brings up the question as to the optimum repetition of a film during the course of a unit. When the film is directly presenting the main ideas of the topic, repetition of its use is extremely valuable. In experimental projects a talking picture has been shown as many as five times in a unit without loss of pupil interest. On the other hand, in some cases even the second showing of a film has met with bored inattention. The cause is obvious. Successful repeated showings and consequent gain in what is derived from the film result from making the film showing function as a direct answer to important new problems which the children have raised, or as the introduction to a new sequence of thought which dominates the reviewing of the film. In other words, where each showing is made purposeful in terms of the child's interests, it is worth while and productive. This discussion, of course, applies very largely to those situations in which the film is used as a means of direct teaching. When the teacher uses the film solely for appreciation or enjoyment purposes, or when the picture is only indirectly related to the topic under consideration, showing the picture only once may be quite valid.

A supervisor of film teaching presents this point of view with regard to repeated showings: 


\section{HOW TO USE THE EDUCATIONAL SOUND FILM}

Repeated showings of films are desirable with most films, for they are so rich in content that all that is necessary for a specific purpose can rarely be grasped at one time. Then, too, children need to use the knowledge gained at a first showing, experiment with it, read and study more, so that they can bring broader viewpoints to subsequent showings of the film. In many cases our teachers used the film only once during a study and at the time felt that once was sufficient; but when they thought over the good gained from the film they could see where a repetition of its use would have added greatly to the pupils' understanding, appreciation, and enjoyment.

A similar reaction is voiced by a teacher who used films in a rural school:

One showing of a picture is not enough. Repeated showings help to fix the desired points. The first showing acts as an introduction in giving an excellent background for the unit which follows. A reshowing and a discussion followed by a showing for final points or a review help to fix the ideas the teacher is stressing.

Differences of opinion among pupils concerning the film content sometimes demand a reshowing. One principal found that "not all pupils saw pictures alike, so in about three days the talking picture Plant Growth was run again to settle arguments that had arisen and to bring out points that had not been observed in the previous showing."

Teaching procedures involving the use of talking pictures may be conveniently grouped as follows: adapting a film to the current interests and capacities of a class; introducing the use of the film in the day's lesson; manipulating the film showing; and teaching after the film showing. Illustrations of techniques developed by teachers in the classroom use of films ${ }^{1}$ will be presented and discussed in this section. For purposes of contrast, common errors in film-teaching methods have also been classified and illustrated.

TECHNIQUES FOR ADAPTING A FILM TO THE CURRENT INTERESTS AND CAPACITIES OF A CLASS

From the point of view of form, the educational talking picture is a standardized presentation of selected subject

${ }^{1}$ See the various procedures demonstrated in the film Teaching with Sound Films. 


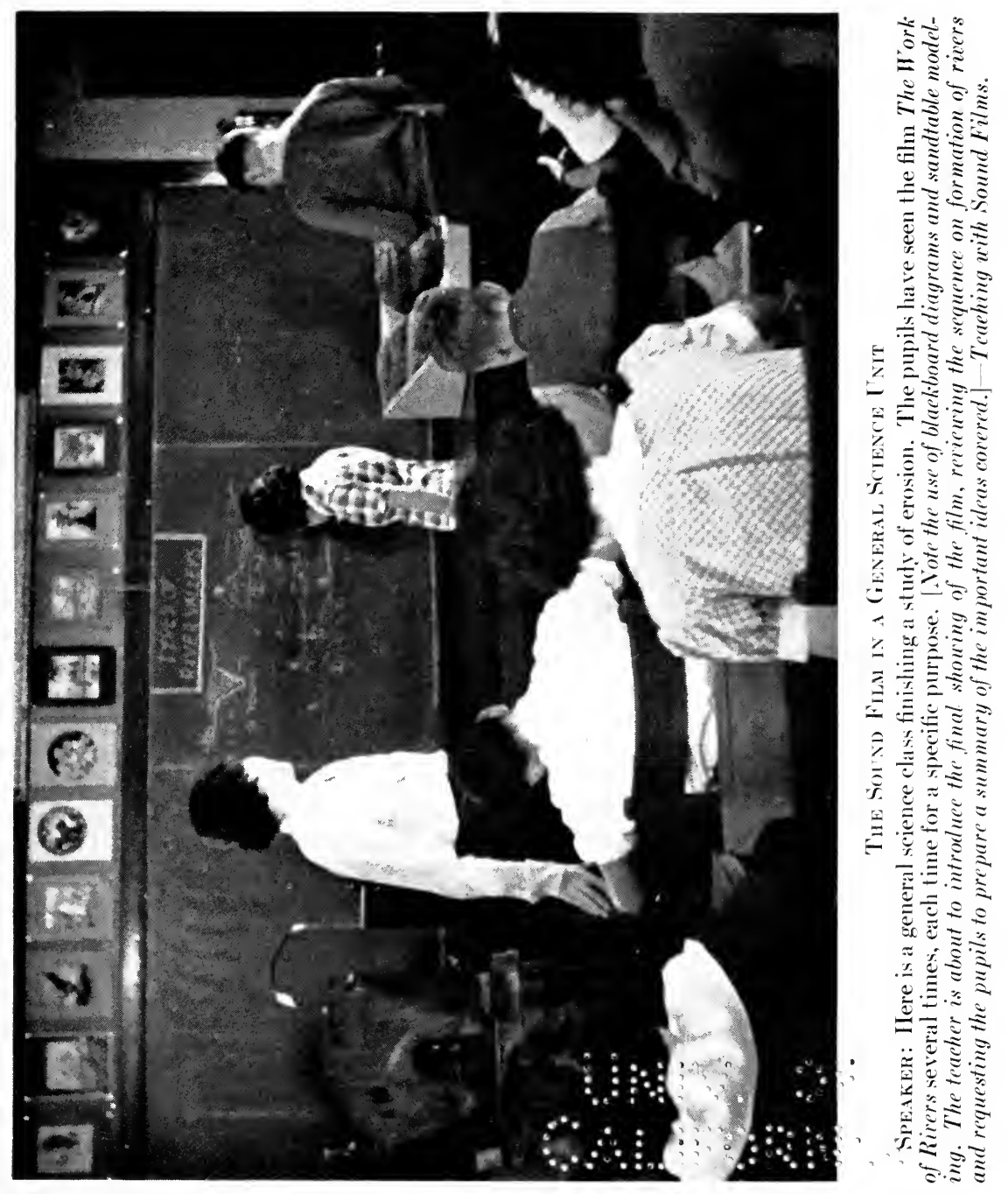




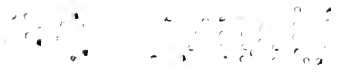

$$
\begin{aligned}
& \therefore, \because ? ; \cdots, \cdots
\end{aligned}
$$


matter, organized according to a definite continuity. It is highly important, therefore, that the teacher adjust its use to the group and individual needs of the class. A teacher may be planning to use a film because of its appropriateness for a particular unit, as the talking picture The Development of Transportation in a sixth-grade unit on "How Man Has Conquered Barriers to Land, Water, and Air Travel"; there is also the need to plan its use in terms of appropriateness for the learners. The students in the class have undergone experiences and exhibited interests which make for a unique situation in which the film is to function. These boys and girls may be living in a metropolitan area and so are familiar with most modern means of transportation; or they may be members of a class in an isolated rural school with little knowledge of the great transportation systems. Either situation demands a special approach to the use of the film if it is to build upon previous experience and lead to new areas of understanding. Again, the class may have engaged before in the study of transportation projects: the reproduction of a famous bridge in the vicinity or a visit to a new ocean liner. The projected film lessons have to be planned in terms of these previous activities - the new linked with the old-if learning is to be cumulative rather than a tiresome repetition of the familiar or a series of detached experiences. Furthermore, there is always the problem of adjusting the teaching to the ability level of the individual. The bright student may require only the pointing-out of one interest angle to lead him into an eager attack upon the many problems which the film raises in his mind. The slower student may need detailed preparation before the film is shown, in order to build up a foundation of understanding to which the film may contribute.

Although the talking picture may be standardized as regards its presentation of subject matter, it is quite flexible as a teaching device. The numerous illuminating scenes contained in a single reel reflect themselves in so many facets of 
student interest that a wide variety of opportunities for the individualization of instruction is afforded. A superior sound film is so highly organized in sequence of ideas, and so stimulating to the perception of interrelationships, that its use may be varied directly according to the individual student's need. A film may be shown simply for appreciation, skimmed through for minimum essentials only, studied exhaustively for a complete mastery of its subject-matter content, or extended in tangent enrichment areas.

It is worth while in this connection to point out that a common source of error in the teacher's use of the film is the unthinking notion that all students see and hear the same things in a talking picture. Nothing could be farther from the truth. A student observing a sound film is conditioned by his background of experience, from which certain interests and understandings have grown; naturally he attends to those elements of the sound-film presentation which attract his attention as both comprehensible and appealing. It is the teacher's task to make sure that the conditioning is adequate for the perception of those sounds and visual images which are important in attaining the purposes of the lesson. Failure to recognize this principle leads to such mistakes as presenting a film "cold" and hoping that it will do its work.

A. FitTiNg THE FILM to THE GRADE LEVEL

A typical illustration of adjusting a film to the needs of a class is the adaptation of a picture designed for a certain level to the understanding of pupils in a lower grade. In one elementary school the teachers at first considered certain films somewhat advanced for their pupils. They spent much time and thought, therefore, upon the problem of stepping-down both the film content and the recorded speech. Among the devices employed to achieve this effect were the study of difficult new words before the film was shown; teaching the general outline of the film subject matter before the children were allowed to see the picture, so that they might more readily 
follow the continuity of thought; concentrating upon a few essentials which the teacher thought appropriate for the children in the group; and presenting only part of the film at a time, with repeated showings.

The opposite situation occurs when a teacher in an advanced class wishes to use a film which in some respects is elementary, but which presents certain relationships or concepts important for the topic being studied. Here the teacher directs the students' attention to the sequences or the ideas which are to be discussed later, thus placing the less useful content in the background.

\section{B. UTILIZING THE ENVIRONMENT}

Environment plays a large part in developing the interests upon which the teacher may capitalize. A third-grade class in a metropolitan school was about to study a sound-film unit on beach and sea animals. By way of preparation the teacher appealed to the children's background through their familiarity with Coney Island and the shells they had found on the beach there. As they began to appreciate that those shells were once the homes of beach and sea animals, they became keenly interested in the types of marine life which the film was to present. The name of each animal shown in the film was mentioned several times, so that the children would be familiar with the sound of those names coming from the loudspeaker.

The boys in a sixth-grade class had become very much interested in the problem of ridding their community of tent caterpillars. Much investigation had taken place. The boys had talked with their teacher about methods of destroying the nests and gradually the class as a whole became interested. In this interest the teacher recognized an opportunity to give some understanding of the complete metamorphosis of insects. She introduced this study with the sound film Moths. Because of their interest in the preservation of the trees by destroying the nests of the tent caterpillars, the chil- 
dren had looked up much information about caterpillars and had shared it by giving reports on their observations, activities, and readings. With this as a preparation for the showing, a very alert class began a unit of work on the life-history of moths and butterflies.

C. RELATING THE FILM TO OTHER SCHOOL EXPERIENCES

School-wide projects are centers of absorbing activities promoting the use of a wide variety of instructional materials. A fourth-grade class was preparing to participate in a circus, as part of the "World Fair" which the school was holding. The problem of immediate interest to the children was that of acquiring more information as to the behavior and appearance of some of the circus animals. The teacher therefore introduced the sound films Animals of the Zoo and Animal Life. The following list of observation points, prepared in a preliminary discussion by the pupils and teacher, shows plainly the teacher's technique in adjusting the use of the film to the current interest of the group.

1. Listen for noises of animals

2. See what the animals look like, especially their markings, so that costumes may be made

3. See how the animals are managed. [The teacher warned the children that they would not see much of this in the picture since it was not the fundamental purpose of the film]

4. Watch the characteristic movements of the animals

5. See how they act when people approach

6. Find out what, when, and how the animals eat

In a second-grade classroom a terrarium inhabited by two chameleons (the children had dubbed them "Minnie" and "Mickey") was a source of constant interest. The pupils had read stories about chameleons, and each pupil had made a scrapbook about animals. When the film How Nature Protects Animals was shown, this provocative background of classroom experience focalized attention on the sequence showing the protection which nature has given the chameleon. 


\section{INTRODUCING THE USE OF THE FILM IN THE DAY'S LESSON}

The teacher's procedure in introducing the use of the film in the lesson is of more significance than is commonly realized. In the first place, it gives the student a perspective for looking at the picture and for listening to the accompanying sound. The questions the teacher asks and the comments he makes throw into bold relief certain elements of the screen presentation, thus controlling to a large extent what the pupils are going to observe in the picture. In this respect it might almost be said that the sound film is a blank check to be filled out by the teacher in accordance with the plans for the particular lesson. The technique of introducing the use of the film therefore overlaps that of adapting the film to the current interests and the capacities of the class, since both procedures involve setting the stage for the use of the picture.

The technique which the teacher uses to insert the talking picture into the frame of the lesson is definitely shaped by the objectives for the lesson or unit. Certain concepts are to be mastered; how is the student's attention to be directed toward their appearance in the film? Specific attitudes and habits are to be encouraged; how are they to be brought to a sharp focus for the duration of the film experience? There is no suggestion of standardized techniques in this emphasis upon controlling objectives. The teacher may seize upon any approaches which suit the lesson purposes and tie in directly with the content of the particular film. The film presentation may be preceded by a group discussion isolating questions for study, by the demonstration of an experiment, by a story or dramatization, or by merely a few comments which arouse curiosity.

It is possible, of course, to overdo the introduction to the film. One teacher pointed this out: "Too much detailed discussion of the film beforehand kills the interest of the pupils." But she went on to say: "I find it better to motivate and to 
make clear to the pupils the things to be learned, so that they can read and find out what is to be learned after the picture has been shown." Perhaps the reason for this attitude is explained in the cautious remark with which she prefaced these statements: "In some cases it may be more efficient if teachers have the opportunity to know beforehand the pictures which are to be shown."

\section{A. LEADING QUESTIONS ON FILM CONTENT}

A special technique was devised in a large junior high school class to introduce the use of films. After the auditorium teacher had previewed the films which he intended to use, he made up a list of key questions and prepared slides on which these questions had been typed. At the start of the period, after a brief announcement, the slide with the list of questions was thrown on the screen and the class was told to memorize these questions so that they could look for the answers in the film to be shown. For a subsequent showing of the same film the teacher indicated the important points to be observed, speaking to the group over the microphone.

The same teacher tried the practice of showing the film at the beginning of the period, leading the subsequent discussion, and reshowing the film at the close of the period. He remarked: "Reshowing the film without requiring some special report or summary does not keep the children's attention. Some definite work must be assigned which bears on the film being shown." This is in keeping with observations made by other teachers. The teacher should provide a fresh viewpoint from which the students may view the film again. It is probable that in the case cited, showing the same film twice in one period allowed too little time for the assimilation and exploration out of which the need for the second showing arises.

B. ADVANCE ASSIGNMENTS BASED ON THE FILM

Advance assignments of activities to be based upon what appears in the film is another introductory technique. Pre- 
paratory to a showing of the film Choosing Your Vocation, boys in a slow Grade VI B class were told that they would be expected to write a short paragraph telling what qualities the boy in the picture lacked that made his first job last only a week. For a subsequent showing, another written composition assignment focused their attention upon the qualities which finally landed the youthful hero in a suitable vocation.

Sometimes the introduction to the use of the film may take the form of individual assignments. For instance, a teacher using the film The Brass Choir gave two or three general questions to the class before the film was shown and at the same time assigned each pupil several things for which he was expected to watch. An interesting outcome of this technique was the fact that after the assigned questions were answered satisfactorily many of the pupils proposed additional questions which they wished to have answered.

\section{PREPARATORY TEACHING OF SPECIFIC FILM ELEMENTS}

In a sixth-grade class studying the film Sound Waves and Their Sources (essentially a high-school picture), the teacher drew attention to the city noise so familiar in the everyday environment of her students. The preliminary discussion centered around the fact that New York is a city of noises. On the blackboard a list of familiar city sounds was made and the pupils were requested to watch for the sources of these sounds as they occurred in the film.

A junior high school teacher was introducing the film Choosing Your Vocation to a group of boys and girls. She began the lesson by getting the students to see the shades of meaning differentiating several terms commonly regarded as almost synonymous - “"job," "occupation," and "vocation." By bringing out the "calling" idea of a vocation, she focused attention upon an important trend of thought occurring throughout the film - the idea that the individual's satisfaction in his work depends upon his choosing an occupation for which his interest and capacities fit him. Note that this type 
of introduction is somewhat more advanced than the one in which students are told simply to watch for specific scenes to be discussed afterwards.

In another class the teacher began a repeated showing of Beach and Sea Animals by asking her students to note the use and application of certain words and phrases in the lecture-“invertebrate," "dig himself in," "claw," “dart," "animals of the beach and sea." A somewhat similar approach was that of the teacher who wished to focus attention upon a specific sequence. For the second showing of the film Work of Rivers she placed a diagram of the river's erosional action on the blackboard and asked the students to watch for that diagram and explanatory scenes in the picture.

By way of introducing the film How Nature Protects Animals in a week's unit on that topic a teacher asked what men must do before they can go safely into the jungle. 'The children, from their readings about African explorers and their acquaintance with theatrical films, replied that men had to provide themselves with guns and spears and bows and arrows. The teacher then raised the question as to what the animals did for protection since they did not have the protective devices which man possesses-“if you watch closely, you will find the answer in this film."

\section{DRAMATIZATION LEADING INTO THE FILM SHOWING}

Dramatization is a favorite introductory activity for sound films in primary-grade classes. In an auditorium group of second-grade children in a platoon school, the teacher had planned to show the film The Frog, using a lecture modified for that level. To introduce the film showing she took the one hundred and fifty children on an imaginary trip to the woods.

"Children, today we are going on a picnic. Oh, I know this is not the time of the year to go on a picnic but we are going to make believe that it is a lovely spring day and go out into the woods. Ready now, we're going to start on our hike." [The children formed a line and marched about the room.]

"Isn't it a beautiful day, children? Let's see how many can find some- 


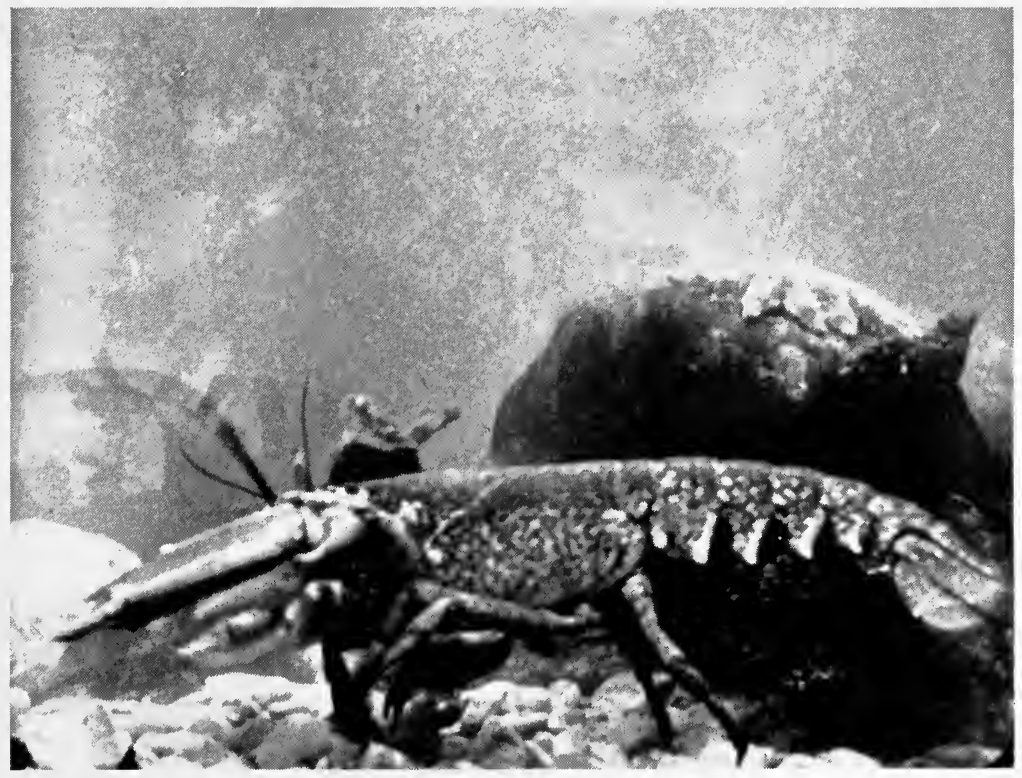

Watching Life inder the SeA

SPEAKER: The lobster has an armor-like skeleton on the outside of the body as do the other animals of this group. This is an advantage at the bottom of the sea where dangers lurk in every corner. Lobsters have their eves mounted on stalks.Beach and Sea Animals. 


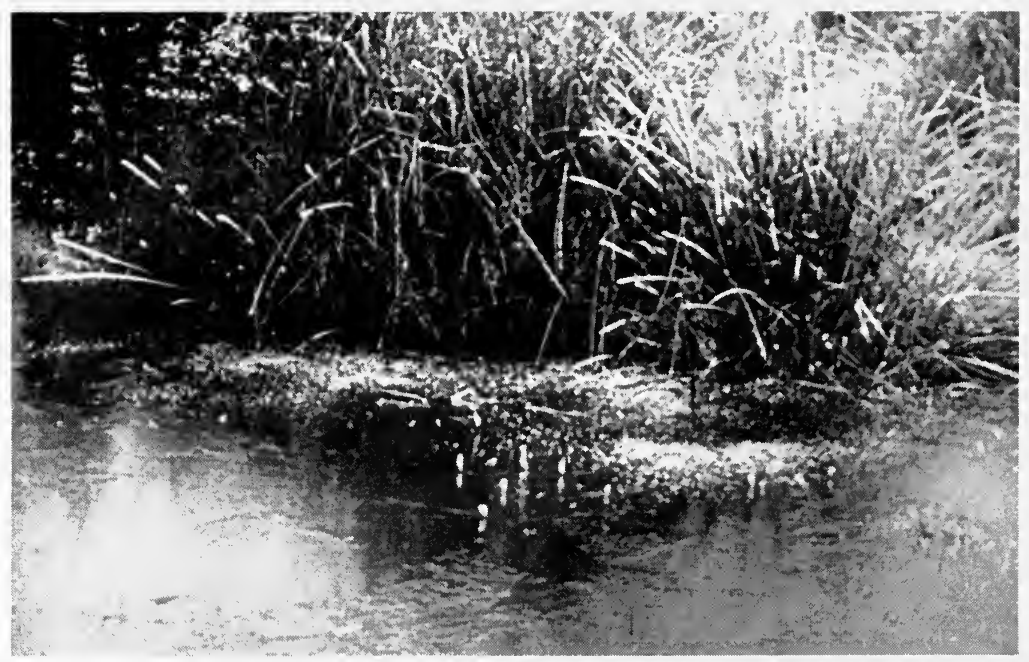

TAKING a Field Trip iN the ClassRoon

SpEaker: We are about to visit the home of one of the most interesting animals in all nature. All winter long this animal has been hibernating deep in the mud at the bottom of the pond.--The Frog. 
thing interesting out here in the woods. Notice the spring flowers along the roadside and the many different kinds of trees. Here is a nice shady spot. Let's sit down by this picturesque little pond." [The children were asked what they observed as they came along: flowers, trees, birds.]

"I see something. Why, what is this, a stone is moving! It's a little frog!" [Teacher holds up a frog.] "I wonder where it came from? Do you know? Don't be afraid. I've heard that frogs are our friends. Why are they our friends? There is something very strange about a frog. A little bird was a little bird when it came out of its egg; but the frog wasn't a frog when it came out of its egg. We are lucky to be here in the auditorium, for now we'll be able to see in a picture just what the frog was when he came from the egg. This little frog seems to know that we are going to learn his secret. I think he's glad, for I know he wants to be your friend."

A similar approach was made with a primary grade class studying Animals of the Zoo. The children were asked to imagine that they were taking a trip to the zoo, stopping at each cage to visit the animal it housed. Another method of introduction used with the film Animals of the Zoo was to ask the children to pick out three very large animals, the meateating animals, and the vegetarian animals.

In the primary grades the appeal to the young child's love of nursery rhymes and the world of imagination provides an excellent introduction to the use of the films such as Jack and Jill in Songland. One teacher, beginning the presentation of written music in a second grade, was using the talking picture Jack and Jill in Songland to motivate the study of the staff. Just before the film was projected the children spent an enjoyable period imagining what Jack and Jill might be doing in Songland.

\section{E. USE OF OTHER VISUAL-SENSORY AIDS}

Visual and auditory devices are sometimes employed to lead up to the use of the sound film. In a music-appreciation lesson on The Brass Choir, the showing of the film was preceded by studying large pictures of the brass instruments, and victrola records featuring the brass choir. One teacher who followed this plan concluded that it might have been 


\section{HOW TO USE THE EDUCATIONAI SOUND FILM}

more effective to employ the sound film first, utilizing the other devices for detailed study between the first and second film showings.

Objects and specimens--things the students can see and touch-are helpful in creating interest and understanding, either before or after the film showing. A teacher of elementary science, preparing to use the film Flowers at Work, brought in an alder blossom from which he shook the pollen and explained its function. He then asked the students to watch the film for the different ways in which other flowers spread their pollen.

In one school system, experiments, collections, and projects were frequently used to initiate the use of a talking picture. A teacher who had studied the picture on Plant Growth and the accompanying manual, helped the children plant bulbs and seeds in windowboxes, as a basis for bringing in the picture after the development of the plants had been watched for a time.

The illustrations found in assigned readings were also used to stimulate questions which the film could answer. In a unit on various forms of animal life one class had done considerable reading and had sought for pictures showing early forms of animal life. When the teacher introduced the film she asked the pupils to give particular attention to new words and new types of animal life they had not met in their previous reading.

Field trips and nature-study hikes provide that definite contact with reality which the sound film supplements and extends. Children who have been trained to observe the rich resources of their environment bring to the classroom a wealth of appreciations which the teacher may tap in beginning the study of plant- and animal-life concepts. The talking picture, recalling to the child's mind things he has seen and presenting further experiences beyond the scope of his environment, serves to organize his knowledge in terms of new relationships. Note in the following illustration how 
the teacher drew upon the pupils' outdoor experiences to motivate the study of the film:

A sixth-grade teacher planned to show the film How Nature Protects Animals as part of a study on "Adaptation to Environment" emphasizing the concept that nature has provided a protective system for the perpetuation of her species. Before the film was shown, the children talked over the experiences they had had in finding birds, in trying to see a bird after they knew it was in a particular tree. They recalled seeing a chipmunk dart away, a toad jump, or a frog leap, when they had not been conscious of the animal's presence. Some had discovered insects which looked so much like the bush, twig, or leaf that they almost went unnoticed. The children then examined aphid-covered twigs which had been brought in to illustrate protective coloration. With this background, the film was shown, the pupils studying it to see if it showed any of the methods of protection they had found on their nature hikes, and to learn if there were other protective devices they had not yet discovered.

Good teachers never seem to be at a loss despite administrative maladjustments and failure of film-distribution schedules. Notice that in the report reproduced below the teacher made the best of what might have been an awkward situation:

Extensive preparation could not be given because I did not know about the arrival of the picture Animals of the Zoo previous to the date of showing. However, since the children had never seen pictures of this type I asked how many had ever visited the zoo. Two pupils in the class had, so I had them tell what animals they had seen in the zoo and what they observed about the habits of the animals. After having heard this report from their classmates, the rest of the children were quite eager to see the picture.

The teacher's preparation for the use of a film in initiating the study of a new unit, particularly in the case of those who are not exceptionally well prepared from the subject-matter standpoint, sometimes "backfires." A third-grade teacher had planned to develop a unit on "Moths." Several weeks before the showing of the film she had brought a cocoon into the class and had talked about it every day to the students. The class was anxiously awaiting the time when the beautiful creature they had been hearing and reading about would emerge from the cocoon. However, much to the teacher's 
consternation (and the pupils' amusement), the cocoon finally hatched out into spiders. Because of the interest aroused by this unexpected event, the sound film Spiders was secured and a unit on spiders started.

\section{TECHNIQUES OF MANIPULATING THE FILM SHOWING}

The sound film's so-called "mechanized presentation of subject matter" holds no terrors for the creative teacher. It is not surprising, therefore, that ingenious teachers have found ways of adapting the film showing itself for special instructional purposes. In addition to the usual complete sound-film presentation the film may be shown as a silent subject with teacher comments, as a silent subject with pupil comments or descriptions, and as a sound film a few sequences in length. Or, during repeated showings, projection may be halted momentarily for comments and discussion.

It may be argued that the educational talking picture is so constructed that its significance is lessened when any such adaptations are made. It is fairly obvious, however, that this contention applies only to the initial showing. During the first showing the student needs to observe the film as a complete exposition with a well-defined development of thought. Once this background has been established, there is no reason to suppose that other teaching purposes may not be served with equal facility through the use of the sound film in ways differing from the ordinary showing.

\section{A. INTERRUPTED SHOWINGS}

Sometimes in second and third presentations of the film, teachers have found it desirable to stop the projection for a brief explanation or the discussion of a point. (This is quite simple mechanically: the volume is quickly turned down, and then the projector motor and lamp switches are shut off.) The following description shows how easily and naturally the teacher may utilize the talking picture at opportune points during the lesson: 
A ninth-grade group was studying electricity, a discussion was under way, and the film was needed. With a statement something like this: "Our talking picture will help us understand this problem"- the teacher stepped to the projector and the boys nearest the windows attended to the shades. The film was stopped three times during the showing for guiding the thought of the pupils. A boy sitting near the light switch turned it on during the questions and discussions. Then the showing was continued. When the film was finished the discussion was resumed. The use of the film made no more break in the thought of the hour than a reference to a picture in a textbook or the demonstration of an experiment.

A normal-school science instructor, in connection with his work as supervisor of practice teaching in nearby elementary schools, gave several programs of films to the entire student body in each building. For each program he presented three sound films. Because he felt that certain scenes might be somewhat advanced for the pupils in the lower grades, and because he wished to weave the three subjects together in a definite continuity of thought, he stopped the projection at times to comment upon the previous scene and to introduce the next scene. This illustrates the flexibility possible in the use of the talking picture. It should be pointed out, however, that the procedure described requires careful planning and skilful commentary if the pupils' attention is to be maintained.

\section{B. QUESTIONS AND ANSWERS DURING THE SHOWING}

The combined impression made by the visual and auditory components of the sound film would seem to tax the students' concentration sufficiently. Indeed, in the early days of the educational sound film, certain critics argued that the child could not attend to one without missing part of the other. However, some teachers have experimented with various methods of securing pupil reactions during the projection of a film.

The stereopticon has been used to present questions while a film is being shown. Sometimes teachers inject a short question or a comment during the showing to keep the children thinking about particular aspects of the picture. A 
fifth-grade teacher boldly explored the problem of attention by mentioning in the preliminary discussion certain things she wished the children to notice, and requesting that each time they saw these things in the picture they should raise their hands.

There is no doubt but that procedures which divide the students' attention should be used cautiously. In the first appearance of the picture in the unit there should be no interruptions; during subsequent showings, when students have become familiar with the film's continuity of thought and are observing specific features, it may not be amiss for the teacher to throw in a parenthetical comment or question now and then. The auditory interruption may be less likely to distract than the visual interruption.

\section{USING THE SOUND FILM AS A SILENT SUBJECT WITH TEACHER COMMENTS}

This adaptation might be expected to occur most frequently for films with integrated explanation. However, it is conceivable that it might be used even with a sound film such as The String Choir if the teacher wished at some point to concentrate the students' attention upon watching the player's fingering and bowing techniques. The purposes for which the teacher may substitute a commentary for the recorded interpretation may be classified as follows:

a) To adapt an advanced film for an elementary class

b) To concentrate attention in a repeated showing on certain purely visual elements in the film

c) To review rapidly important visual elements depicted

A first-grade class studying Animals of the Zoo saw the film the first time in its natural form. After some study in which various art projects growing out of the film were undertaken, the teacher presented the film for the second time, but without the sound, so that she might explain how certain animals should be drawn. According to the teacher, this procedure was quite satisfactory.

A fourth-grade class was studying a film on Butterfies. 
The subject was somewhat foreign to the children's experience since they live in the metropolitan area. Realizing this and wishing to adapt the recorded explanation to their understanding and background, the teacher prepared a special commentary. Standing behind the projector, she described each scene as it appeared. The commentary was excellent, very well synchronized, and quite animated. It is evident that this teacher had solved the difficulties which beset the path of those attempting for the first time to give a running commentary for a sound film projected as a silent subject. Without careful preparation and much practice, it is impossible to integrate description with the screen image appearing rapidly and moving steadily toward each succeeding scene. Some teachers tend to talk too much about each scene, which not only gets them out of step with the screen but also loses the students' attention.

\section{USING THE SOUND FILM AS A SILENT SUBJECT WITH PUPIL COMMENTS}

This device has been found useful as a review exercise, because of the ready command of the subject which the student must have in order to explain the film action clearly and quickly. A variation of this technique was proposed by a teacher who had used the film Electrostatics in a general review exercise. He suggested showing the film without sound, following a brief introduction of the subject. He would then have the pupils write a dialogue to accompany the film. Then the film would be shown with sound, to compare the recorded explanation with that made by the pupils. The film would be available for projection several times during the script-writing process. As another means of review and general checkup, there would be demonstrations of experiments not understood from the film presentation. This might be an interesting exercise toward the end of a unit. However, the film should be shown with sound at the beginning of the unit so that the students may have the advantage of the recorded 
explanation at the outset. The efficiency of the recorded interpretation should not be wasted.

A somewhat similar device was used by a fifth grade teacher who showed the film Spiders four times during a unit on that topic. The film was shown with sound the first time, silently the second and third times, and again with sound for the fourth time. During the first silent presentation the pupils were asked to write questions they could not answer from the film. After the last showing the pupils checked those questions which were answered by the film explanation.

E. SHOWING ONLY A FEW SOUND FILM SEQUENCES AT A TIME

The use of only part of a talking picture for a lesson has sometimes been proposed as an advantageous procedure. After an initial full-length presentation of the film, when the students have a chance to study the material in its complete organization and context, subsequent showings of particular sequences may result not only in greater concentration of thought and attention, but in a saving of class time as well.

The teacher who developed the vocational guidance unit mentioned on page 51, utilized the sound film several times. The first time it was shown in its entirety to give an appreciation of a typical boy's experiences in finding the right occupation. Following the initial showing, subsequent lessons were built around more specific elements of the unit, one or two appropriate sequences being shown for each lesson. For example, at the third meeting of the group the teacher stressed the importance of analyzing a vocation before trying to enter it. After a preliminary discussion which centered around a previous episode in the film, the pertinent sequence in the film was shown. Here the boys and girls followed their friend "Bill" as he tried to work at an occupation for which he had no aptitude; after he was discharged, they watched him analyze his traits and abilities by means of a vocational selfanalysis form. The film was then stopped, after approximately four minutes of projection. In the ensuing discussion, the class talked over the reasons for "Bill's" dismissal, and esti- 


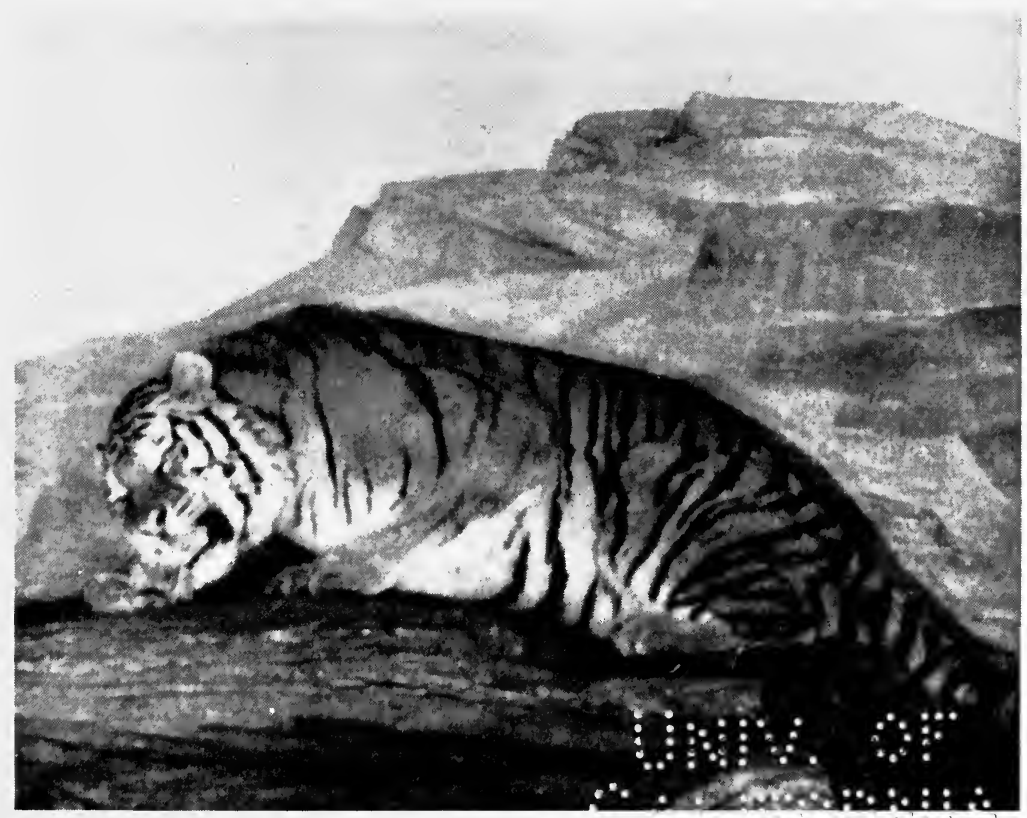

Ising tue Sorvd Filu as a Review Device

Voice of Thind-Grade Girl [the recorded sound has been turned off, and the pupil is describing each scene as it appears]: This tiger eats raw meat. He misses his home in the jungle. His stripes would make him hard to see in the tall grass.Teaching with sound Films. 


$$
\begin{aligned}
& { }^{4} \cdot, \cdot a \\
& \therefore \vdots: \therefore i, \quad .
\end{aligned}
$$


mated his chances for success in the new occupation he had decided to tackle. As an assignment, the teacher asked each student to prepare a vocational self-analysis. The remarkably keen interest and participation of every member of this large group proved the effectiveness of the "sequence showing" technique in the hands of a good teacher.

\section{TECHNIQUES OF TEACHING FOLLOWING THE FILM SHOWING}

The procedures which have been discussed so far are in general those leading up to the main study of the unit. The preparation of the students for the initial film showing involves the linking of past experience with that to be presented by the film-a linking controlled by the purposes which the teacher has set up for the lesson. Preparation for subsequent showings establishes viewpoints for observing specific film elements, in line with the questions and problems on which the students have been working. The form which the use of the film may take has been shown to be adaptable to the needs of various occasions. After the film showing the student is ready to react to what he has seen and heard, to investigate, to acquire more information, and to put his knowledge to work.

\section{A. Discussing THE FILM}

Discussion will naturally follow the film showing. After the initial showing the teacher is intent on bringing out (1) interest leads - things seen or heard in the film which appealed strongly either to individuals or to the whole class; (2) connections with past experience-an extension of the teacher's introduction to the film in which he developed connecting links; (3) the discovery and correction of any mistaken ideas which may have been formed; and (4) those new ideas which will require further study for their understanding.

After subsequent uses of the film, the discussion serves to bring to a focus what the students have derived from the showing, in terms of the purposes for which it was held. For 
example, an initial showing of the film The Frog may have been given to provide a general appreciation of the stages in the life-cycle of the frog. One of the subsequent showings may be planned for the specific purpose of giving the students an accurate picture of the appearance and characteristics of the tadpole as it grows into a frog. There would be a marked difference in the character of discussion after each of these two film uses.

In the discussion, learning activities involving the film subject matter may be initiated. It is important to remember in this connection that the impetus derived from the film showing should be utilized throughout the various stages of the unit by references to what the film has explained or demonstrated.

During the final stage of the unit when the film has been shown as a summary device, the discussion after the showing naturally becomes a review exercise. The methods of reviewing the concepts of the unit by means of the film follow in general those used for any good review teaching. The difference here is that a powerful recall device is presented as a preliminary, so that the students not only have an immediate check upon what they have learned and what they may have missed but also have the opportunity of seeing in perspective the larger thought relationships in the subject matter as organized by the film.

A variety of discussion activities may follow the film showing. The teachers in an elementary school made the following list of methods commonly used:

a) Answering questions on the blackboard

b) Asking questions for answers

c) Making riddles about what was seen

d) Listing names of things mentioned in the film

e) Naming parts on diagram after intensive study

f) Flashing homemade slides on the screen as a basis for further discussion

In a large-group science class a favorite device for guiding the pupils' observation of the film and directing the subse- 
quent discussion was to throw a slide on the screen giving a list of questions to be kept in mind during the film showing. After the film had been presented, the questions were again thrown on the screen and answered by pupils who had received previous assignments. In their talks the pupils made use of drawings on the blackboard.

An interesting type of discussion centering around the idea of identification is given in the following transcript of part of a film lesson on Spiders. In the introduction the teacher had emphasized the special life of different kinds of spiders. After the film showing the discussion proceeded as follows:

T.: Each kind of spider was given its name for a particular reason. Let us first take those whose names you will be able to explain. Why do you think the Nursery Web spider was so named?

P.: Because that spider watches the little spiders in the web [or nursery].

T.: Yes, and this spider has still another name. This spider does not stay in its home and wait for food to be brought to it. She goes out to look for her food. What other name would you give her?

P.: Hunting spider.

T.: Fine, good reasoning. Can anyone think of a reason why the Orb-Web spider was so named? (No hands.) Does anyone know what the word "orb" means? (No hands.) This word comes from a word meaning "round." Now can anyone think of the reason?

P.: That name was given because this spider spins a round web.

T.: Good, that is the reason. What about the Trapdoor spider?

P.: This spider makes a door at the end of her home to keep out strangers.

T.: Very good. What sort of strangers, particularly, does she want to keep out?

P.: Insects.

T.: What else?

P.: Bees.

T.: Yes, and why does the spider want to keep these from entering?

P.: Because she thinks they want to do her harm.

T.: What do you call such people, or beings, or insects?

P.: Enemies.

T.: Exactly, that is why she builds that trapdoor. What other spider was shown in connection with this one? (No hands.) Did you notice one 
spider who builds her web or home in this shape (illustration on board), a thing your mother uses for pouring liquid into a bottle, with a very narrow neck?

P.: Funnel spider.

T.: The Trapdoor spider has the door at the end of her home, but the Funnel-Web spider leaves her home open.

B. COMPLETING ACTIVITIES STARTED BEFORE THE FILM SHOWING

The discussion and the learning activities following the film showing are conditioned to a large extent by the preparation which has been made for the use of the film. Herein lies the most obvious advantage for planning the film lesson in terms of a unit of work. To illustrate the integration of activities before and after the film showing, a teacher's description of a sixth-grade unit on insects is reproduced here. In this unit the direction of the study was dictated by the unfolding student interests. The topic itself was suggested after the children had learned, in their social-studies work, of the destruction wrought by harmful insects along the entire coast of the eastern United States. In their investigation of various insects special interest developed in the aphid. The teacher secured the sound film Aphids and a detailed study, aided by the picture, was made regarding the life-cycle and habits of this insect. Of special interest in this project is the correlation of visual aids with the use of the sound film. 'The teacher's account follows.

\section{OUR UNIT ON INSECTS}

In planning for this unit, our aims were:

1. To have the pupils make a thorough study of the life-history of different types of insects, both harmful and helpful

2. To show that many insects, though harmful to man, serve a definite purpose on earth

3. To have the pupils identify these insects

4. To have the pupils know how man attempts to control insects that are harmful to him

5. To have the pupils understand in what way certain insects are useful to man

6. To have the pupils understand the tremendous damage done by insects to crops in the United States 


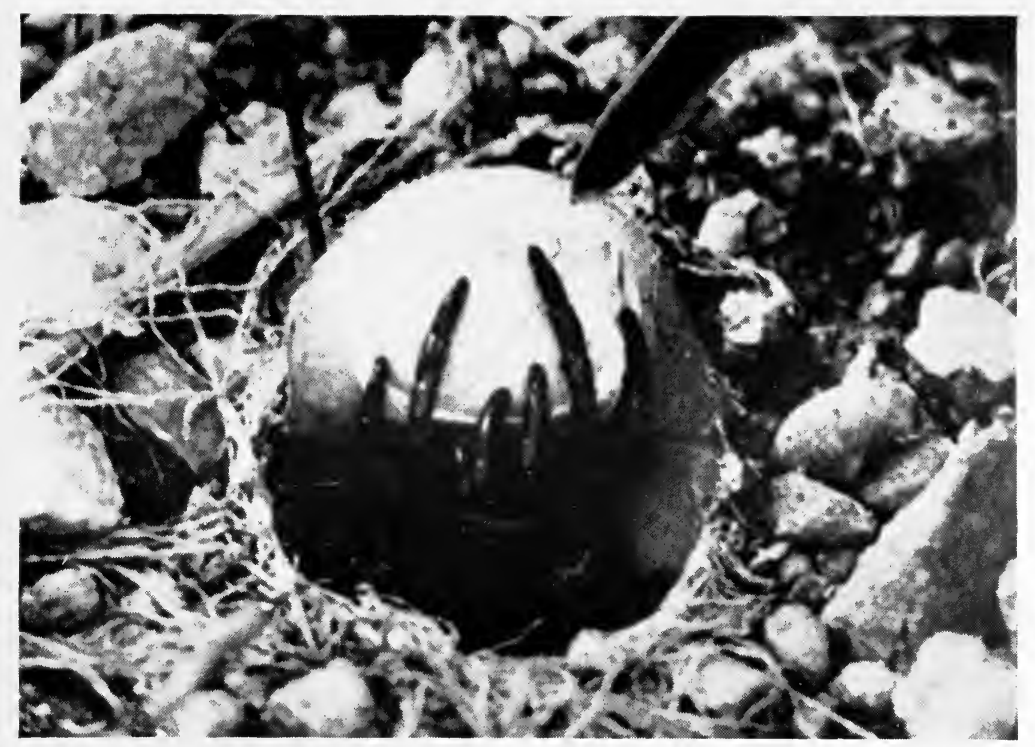

The Trapdoor SPIDER

SPEAKER: This spider digs a hole in the ground which it closes at the top with a trapdoor. The door is lined with silk which serves as a hinge, and is beveled to make it fit perfectly with the top of the tunnel. Considerable force is necessary to pry open the door, as the spider holds it tightly closed with its claws.-Spiders. 


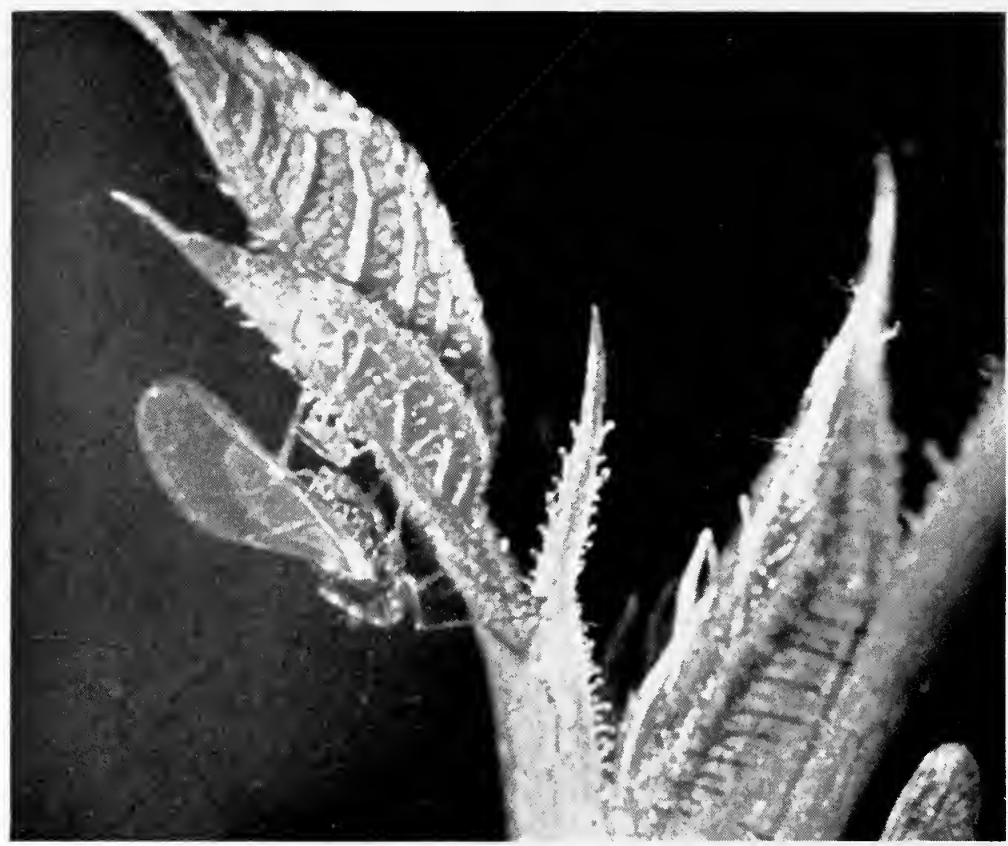

A Destructive Insect Pest-the Aphid

Speaker: The first generation of the spring and the following generation are all females and wingless. Their young do not pass through the egg stage but are born alive.-A phids. 
The pupils' aim was to be able to identify and to discover all they could about the insects of which they had read.

From the many insects suggested the class selected the following for an intensive study:

1. The fly

2. The mosquito [Culex and Anopheles]

3. The paper wasp

4. The honey bee

5. The termite

6. The common ant
7. The Japanese beetle

8. The boll weevil

9. The tent caterpillar

10. The silk moth

11. The monarch butterfly

12. The aphid

13. The ladybird beetle

As we approached the study of each insect, a list of questions was prepared by the group. Every available source of reference material was used to answer these questions to the children's satisfaction.

The following questions prepared for the study of the aphid illustrate those used in the study of each insect:

1. How large is an aphid?

2. Have aphids protective coloration?

3. Why are aphids harmful?

4. Is the aphid at all useful?

5. Do aphids shed their skin?

6. Is the aphid a social insect or does it live alone?

7. Does an aphid lay eggs or are the young born alive?

8. Do aphids pass through four stages in their lifetime?

9. How do aphids breathe?

10. Which is more harmful, the male or female aphid?

11. Is the male active or is he like a drone?

12. What kind of mouth parts has the aphid?

13. How long does an aphid live?

14. Are the young born all at one time?

15. Does the mother aphid stay with her young?

16. Has an aphid eyes or are its antennae its only source of sense?

17. What are the natural enemies of the aphid?

18. What methods are used to destroy the aphid?

After the preliminary work on the aphid was completed the sound film Aphids was shown to the school. Although the class saw it twice, we had to show it a third time to answer numerous new questions that arose. Here are some of them:

1. In what climate do aphids thrive best?

2. Could aphids live on anything other than plant juice? 
3. What causes the plant leaves to curl if aphids are on them?

4. How can aphids give birth to young without a mate?

5. Why do female aphids give birth to live aphids in summer and lay eggs in the fall?

6. Why do the aphids allow the ants to take the sweet substance from them without giving fight?

7. How does the ant protect the aphid?

8. Why are male aphids born only in the fall?

9. Has the aphid enemies other than the syrphus fly larva, the ladybird larva, the ladybird beetle, and man?

10. Why have some aphids wings and others none?

11. Why haven't the aphids wings until they last molt?

12. Why do aphids eat more than they need?

13. How are aphids protected from the weather?

14. Why is a soapy solution particularly good to fight aphids?

These were individual questions, many of which could have been answered if opened for class discussion, but the children preferred to satisfy themselves, if possible. Several answers were not found in the film and necessitated much additional reference work.

Two boys discovered both black and green aphids on a bouquet of flowers in the classroom and showed the different sections of the body, the antennae, the proboscis, the head, and the legs under the microscope. The class was delighted but amazed at the intricacy of the insect. The following day one child brought in several leaves, completely covered with aphids, in a quart jar. When it came time to examine them, everyone was thrilled to find we were fortunate enough to have two enemy larvae as well.

Among the materials of instruction employed in the unit were the following:

1. A small ant nest for observation

2. Exhibit of walnut wood taken from chest destroyed by termites

3. An observation beehive filled with a swarm caught in the woods near school. [Last year we were given one frame from a honey beehive, without a queen, but containing day-old eggs and energetic workers. It was most fascinating to watch. In fifteen days a queen developed, making our colony complete]

4. A case showing the different stages in the life of a bee

5. Discarded paper wasps' nests

6. A field trip to observe the tent caterpillars at work and the damage done; also the removal of nests on the school property

7. A three-reel motion picture on the silk moth and the silk industryloaned by a Japanese parent 
8. The sound film Aphids

9. Stereopticon slides and filmslides from the Visual Education Department

C. ORGANIZING ACTIVITIES FROM THE FILM SHOWING

A first-grade class which had seen the picture Jack and Jill in Songland twice engaged in a very interesting study of the writing of notes. Notes "with and without stems" were drawn and discussed. The children studied the staff and the scale, and made their own tunes. The teacher reported that "books galore about elves were brought in, and the story of Jack and Jill was read and re-read. Not only was the little song from the picture learned and sung, but the children dramatized it. They drew pictures of incidents in the film and asked for frequent repetitions of the film." Other activities which have been undertaken in connection with this film are the composition of original songs and the organization of a toy band.

As an outgrowth of the film unit Beach and Sea Animals in a third grade, the pupils produced a play written by one of the children-Birthday Party of Pat, the Sea Cucumber. The program was completed by the recitation of jingles which the children had written about these animals. Another follow-up activity in this class involved oral composition. Large pictures of each of the beach and sea animals seen in the film were drawn on charts. Each child made up a story concerning a pictured animal and presented it before the rest of the class; it was significant that the children drew freely upon the vocabulary of the film.

A well-selected film stimulates a variety of learning projects. A third-grade teacher who used the sound film Animals of the Zoo found that the film could be made to contribute to such subjects as English and geography. After the film showing each child was asked to select three of the zoo animals and write a story for the English class telling what he had learned about them. The giraffe, the elephant, the monkey, and the polar bear proved most popular. As a related activity riddles 
were devised about the animals seen in the picture. In the discussion which took place after the screening of the film some of the children raised the question as to how large the elephant really is. This led to a reading project which brought to light many interesting facts about elephants: how they are captured, their value, their habits, their size and length of life, and what they do in the circus.

The teacher made use of the children's interest in the homes of these animals to start a geography project. From various books in the classroom the pupils learned the native homes of the various zoo animals, and discussed the reasons why the zoo homes are built as they are. By way of a general review on this picture the teacher brought in pictures of all the animals; these pictures were used as an identification game.

Most of the activities which start after a film has been shown are of the type which may also be developed along the lines of individual or small-group interests. Below are listed activities developed in an elementary-junior high school, in connection with certain film units:

Scrapbook-Animals of the Zoo, The Work of Running Water, and Spiders Collections-Beach and Sea Animals, The Frog, and Butterflies

Classroom experiments-Sound Waves and Their Sources, Energy and Its

Transformations, and Molecular Theory of Matter

Composition and poetry-All films

Plastic molding-The Work of Running Water, Animals of the Zoo, and Beach and Sea Animals

Drawing-The instruments in the music films, the specimens in the films on plant and animal life, and the soil and river formations in the geography pictures

An illustration of the socialized approach in the initiation of class activities after a film showing is presented in the case of a sixth-grade class which had been studying transportation in China. The teacher had used the talking picture The Development of Transportation to show the contrast with conditions in the United States. After the class had viewed the picture the teacher appointed a committee of children to 
write up the findings of all of the previous study, including the film showing. The following day the lesson was turned over to this committee. Under their leadership the entire class participated in questions and discussion concerning the report on transportation.

A combination of several types of learning devices and activities was employed by a sixth-grade teacher whose class had been studying the adaptation of animals to their environment. The group, after studying special methods of adaptations, saw the picture How Nature Protects Animals and engaged in a general discussion of the new material it presented. As various questions were raised, special reports were assigned to individuals in the class-reports which required considerable reading in the library. Magazine articles were investigated and those of special interest brought in for the enjoyment of the class. Little branches or twigs on which aphids were living were exhibited in the room to show protective coloration. Birds were studied and classified on the basis of their adaptation to environment. Pictures showing a variety of nature's protective devices were brought in and discussed before the group. Special discussions were led by groups of Boy Scouts and Girl Scouts.

On the high-school level, demonstrations and experiments are frequently utilized in connection with science films. The following description is suggestive:

In all our science classes, the showing of the films was followed by laboratory experiments, performed by the instructor or the students. In connection with the film Tiny Water Animals, a micro-projector was set up to show students the micro-organisms in a drop of water. The instructor found the suggestions in the manual helpful for planning related experiments, which might not have been used otherwise.

Discussion following the showing of films was guided by student comments. Subject matter was amplified and further explanation of scientific terms was sometimes necessary. Units covered by the films were then outlined in the students' notebooks. Repeated showings of the films followed much the same method, with features missed the first time especially stressed. 
SOME ERRORS IN FILM-TEACHING TECHNIQUE

Analysis of sound film-teaching methods which have been observed or reported reveals certain errors which are typical either of lack of training or faulty administration of the film program. Some mistakes may be charged, in part at least, to poor organization of film and equipment facilities, especially where films are available to the teacher only at arbitrarily scheduled intervals. On the other hand, the casual presentation of five or six reels at a time clearly demonstrates the teacher's lack of familiarity with the sound film as an instructional medium.

Where direct teaching through the use of the film is to take place, it is probably unwise to show more than one or two reels. A teacher in one building scheduled a projection period long enough to enable her class to see a great many of the twenty subjects in the school film library. The second time the films came to that building the pupils saw the same program. The third time the children rebelled at such a large dose of films and eliminated some of the pictures on the list. Educational talking pictures are not intended to compete with entertainment films in holding attention over a threehour program. A series of carefully taught film lessons developed around one picture produces lasting effects. Even for general appreciation programs the number of films shown should be limited.

The presentation of a group of more or less unrelated films is another faulty technique. The children in the fifth and sixth grades of a rural school were taken to the auditorium on one occasion to see three films-Wearing Away of the Land, Animals of the Zoo, and How Nature Protects Animals. Before the screening of the films the teacher reviewed with the children what they had learned in their study of geography about the formation of soil; she talked to them about those animals they had studied in the geography of Africa and South America; and recalled the science project in which 


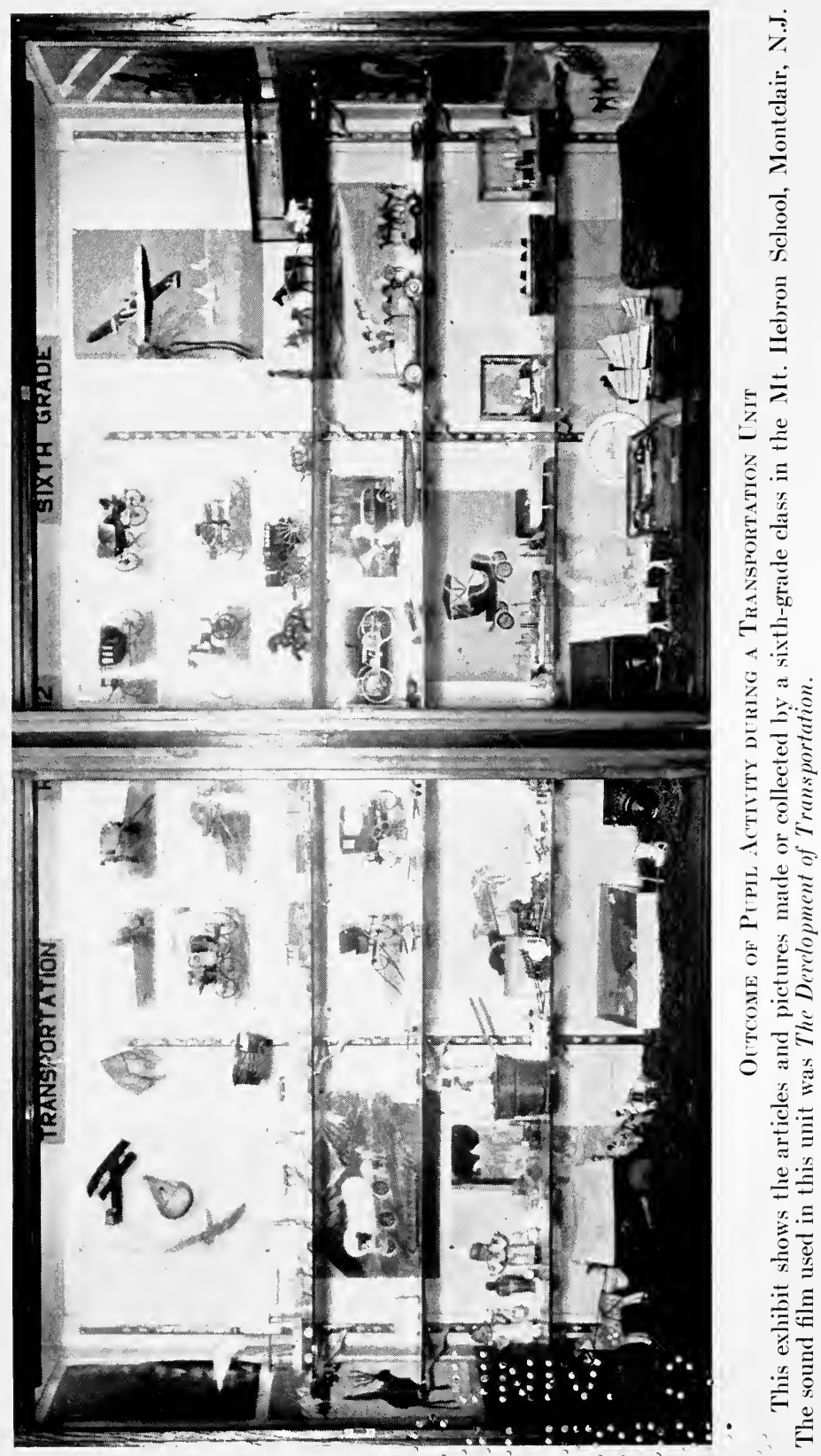



they had learned how animals change colors for protection. After the children had seen these three films in the auditorium, they returned to their classes and wrote compositions on How The Pictures Helped Me. Surely this was about the only assignment possible as the aftermath of such a varied diet of films.

Another type of mistake is that of showing the picture at the wrong time. When the teacher has carefully developed both interest and organization of thought up to the point where the use of the picture achieves the greatest contribution, a delayed showing is an anticlimax. Definite loss of interest results from postponed showings - a fact recognized by many teachers who have had the experience of being unable to secure a particular picture just when it was needed.

Some teachers have utilized only part of the sound film's contribution by having only one showing of a film in a unit. While the single showing may be effective enough in the case of an appreciation-type film or of a film whose connection with the unit is only incidental or of an elementary nature, a superior educational talking picture contains so much that it cannot be completely assimilated or its possibilities exhausted in a single showing.

Teachers who have utilized the manuals accompanying sound films have found them especially helpful in preparing for the use of the film and in organizing activities after the film has been presented. However, in one case noted the manual was overworked. A teacher who evidently was still thinking of the new sound-film device in terms of the textbook, prepared for a showing of the sound film Fungus Plants by scanning the material in the accompanying manual and reading aloud to the class those parts which she thought suitable. The names of new plants were placed on the blackboard and the pupils discussed what had been read. It is questionable whether this procedure did much to arouse the pupils' curiosity about what they were going to see.

By far the most serious mistake in the use of sound films is 
the failure to introduce the film as a stimulating learning activity. Merely presenting the film, instead of building it into the framework of the lesson so that the students are concentrating on certain aspects of the film which they will develop later, minimizes the advantages which may be derived. An inadequate introduction to the film showing naturally weakens any effort to make use of the film in subsequent activities.

Aimless discussion following the showing reveals the lack of specific purposes in developing important concepts. As part of the training of teachers in one school system the superintendent suggested that they emphasize such questions as "What did you like best in the picture?" "What did you learn that you did not know before seeing the picture?" "In what ways did the picture change your ideas about things?" Leading questions may be adequate for beginning the discussion of a film, but usually are the substitute for definite planning of the film follow-up.

In summary, typical errors in teaching with films are the showing of too many pictures at one time; the use of two or three unrelated pictures in a showing; the presentation of a film at the wrong time; failure to introduce the picture in a proper setting; aimless discussion after the film showing; limiting the use of a film to a single occasion during the course of the unit; and poor selection of a picture for a lesson or unit. The effective use of the sound film in the classroom requires the same thought and adaptiveness which should characterize the teacher's use of any other instructional material. The deficiencies in film-teaching methods which have been cited here may be readily overcome by integrating films with the local courses of study (thus familiarizing teachers with film content and the supplementary materials available); advance planning of film use by the teacher; and a program of training and supervision which assists the teacher to become adept in the basic techniques of sound film instruction. 


\section{CHAPTER IV}

\section{ORGANIZING AN AUDIO-VISUAL INSTRUCTION PROGRAM}

T HE administrative staff planning to organize audiovisual instruction as part of the local educational program is confronted immediately by certain obvious questions - what kind of films to buy and how many, what type of projection equipment to secure, and how to use the materials upon their arrival. But the problem is more fundamental than that of merely ordering a few films and arranging them neatly in the school supply closets; it is essentially that of integrating basic instructional materials with the local classroom teaching. How are films to function in the child's learning? How are the teachers to become adept in utilizing the sound-film medium? How may films be distributed so that the routine of their use is easy for the teacher? A thoughtful approach to the organization of the film program will insure that the investment in films and equipment is economical in terms of the educational returns realized.

It has been pointed out in a preceding section that the use of films and other instructional materials should be developed as a program, with all the implications for planning and coordination that such a term involves. The administrative services and the integration of films with the curriculum will be discussed in this chapter. The following chapter will deal with the problem of helping teachers acquire skill in the use of the film medium, and chapter vi will present suggestions relating to the mechanical aspects of talking-picture programs.

One of the school administrator's major functions in connection with classroom instruction is that of setting up conditions under which the teacher can do the most effective 
work. Creative administration demands vision before supervision in outlining the direction of the educational program. It solves the minor problems of class schedules, plant facilities, and the provision of supplies so that the teacher is free to concentrate on the growth of the individuals in his charge. When materials of instruction are to be provided, it is the responsibility of all concerned to make sure that they meet recognized needs and that they will be utilized to the best advantage.

Upon the superintendent of schools rests the general direction of the film program. He must work out tentative solutions to the practical problems attending their use in his school system. He will utilize the services of staff specialists, curriculum committees, principals, or supervisors, or he may even call in experts in audio-visual instruction to advise him; but his is the final decision in matters of policy and procedure. He has also to co-ordinate the use of films with other aspects of his administration-the school building program, curriculum revision, supervision, and community relationships.

To many school administrators the organized use of films and similar instructional materials presents a rather new problem, for comparatively few school systems have built up strong departments of visual instruction. Frequently the use of films, slides, specimens, and the like has been only incidental to the major educational program-a hobby or harmless diversion in which a few teachers are permitted to indulge. Studying audio-visual materials of instruction to discover the most effective ways of utilizing them in the teaching process has been neglected. Promotion of film instruction sometimes has been limited to some energetic principal with a generous parent-teacher association, who succeeds in buying a projector and renting a few films, while the children in less-favored sections of the town go without the advantages of these study materials.

School executives who have given serious thought to administering the use of instructional materials realize that in- 
troducing the use of sound films in the local educational offering demands no less of planning than does the construction of a new course of study. A program for the use of audio-visual instructional aids should secure adequate materials and insure their contribution toward the achievement of definite educational objectives. It may be described as follows:

1. Audio-visual aids are utilized by the entire teaching staff rather than by a few teachers only.

2. Materials used are in general those which have been integrated with courses of study and requisitioned in advance of current units of instruction. None are used "on the spur of the moment" as hastily devised makeshifts.

3. Mechanically, the use of audio-visual aids in the classroom is easy because the necessary equipment has been installed.

4. There are provisions for the interchange of ideas and successful techniques among teachers.

5. The educational rather than the entertainment value is stressed.

STUDIES PRELIMINARY TO ORGANIZATION OF

A SOUND-FILM PROGRAM

The effective utilization of audio-visual materials of instruction must be planned in terms of local objectives, curriculum needs, available services, and plant facilities. It is clearly evident, therefore, that before plans are made for the use of films, the local situation should have been thoroughly studied.

Of primary importance is the analysis of the local courses of study to determine the units and topics which could be best presented through the use of specific audio-visual aids. The investigation may be planned to cover the following curricular and extra-curricular elements:

1. Courses of study for which superior films are available.

2. Courses of study which need more effective materials of instruction.

3. Courses of study for which teachers need more command of the subject matter.

4. Desirable courses which might be initiated if the problem of securing suitable materials of instruction might be overcome. 
5. Special projects and activities-extra-curricular work, teacher training, adult education, parent-teacher programs, and the like-to which audio-visual aids might contribute.

A closely related factor is the current use of visual aids in the local system. A survey should be made of the kinds, number, condition, and location of all the audio-visual materials owned by the local system. The devices to be classified and inspected will include:

Films

Silent: $16 \mathrm{~mm} .-35 \mathrm{~mm}$.

Sound: $16 \mathrm{~mm} .-35 \mathrm{~mm}$.

Film slides

Glass slides

Flat picture collections

Specimen and model collections

Maps and charts

Exhibits

Radios

Phonographs

Phonograph records

\section{Projectors}

Slide projectors of various types

Silent film projectors: $16 \mathrm{~mm}$.$35 \mathrm{~mm}$.

Sound film projectors: $16 \mathrm{~mm}$. $-35 \mathrm{~mm}$.

Projection screens

Classroom

Auditorium

The investigating committee will inquire into all aspects of the use of these materials in the local schools: Are some of them obsolete? Where are they utilized most? Do they meet the needs for which they were acquired? Are the materials catalogued? To what extent should the local library of visual and auditory aids be enlarged? What arrangements could be made for increasing the frequency and efficiency of their use? How many classrooms in each building are equipped with darkening facilities, screens, and electrical power supply? Are auditoriums equipped for motion-picture projection? Are the slide and film projectors owned by the school in good condition? A checkup on the visual and auditory aids of all types will frequently reveal a surprising amount of excellent material which is not used as frequently as it should be simply because it is not easily accessible or all teachers do not know of its existence.

The survey of audio-visual aids should investigate the 


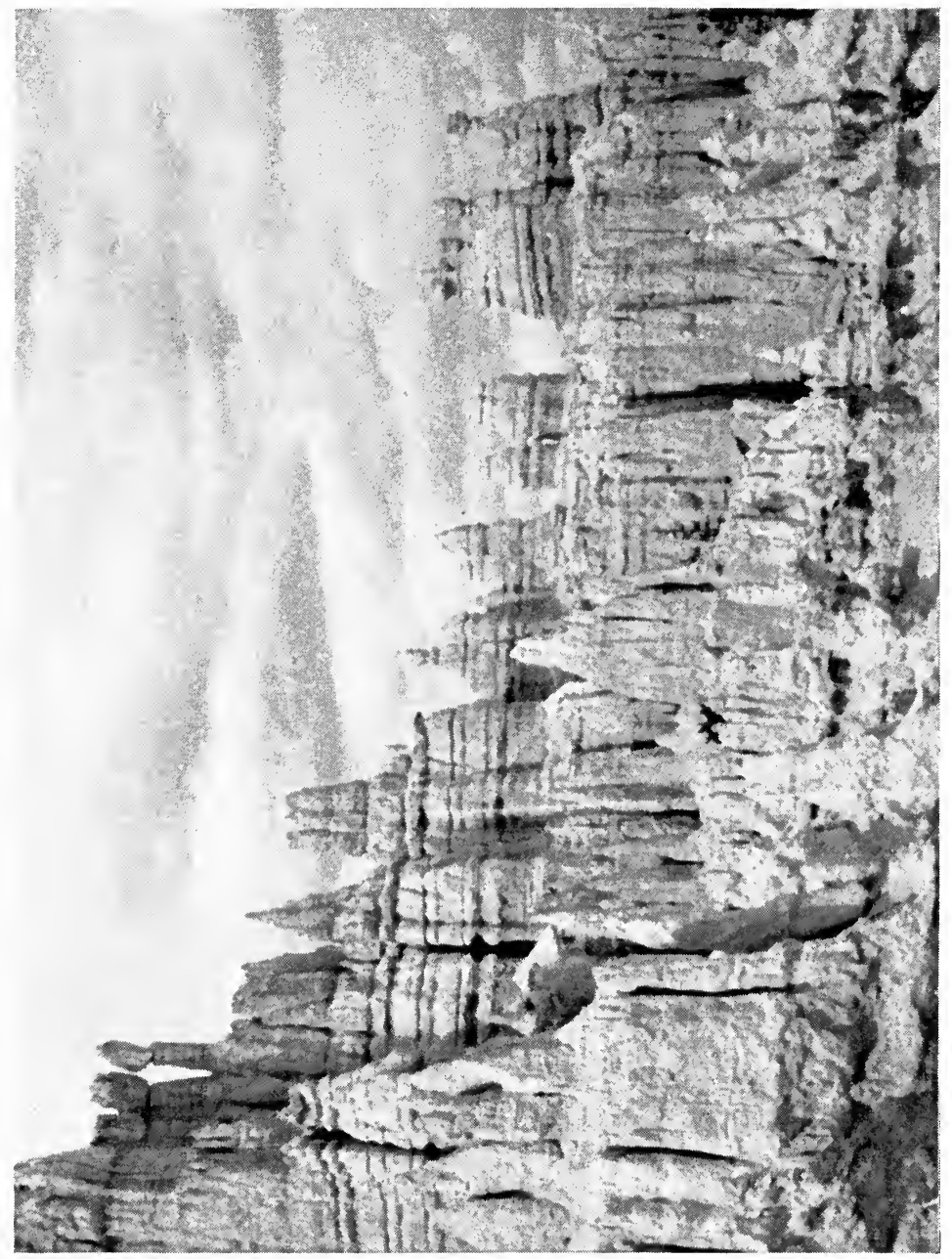

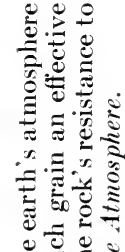

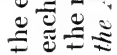

$1 \dot{\Xi} \Xi$

芯蓄

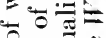

$\exists$

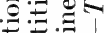

0

Q

¿

송

I.

t)

莎

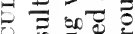

o to

1 $\frac{0}{2} \stackrel{0}{0}$

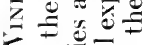

$=$

$\approx$ ฮ

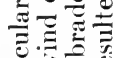

政

造要

का

을

的

궁

空它的

$>$.

보용

픙

궁흐

$\Xi 0$ 

teachers' competence in their use. Do the teachers know how each type of aid may best be employed, and under what conditions? Have they been made aware of the devices which are available, in bulletins or supervisory conferences? Do they include audio-visual aids in planning their work? Do they know what materials may be collected, borrowed, or rented? How many teachers are able to operate slide and film projectors? 'The skill with which teachers employ aids to instruction usually reflects the assistance given them through supervision. Do principals and other supervisors consider the use of instructional materials in analyzing the classroom procedures? Do committees revising courses of study include the applications of specific audio-visual materials? Is there a definite policy which gives prominence to interesting new materials and methods devised by the local teaching staff? Are bulletins issued describing instructional aids and their use?

Administrative arrangements should also be analyzed. Is there a competent individual directing the use of these aids? If there is a central library of materials, is there a convenient method of requisitioning and distributing the materials? Are records of distribution maintained? Are materials kept in good repair? Is there an annual budgetary appropriation for the purchase of new materials, or must principals rely upon donations from interested parent groups and the receipts from cake sales?

The survey of the local school system with respect to the development of a program of audio-visual instruction must, of course, go beyond the extent to which such materials are now being utilized. For example, a very important problem is that of studying the local staff to determine the individual or individuals most competent to direct the program which is to be started. In case committee work is desired, which teachers or principals would be best fitted to participate? If an additional staff executive is to assume the direction of film use, are there other functions which he could perform 
during the beginning stages of the program? Is course-ofstudy revision contemplated which could be co-ordinated with certain aspects of the program?

The number, size, and location of school buildings should be considered, as affecting the size of the prospective film library and the distribution system which would be required. The choice of the most efficient method of circulating films may depend upon the local procedure for distributing supplies; many school systems maintain regularly scheduled supply distribution which can take care of circulating the films very readily. Or, if continuous use of a group of films is anticipated in a very large building or in a highly specialized school, a unit library may be established in that building in place of the central-library plan. The best location for film storage, both for convenience in filling requisitions and for safety, is another factor which must be taken into account.

The administrator will find it advisable to enlist the services of the teaching staff in making the study which is to serve as a foundation for the audio-visual instruction program. An administrator who seeks to lead encourages the demand for instructional changes and additions from his faculty, rather than arbitrarily announcing that the change has been made and that "teachers will please govern themselves accordingly." If the sound film is to be utilized successfully in the classroom, it follows that the individual most directly concerned-the teacher-should be given ample opportunity to co-operate in planning for its inclusion in the local program.

An approach which has been followed successfully in a number of school systems is that of appointing a committee of principals and teachers to study the problem of adapting the talking picture, or more broadly, audio-visual aids, to the local instructional program.

In school systems where energetic committees thoughtfully analyze all angles of the problem, their report to the superintendent provides the foundation for his recommenda- 
tions to the board of education. Any requests for film and equipment expenditures are fully justified by supporting data. The board's consideration of the proposed program, thus is very definitely affected by the facts that not only do the superintendent and his faculty believe there is a real need for a talking-picture program, but also that they know precisely how they are going to use the requested materials.

To summarize - the initiation of a program, with the acquisition of a library of instructional sound films and the necessary projection equipment, should come about as the culmination of a careful study of audio-visual devices and of the problems attendant upon their effective use in the local school system. The preliminary study will provide a clear picture of the framework into which the local use of films is to be fitted.

\section{PLANNING THE FILM PROGRAM}

The plans which are drawn up and adopted as a result of the study should be built around the essential elements in a final program, outlining tentative procedures for problemis of immediate interest and providing gradual expansion of activities. It should be remembered that successful operation of this new undertaking cannot be attained overnight. The smooth functioning of the program will come about as a result of continuous, co-ordinated effort on the part of the entire staff, working to reach certain predetermined goals. It is for this reason that planning is so essential in making a practical beginning and progressing in easily attainable steps.

Chart I presents a plan for developing a program of audiovisual instruction in a large city school system. Recommended procedures are suggested for each of three stages: preliminary preparation, experimentation and study, and expansion of the program. It should be noted that the activities indicated are continuous, beginning with a few immediate needs and reaching out into a comprehensive provision of 
Procedures in Developing the Audio-viso

\begin{tabular}{l|l|}
\hline \hline Program Elements & \multicolumn{1}{|c|}{ Step I. Premiminary Preparations (1934-35) } \\
\hline $\begin{array}{l}\text { A. Training teachers in } \\
\text { the effective use of } \\
\text { audio-visual aids }\end{array}$ & $\begin{array}{l}\text { 1. Preliminary training course is organized for principals, } \\
\text { supervisors, and selected teachers from each shool } \\
\text { 2. At the same time, all teachers help set up a "laboratory" } \\
\text { unit of instruction in each school, utilizing sound films and } \\
\text { other devices } \\
\text { 3. As many teachers as possible should take courses in this } \\
\text { field in summer school }\end{array}$
\end{tabular}

B. Selecting audio-visual materials and integrating them with the curriculum
1. The teachers in each building co-operate in selecting audiovisual materials for the "laboratory" unit above

2. One or two superior films are reviewed in terms of recognized standards to give teachers a background for integrating audio-visual materials with courses of study

3. The slides owned by the schools should be inventoried by title and evaluated. Teachers may help arrange the data collected in card-index form for central office files

4. Teachers participate in collecting a complete catalogue library of available educational talking pictures, and of supplementary audio and visual aids
C. Developing new areas of instruction

1. Special committees of principals and teachers initiate course of study construction in science for $(a)$ intermediate grades, (b) primary grades

2. Current revision of the tentative elementary syllabi includes study of new objectives which might be achieved through talking pictures

3. A group of interested teachers is assigned the task of studying the appreciation of motion pictures as a new art form, prelininary to developing a special course of study

D. Providing films, equipment and projection facilities

1. An initial sound-film library is purchased, the subjects and number of duplicate prints to be approved by supervisory staff and audio-visual instruction committee
2. Six $16 \mathrm{~mm}$. sound-on-film equipments and portable classroom screens are purchased on specifications

3. In each building 2 or 3 rooms are equipped with electrical outlets and opaque shades

4. Temporary film storage space in the administration building is secured

1. Present staff administers program in the first two steps: superintendent acts as director; of most of mechanical services; assistant superintendent and high-school supervisor d schools respectively, assisted by special audio-visual instruction committee (see Chart II)

2. Committee works out tentative schedule of use for the sound-picture equipments, grouping schools to be served by the same machine

3. Tentative distribution schedules for available films are prepared

4. Several individuals in each building learn to operate the equipment

5. Contract is made with local dealer for repair service covering films and equipment

\section{Step II. Experime}

4. Teachers in each buildin course which follows the

5. Libraries and periodicals 0 for each school. Special a current research in the use

6. Teachers demonstrate exp and subject

7. Suggestions for using talki in mimeographed form frc ous refinement of method: mary grades, intermediat departments

5. The present elementary ct school departmental com available materials with $\mathbf{r}$

6. Accepted standards for ed sound basis for selecting

7. Tentative mimeographed terials for each syllabus a

8. Teachers help to constru used, noting especially its levels

9. A museum committee fro works with the director of ing picture folios and exh

10. A special committee begin radio in the schools

4. Club advisers co-operate visual materials to the pr

5. The platoon school teach audio-visual materials to

6. A tentative course of stud

7. Studies are made of the $t$ parental education, throu

8. Local adult educational tural lines, are surveyed

5. Tentative budget appropr are established

6. Rental of films approved arranged

7. The possibility of remode as audio-visual studios is

8. Plans and specifications a

9. Temporary quarters in th as a film depository

10. Slide projectors are purch ing them

6. Part-time assistant for s and repair films

7. The system of requisitio tory is perfected

8. Printed forms are prepar use, and requisition blanl

9. Teachers aid in collecting of distribution service

10. The number of teachers creased through a labora 


\section{IN AND Study (1935-36)}

icipate in an extended training is of the preliminary course tio-visual instruction are provided on should be given to reports of $t$ king pictures in other centers cital film lesson units in each grade

ptures and other aids are developed ching experiences in the continuharate guides are prepared for pries, junior and senior high school

um revision committees and high:s begin a systematic survey of tse to the courses of study

inal films are studied to provide a als

which list in detail approved manared

ard system of data for each film veness for specific units and grade

vocial studies and art departments useum in classifying and correlatith the courses of study

dy the problem of effective use of

iending the integration of audioof extra-curricular activities

lyze the possible contributions of i) rium activities

veloped in photoplay appreciation offering which might be given in operation with local P.T.A. units nd interests, especially along cul-

3 for enlarging library of materials dio-visual instruction committee is 1e or more rooms in each building tigated

loped for new audio-visual studios inistration building are remodeled

ir the one or two schools now lack-

ss manager and his staff take care program in elementary and high

lerk is secured to re-wind, inspect, 1aterials from the central deposifilm stock records, history of film for records and the improvement d in operating equipment is inourse

\section{Step III. Expanding the Program (1936-)}

8. Teachers are encouraged to seek supervisory assistance on problems of film use and integration with the curriculum

9. All teachers participate in a continuous program of informal experimentation, to solve the utilization problems which occur and to stimulate creative teaching

10. Demonstration lessons of new teaching techniques developed in experimentation program are featured in each school

11. The handbook of film teaching methods is revised and elaborated

12. Superior film teaching units developed locally are prepared for general publication

13. Experts making contributions in sound-film instruction and related fields are secured for faculty meeting programs

11. The incorporation of tested films and other devices with the curriculum is carried on as a continuous process at all levels

12. From teaching experiences, the tentative "Audio-Visual Aids Supplements" are revised and incorporated in the succeeding editions of the various syllabi

13. Teachers aid in developing lists of minimum standard audio-visual materials, for individual schools and for different types of departmentalized classrooms

14. Elements of film composition are studied, to promote increasingly wider application to course-of-study objectives

15. A permanent film-curriculum committee is organized to evaluate and classify promising new educational films as they appear

16. From teachers' requisitions, annual or semi-annual schedules of films to be rented or borrowed are prepared

17. Museum service is capitalized on a wider basis, as teachers and supervisors enlarge the contributions of exhibits to the courses of study

18. A systematic program of radio use is developed and the co-operation of the local broadcasting station enlisted

9. Motion-picture clubs are organized in each school

10. The course in photoplay appreciation is revised and extended

11. A comprehensive program for auditorium activities in the platoon schools is developed, based on the use of audio-visual material

12. Large-group instruction in combination with individualized instruction is investigated in sound-film courses

13. Film-centered courses in parental education are arranged for patrons of each school

14. In co-operation with the Museum of Fine Arts and History, illustrated courses in appreciation of various art forms and travel series are made available

15. Other experimental courses in adult education are carried on in directions indicated by the adult-education survey

11. Budgetary appropriations are provided to purchase the minimum standard equipment

12. Central office quarters are provided for audio-visual instruction department

13. Storage facilities for audio-visual materials in the central depository are enlarged as the size of the local library increases

14. As the use of sound films is extended, an adequate number of rooms in each building are equipped for projection

15. Audio-visual studios are incorporated in new buildings constructed

16. All a uditoriums are provided with facilities for showing sound films readily

11. On the basis of the personnel needs apparent for administering the extended program, an adequate departmental staff is organized (see Chart III). The staff may be enlarged as conditions warrant

12. The department becomes a service center for audio-visual instruction, co-operating with teachers, principals, supervisors, curriculum committees, and the business management staff

13. Projectionist working on assignment supplements the operation of equipment by teachers

14. Technicians in the department take charge of minor equipment repairs

15. The audio-visual records and reports are enlarged in line with the increased use of films and other materials

16. System of delivery for circulating materials from the central library is extended 


\section{count describes the plan worked out in a large junior high school. $^{1}$}

A science teacher who was particularly interested in this work and had had considerable experience in the use of projectors was selected by the principal to act as director of this department. Working in conjunction with the principal and other interested teachers, he established the following duties of the department and carried out the subsequent organization of the program:

1. To supervise the maintenance and operation of all machines.

2. To collect all slides, films, etc., previously held by various teachers; to catalog titles and publish a list of available materials (such materials to be held in a central office and distributed as required).

3. To provide a library of film catalogs for the use of teachers in requisitioning materials.

4. To set up any necessary routines for handling films and recording their use.

5. To train teacher and student operators in the use of the machines.

6. To aid teachers in selecting and scheduling such materials as best fit their course of study.

7. To order required films and slides from film libraries and schedule their use throughout the school.

In working out the program, the following steps were taken:

All machines were collected in a central office, overhauled by an expert repairman and put in order. Spare lamps were ordered, extension cords made, permanent extensions installed in the auditorium, and all facilities such as dark shades, curtains, and wall outlets, procured and installed. Three classrooms and the auditorium were thus equipped.

Slides and films held by teachers were collected and stored in the central office. Their titles were cataloged and lists were distributed to the teachers.

Film catalogs were secured from various distributing agencies and sources. These were placed in the central office where teachers might have access to them at all times.

To requisition materials, teachers filled out a special form and turned it in to the department. The department then scheduled the material for use on or as near the date requested as possible. The record of the schedule was entered in a department "Schedule Record" and the requisition, with the schedule date inserted, was returned to the teacher for her information.

Upon receipt of the material in the department, a notice was sent to the interested teachers announcing a time for a preview. The preview was given at least one day in advance of the scheduled date. Since nearly all

${ }^{1}$ Englewood Junior High School, Englewood, N.J. The program was developed by F. M. Worrell, under the direction of the principal, Dr. W. D. Kuhlmann. 


\section{HOW TO USE THE EDUCATIONAL SOUND FILM}

the films used were new to the teachers and were ordered by title, it was necessary that the contents be reviewed in advance and the teaching program adjusted to bring out the worth-while facts presented in the material.

Those teachers attending the preview who found the contents of the material suitable for their use, notified the department when they desired the material to be shown to their classes.

After reviewing all requests, the department scheduled the material for certain periods in certain rooms. The interested teachers moved their classes accordingly. The person in charge of operating the machine prepared the designated rooms for projection and exhibited the material at the time mentioned.

A record was kept in the department of all materials clearing through it, showing the nature of the materials, the source from which it was secured, important facts included in the contents, where these might best be used in the curriculum, how they might best be used, and criticisms. To aid in keeping this record, a special form was filled in by the teacher using the material; upon its receipt in the department, the contents were transferred to record cards from which others desiring to use the same materials, secured advanced information before requesting a showing.

Three teachers were taught to run the machines. Later, because of the difficulty of scheduling a teacher whenever needed, four boys were trained as operators. It was found that, with a little practice, the boys became as adept as the teachers and were more interested. Their work freed the teacher for supervision and directed study.

With this much of the organization of the program completed, a regular monthly teacher's meeting was called to discuss important aspects of the department's work and the teachers' use of its materials:

1. Routine in requisitioning and handling material.

2. Need of returning comprehensive reports.

3. Need of integrating visual materials with the course of study. (Films illustrating specific facts should be scheduled so that they may be used at times coincident with the actual teaching of the problem. Material irrelevant to the problem being studied might better be excluded entirely.)

4. Need for using films and like material as definite teaching tools, not as entertainment for the pupils or an excuse for reducing work on the part of the teacher. (For this reason a definite program should be planned whereby the most can be obtained from the material. Films must be previewed and a teaching plan devised so that the material may be used to the best advantage in the working out of a specific problem).

5. Use of the film catalogs in selecting and requisitioning material. 
Reference books explaining ways of using visual material were provided in the principal's office for those desiring to plan an extensive program. Mimeographed instructions covering general routines and aids in solving general problems were distributed periodically.

\section{ORGANIZING SERVICES FOR AN AUDIO-VISUAL INSTRUCTION PROGRAM}

Organizing the services necessary to administer the use of sound films is an essential, but not a complicated, task. Devereux ${ }^{2}$ points out:

In order that talking pictures and certain other aids to instruction may function in the school program as they should, a definite organization is needed to administer their use. Such an organization is vital even in the smaller school systems. It is certainly necessary in the large school systems. With modern trends in educational method, the tendency is very definitely toward the use of more materials of instruction. The organization of such materials must be achieved if the educational program is to advance smoothly. In many school systems little thought has been given to this problem, and yet if an analysis were made of the time spent in the discovery of materials and in their assembly for specific class purposes, it would probably be found that a comprehensive plan developed in advance of the year's work, and put under the guidance of one individual, would save much in time as well as in the services of workers for which money is paid.

\section{He goes on to state:}

The essential fact about these services is that they must be recognized before the need appears and provision made in advance for their management. ... . In a small school system these functions may be performed by one individual in addition to many other types of service. In a large school system a department of audio-visual instruction is essential. ${ }^{3}$

In beginning the use of sound films, the administrative, clerical, and mechanical services usually can be handled by existing personnel. There are advantages other than financial when the present staff administers the initial stages of the program. This insures the immediate participation of all indi-

${ }^{2}$ The Educational Talking Picture, pp. 115-16. The reader is referred to this excellent analysis of administrative functions in connection with the use of audiovisual aids, pp. 115-38.

${ }^{3}$ Ibid., pp. 116-17. 
viduals on the staff and familiarizes them with the problems which are to be solved. Solutions for routine activities such as the distribution of films will be more readily achieved by persons who are already acquainted with the school system. The interest which the staff members derive from initiating the program will continue even when the wide extension of the program in the future may render it desirable to establish a special audio-visual instruction department.

The assignment of specific responsibilities in managing the use of audio-visual aids to certain executives sometimes is merely official recognition of the activities which those individuals have been carrying on in the past, on their own initiative. In a small school system with seven elementary schools and a large junior-senior high school, recommendations for beginning a sound-film program included placing one of the elementary-school principals in charge of film distribution and curriculum study at that level. This principal had worked out an efficient system for handling silent films, slides, flat pictures, specimens, and mimeographed materials in his building; his new functions would mean only the extension of routine procedures to the other buildings. In the junior-senior high school, the biology teacher had been accustomed to order and issue slides and films; it was proposed that he also distribute sound films used in this building. The superintendent would direct and co-ordinate the use of the films at both levels, with the aid of a film-curriculum committee in science. An interne teacher would be given charge of the central library established in an unused basement room of one of the elementary-school buildings. His duties were outlined as follows: (1) assisting teachers in planning film lesson units, (2) filling requisitions for films, (3) keeping records of film use, (4) helping teachers learn to operate the projector, (5) oiling the projectors and making minor adjustments, (6) inspecting, rewinding, and repairing films. 
Even small school systems may profitably organize a department of audio-visual instruction. An example is the outstanding department operating in a school system of eleven buildings. Here a real contribution to the enrichment of teaching has been accomplished through the efforts of a parttime director, assisted by a secretary-clerk. The amount of material acquired, catalogued, and circulated by this small department, and the close contact maintained with the teachers, shows what can be done even where staff services are limited.

Large school systems lacking such a department are not required to make a heavy investment in additional personnel in order to establish a systematic program of audio-visual instruction. Chart II presents the functions suggested for the administrative and instructional staff of a large system, by way of initiating the organized use of sound films and other teaching aids. ${ }^{4}$

Energetic leadership, capable supervision, and gradual enlargement of the audio-visual library will expand the services to be rendered for the instructional program. Chart III indicates how a specialized department might eventually be established to assume the functions indicated in Chart II. The suggested personnel and activities are described as follows:

The department is under the immediate direction of an assistant to the superintendent. He will doubtless be called upon to assist the superintendent in other functions. His work will involve curriculum analysis, supervision, and administration.

The director operates in close contact with the line officials, the supervisors, and the business management department. He is given special assistance by a Film Curriculum Committee, a group which is divided into sub-committees for each school level. This committee assists the director and his staff in selecting and integrating audio-visual materials with the courses of study; it also serves in an advisory capacity on instructional problems. The director will supervise the activities of a curriculum specialist, who works constantly in making films and other devices function effec-

${ }^{4}$ A program of audio-visual instruction charted for the public schools of Evansville, Ind. This program has been adopted in large part. 


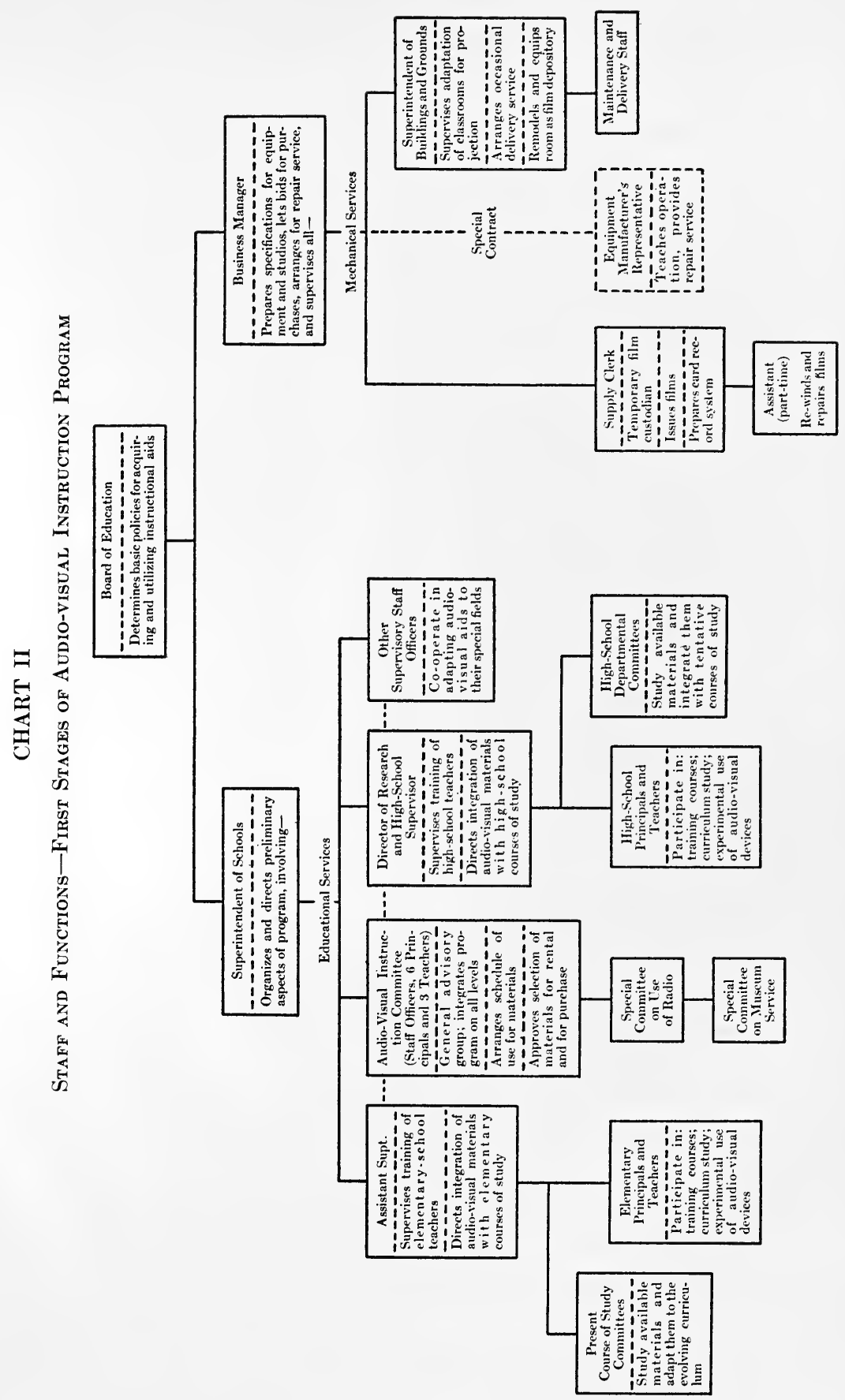


tively in the courses of study. The curriculum specialist may have for his province the whole field of curriculum revision; the application of audiovisual aids will be one phase of his contribution to the curriculum.

The staff of the proposed audio-visual instruction department will undoubtedly expand until it includes one or more of the following: a secretary, a stock clerk who is also a film technician, a projectionist, and a delivery crew. In the advanced program the services of a secretary will be essential for handling the increasing clerical work of the department. The stock clerk will have charge of the film depository; he will keep a systematic record of all the materials, handle the physical distribution of the

\section{CHART III}

Administrative Organization for Comprehengive Audio-visual Instruction Program-Evansville, Indiana

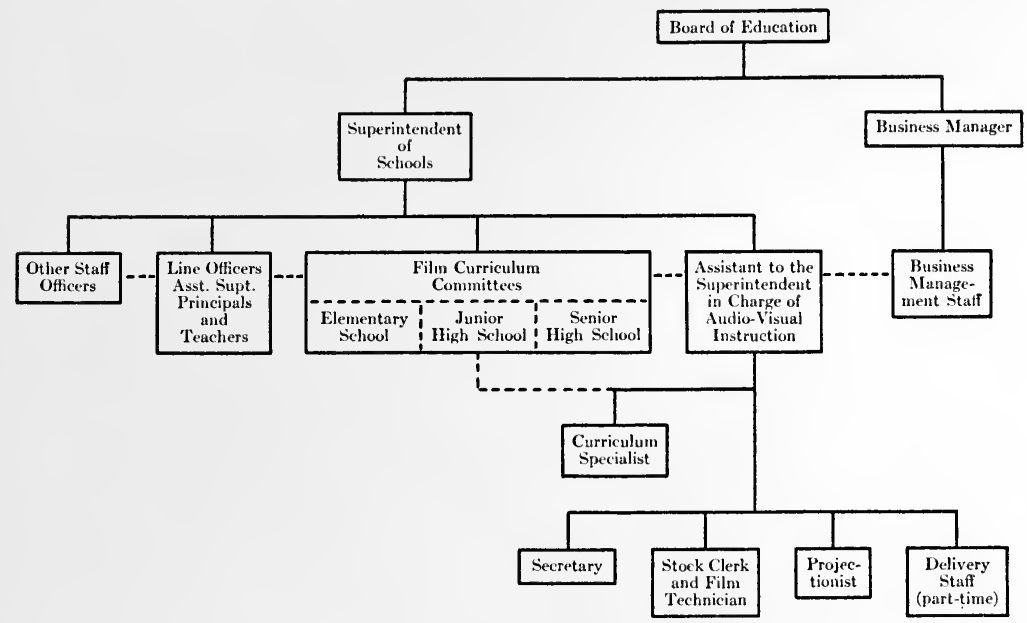

films, and keep them in repair. The projectionist will work on assignment, taking care of showings for teachers who have not learned to operate the equipment. He should be able to make minor equipment repairs. As regards delivery service, it is expected that this will be a part-time function for the individuals now operating trucks in the maintenance program and in the occasional distribution of supplies.

The recommendations which have been made for personnel and functions in the department call for an organization which in reality is a service center for audio-visual instruction. It is not the purpose to complicate the existing organization by adding just another department. The justification for this new staff appears when it facilitates the whole process of instruction, strengthening the arm of the teacher by providing easy access 
to those materials which bring reality to education. To this end, there should be constant co-operation between the department and the teachers, principals, supervisors, curriculum committees, and business management staff. 5

SELECTING AUDIO-VISUAL MATERIALS AND INTEGRATING THEM WITH THE CURRICULUM

Of primary importance in developing the use of audiovisual aids is the selection of effective materials and their systematic incorporation into the scheduled work of the classroom. It should be pointed out that it is not necessary to plan for the immediate acquisition of an elaborate library of films and other devices, for the use of which teachers may not as yet have been trained, and for which demand has not been created. The expansion of the library consistent with progress in curriculum enrichment and teaching skill avoids the wasting of school funds.

An essential step is the analysis of sources of audio-visual materials, especially those for the distribution of films. It will be found helpful to collect a complete set of film catalogues. Teachers should constantly be on the alert to discover new materials in their fields of special interest, and should work through their principals or course-of-study committees to acquire those materials which will strengthen their work.

The films selected for use in the audio-visual instruction program should meet accepted standards. Committees at work upon the selection of materials will find it desirable to devise or adapt rating forms. In this connection, any visual or auditory aids owned by the various schools should be inventoried and evaluated, so that those which are obsolete may be discarded.

An intensive study of films was made by a committee of teachers in one school system, as a basis for selecting films

${ }^{5}$ Adapted from M. R. Brunstetter and others, A Program for the Utilization of Audio-visual Teaching Aids, Evansville, Ind. (New York: Erpi Picture Consultants, Inc., 1935), pp. 183 (mimeographed). 
and tying them into a new course of study in elementary science. The assistant superintendent asked each principal to choose two teachers from his school to serve on a previewing committee. About thirty reels were screened. The members of the committee filled out rating forms for each film, as a means of securing a more objective group judgment on the pictures to be selected for the local library. Sections from a typical analysis are reproduced here:

Name of film: Earth's Rocky Crust

Name of teacher: Irene M. Lanning Grade Taught: IV

This film is suitable for unit on: "Erosion"

Very first pictures would be excellent for "Origins of the Earth," in Pre-

historic Man. (I could use it during the month of March or April.)

Strong points of film: Few pictures well chosen on each point made.

Weak points of film: The pictures and the talking that accompanied the

picture were too fast for a fourth-grade child to get the full value of each picture and remark.

Observations and remarks: Water cycle was good, as it showed well the soft rocks and rocks that were harder in composition. Also this film showed well the marked differences between sedimentary rocks, igneous rocks, and metamorphic rocks.

What does sound add? The sound in this film is very important, as it explains and gives meaning to each picture which a child could not get otherwise.

Does it add new information? Yes. The action of water and the effects of erosion are very hard for a fourth-grade child to get from any picture. This film pictured erosion on such a large scale, with the changes taking place before the child's eye (of course the film speeds up the process so it is even easier to get), that he feels he is actually seeing it happen.

The previewing was scheduled from four o'clock to sixthirty almost every afternoon for two weeks. The showings were utilized also as an opportunity to accustom the teachers to the operation of the equipment. At the end of the previewing the ratings were summarized and the film library selected.

This procedure possessed several advantages. In the first place the teachers became familiar with the content of films they would later use. Second, since the pictures were selected largely on the basis of their appropriateness for local units, the integration of the films with the curriculum was accom- 
plished at the very outset, as part of the selective process. The rating sheets were utilized to prepare a mimeographed guide which gave definite information as to where each film fitted into specific units in courses of study. Third, a great deal of interest and enthusiasm had been aroused in the teachers, and the two representatives from each school served as centers of information for their associates.

It should be pointed out that the value of teachers' judgments in previewing films is dependent somewhat, of course, upon their familiarity with the sound film as a teaching device. For example, in the previewing, a film on energy was voted almost unanimously as too difficult for elementaryschool children. However, after completing the energy unit in the sixth grade and utilizing this sound film, the teachers were agreed that the picture conveyed information to the children which they otherwise would have been unable to present effectively.

If a permanent film-reviewing committee is appointed it may also advise concerning the films to be rented. It will be desirable at the outset to differentiate between films to be purchased and films to be rented. Here such factors as extent of possible use, costs, and availability are involved. The whole problem centers around the issue of whether the particular film is important enough in the local courses of study to involve repeated use; if it, is, outright purchase will be more economical than rental. On the other hand, there are certain films bordering upon the courses of study which make valuable contributions at infrequent intervals; these might be considered as falling into the category of films to be rented. Teachers should submit requisitions annually or semiannually for the films which are to be rented or borrowed; these requisitions may be checked by the reviewing committee and also considered in terms of the budget under which the program is operating. Renting or borrowing films through a central agency in the school system, rather than by individual schools, will promote economy through greater utilization 


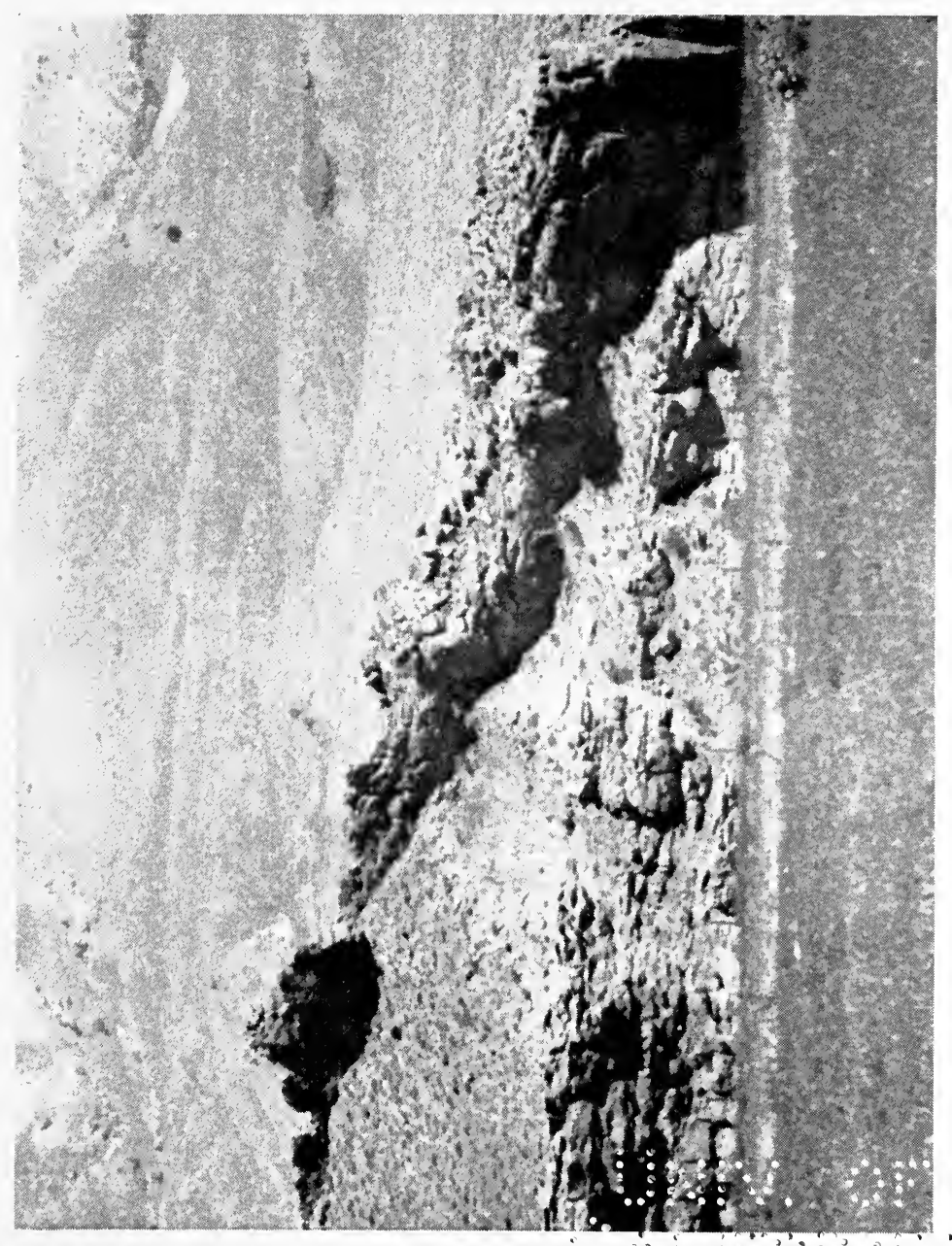

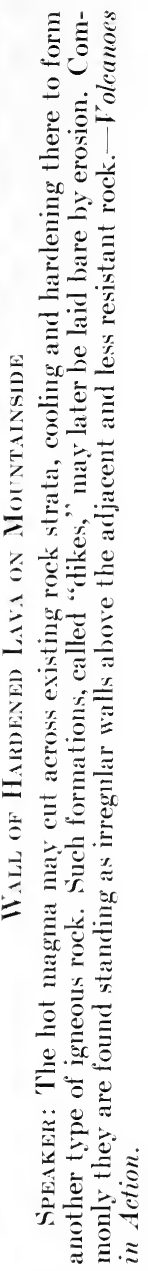




$$
\begin{array}{r}
=+\cdots: \vdots: \vdots \\
\therefore \ldots+\cdots
\end{array}
$$


of the materials while they are available. The approval of this committee also provides a check against the use of films which are technically poor, obsolete, or undesirable in other respects.

The integration of audio-visual aids with the local courses of study or list of approved units is simply a matter of indicating their application and possible uses under specific topics and objectives, so that teachers know in advance what materials are available and what each may be expected to contribute. This work may be accomplished by course-of-study committees in large school systems, or by a special filmcurriculum committee in the small system. As has been illustrated, an effective procedure is to schedule preview showings for the committees; this familiarizes teachers with the content of the films and enables them to discuss such questions as grade placement, application to specific course-of-study units, and possible teaching techniques with the film.

In another school system where the use of sound films was initiated, the director of visual instruction made a tentative listing of films for various units in the elementary-science course of study, and checked the listing with the science committee. It should be noted that the elementary-science course of study in this school system is sufficiently broad so that teachers may select for study those topics in which their pupils become especially interested or for which the need is clearly evident. The director stated:

As I work so closely with the teachers throughout the year, I know the units of work they are studying or intend to take up. Thus, when I suggested to them the other visual aids that would help them accomplish their objective, I included the appropriate sound pictures.

By way of illustration, the listing of elementary-science topics with certain films is reproduced below:

Fourth grade:

Animals

Films: Animals of the Zoo

How Nature Protects Animals

Beach and Sea Animals 


\section{HOW TO USE THE EDUCATIONAL SOUND FILM}

Water, Rain, Fog, Clouds

Magnets

The Old, Old Earth

Fifth grade:

Birds

Insects

Films: Spiders

Aphids

Moths

How Nature Protects Animals

Flowers and Trees

Films: Plant Growth

Plant Roots

Seed Dispersal

Weather

Fungus Plants

Stars and Planets

Electricity

Film: Electrostatics (parts)

Sixth grade:

Air and Its Importance to Man

Film: Sound Waves and Their Sources

Story of Formation of Earth

Balance of Nature

Films: Aphids

How Nature Protects Animals

Tiny Water Animals

Stars and Planets

Electricity and Its Importance to Man

Film: Electrostatics

'This tentative analysis would of course be carried out in greater detail when the results of the first semester's use of films could be reviewed.

The following example presents another way by which films may be written into a course of study.

\section{COURSE OF STUDY IN SCIENCE ${ }^{6}$}

(GRAde V)

XIV. Protective Coloration

WINTER

A. Problems and Experiences

1. To extend knowledge of protective coloring

6 "Pennsylvania State Course of Study in Science-Grades Four, Five, and Six," Bulletin 72A (Harrisburg, Pa.: Commonwealth of Pennsylvania, Department of Public Instruction, 1932). The "Protective Coloration" unit is given on p. 21 of the bulletin. 
B. Suggested Activities

1. Consider protective coloring of the polar bear, lion, chameleon

2. Consider advantages of animals with protective colorings in escaping from hunters and other enemies

3. List some animals whose colorings differ at different seasons of the year

The application of specific films might be shown by adding another section:

C. Helpful materials

1. How Nature Protects Animals [one-reel sound film; consult teacher's manual for suggestions]

Scenes of particular interest for this unit: raccoon in tree, giraffe among trees, lion in undergrowth, herd of zebra on plains, camouflage of grouse and chameleon

This course-of-study analysis may be published for general use by preparing a mimeographed guide for each syllabus listing the approved materials in detail. Another procedure is to indicate the use of specific aids directly in the mimeographed course of study. Some large school systems simply issue a catalogue of audio-visual aids available in the central library for circulation.

It is desirable to begin immediately a collection of utilization suggestions for each film. Teachers can provide much material for the curriculum committees by helping to construct a card-index record for each film which notes its worth for specific units, the projects it stimulated, and its adaptability to the grade in which it was used. This type of film integration makes it easy to preserve for general use the interesting approaches and special techniques which individual teachers have created with various films.

Thorough study of specific films in connection with the courses of study will make possible the detailed co-ordination of screen subject matter with unit content in the local film guide. When the teacher can see at a glance how a film meets the requirements of a particular unit in the course of study, his planning of the use of the film is greatly facilitated.

Leaders in the field of sensory aids to instruction encourage the development of lists of minimum standard equipment 
of this type for classrooms. Teachers will find it valuable to participate in drawing up minimum standard lists of audiovisual materials for their classrooms. The lists may be discussed, refined, and consolidated in each building, to be passed on to the general advisory committee, director, or superintendent as a basis for establishing policies for the purchase and allocation of materials. When teachers have studied the question of what constitutes essential material for their teaching problems, the way has been opened not only for a sound purchasing policy, but for increasingly effective use of the materials which are acquired.

DEVELOPING NEW AREAS AND MODES OF INSTRUCTION

In school systems where the sound film is being incorporated into the local program of instruction, its potentialities for implementing new undertakings should not be ignored. The previous section has suggested ways in which audiovisual devices may be made to function in the established work of the classroom. But many who are challenged by the sound film's expressiveness and convenience of presentation will wish to include in the organization of the new program projects and studies for which the sound film seems to offer special promise. How may this device be made to facilitate the individualizing of instruction? To vitalize large-group instruction? To enrich the student activity program? To satisfy adult learning desires?

The illustrations of teaching techniques given in chapters ii and iii included several interesting examples of the application of the sound film to the special problems of the platoon school. The platoon school with its specialized administrative and curriculum set-up, especially the auditorium program, can profit by the use of a device efficient in large-group instruction. The use of the auditorium for instruction calls for a new type of teaching skill and an experimental attitude toward new methods and materials. Reliance upon verbalism-the substitution of verbal images for activity and ex- 
perience-is even more unsatisfactory in the auditorium than in the classroom situation. From the curriculum standpoint, there are two major opportunities for the use of motion pictures in auditorium instruction: (1) those courses such as health and music which normally can be, and frequently are, taught to large groups, and (2) those classroom subjects for which information can be given to large groups in the auditorium, with subsequent study in individual classes.

The possibilities the use of the sound film provides for developing new courses of study are also being explored. In certain school systems the availability of sound-film material is facilitating the introduction of elementary-science courses. Many high schools are teaching appreciation of the sound film as an art form, in regularly scheduled classes. 


\section{CHAPTER V}

\section{HOW TO TRAIN TEACHERS IN THE USE OF SOUND FILMS}

HE fate of any program for the improvement of in-
struction rests largely with the teacher. The use of
sound films in the classroom is no exception to this rule. The part the teacher plays in co-ordinating the film with the interests and abilities of the students, and making it function as an aid in their learning, is essential.

Some administrators have been prone to feel that they have discharged their responsibility when they have approved the requisition for the purchase of films, slides, or projectors. The preceding chapter pointed out the advantage of undertaking the use of audio-visual aids upon a program basis, in which all the aspects connected with their utilization in the classroom had been planned in advance by teachers, administrators, and supervisors. Certainly the degree to which teachers are prepared to make effective use of the films selected and purchased is a matter of paramount importance in carrying through the program which has been planned.

One of the most important considerations in beginning the use of sound films, therefore, is that of building up this skill. Teachers who have the advantage of a local film library will wish to explore thoroughly the possibilities for increasing the effectiveness of their work. Yet comparatively few teachers have had visual-instruction courses as part of their professional preparation, nor do many school systems maintain departments of visual instruction supervising the application of visual aids in classroom teaching. It is to be expected that the in-service training of teachers in methods of utilizing sound films and other audio-visual aids will constitute an immediate and important problem. 
The fact that most teachers are untrained in the use of audio-visual materials of instruction is due to the lack of professional courses in this field in teacher-training institutions. It is true that many normal schools and teachers colleges introduce some aspects of this work as part of subject-matter courses, but frequently attention centers upon mechanical details such as projectors, size of lenses, and slide-making. Some idea of the limited opportunities for professional preparation in visual instruction is given in Table $\mathrm{I}$.

\section{TABLE I*}

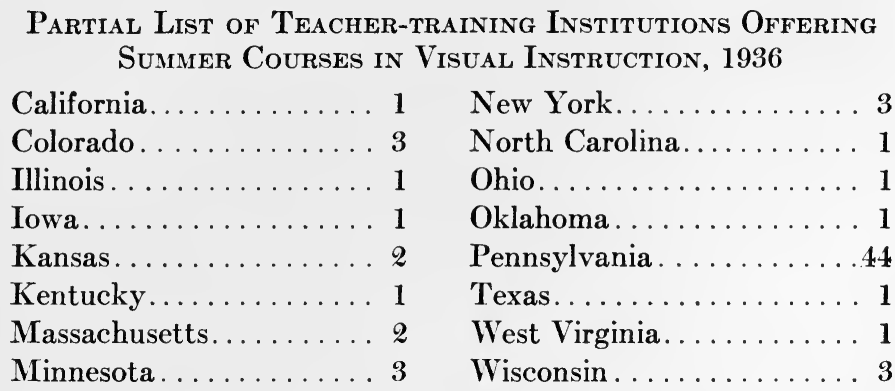

New Jersey . . . . . . . . . 3

* Data taken from The Educational Screen, XV, No. 5 (May, 1936), 148.

It should be noted that almost two-thirds of these seventytwo training centers are located in one state-Pennsylvania. The rapid increase in visual-instruction courses in this state was occasioned largely by the requirement of a laboratory course in visual instruction for the teaching certificate.

Progressive departments of visual education in local school systems have pointed the way in solving the problem of aiding teachers in the use of materials of instruction. One director of visual instruction ${ }^{1}$ suggests the following means for rendering service to teachers, both in the selection of materials and in the techniques of their use: (1) planning with the teachers and pupils, (2) visiting the teachers, (3) holding meetings, (4) giving demonstration lessons, (5) issuing bulle-

${ }^{1}$ E. W. Crawford, "Director Guides Teachers in Use of Visual Aids," Nation's Schools, XVI, No. 5 (November, 1935), 32-34. 
tins, (6) compiling lists of sources, (7) arranging teachers' visitations, and (8) making materials available. It is worthy of note that this director spends practically all her time in supervisory contacts; a secretary-clerk handles the routine of the department.

The superintendent or principal interested in helping his teachers achieve confidence and skill in the use of films may plan training activities in this field as an opportunity for professional growth and advancement comparable to that which teachers receive from participating in a program of curriculum revision. Studying the use of aids to learning, such as the sound film, cuts across almost every aspect of the teacher's work-his philosophy of education, his knowledge of the psychology of learning, his methods of instruction, and especially his command of subject matter. Training in the use of educational films, therefore, may profitably be undertaken as a year's project in the general program for improving the quality of instruction. Although study projects in the utilization of instructional materials may embrace all the working equipment of the classroom and laboratory, the suggestions given here are limited mainly to the sound film as typical of audio-visual devices.

\section{DESIRABLE OUTCOMES FOR A TRAINING PROGRAM}

The scope and direction of a program for developing skill in the use of audio-visual materials of instruction is necessarily determined by the goals to be achieved. Thus administrators, supervisors, and teachers should know definitely just what they expect to reach in the way of outcomes-attainable knowledges, skills, and appreciations. Let us suppose that the administration and the faculty of a school system are planning to stress film-teaching techniques as part of the program for the improvement of instruction during the school year; what changes are to be accomplished?

To begin with, the training activities should result in developing in each teacher who expects to make use of sound 



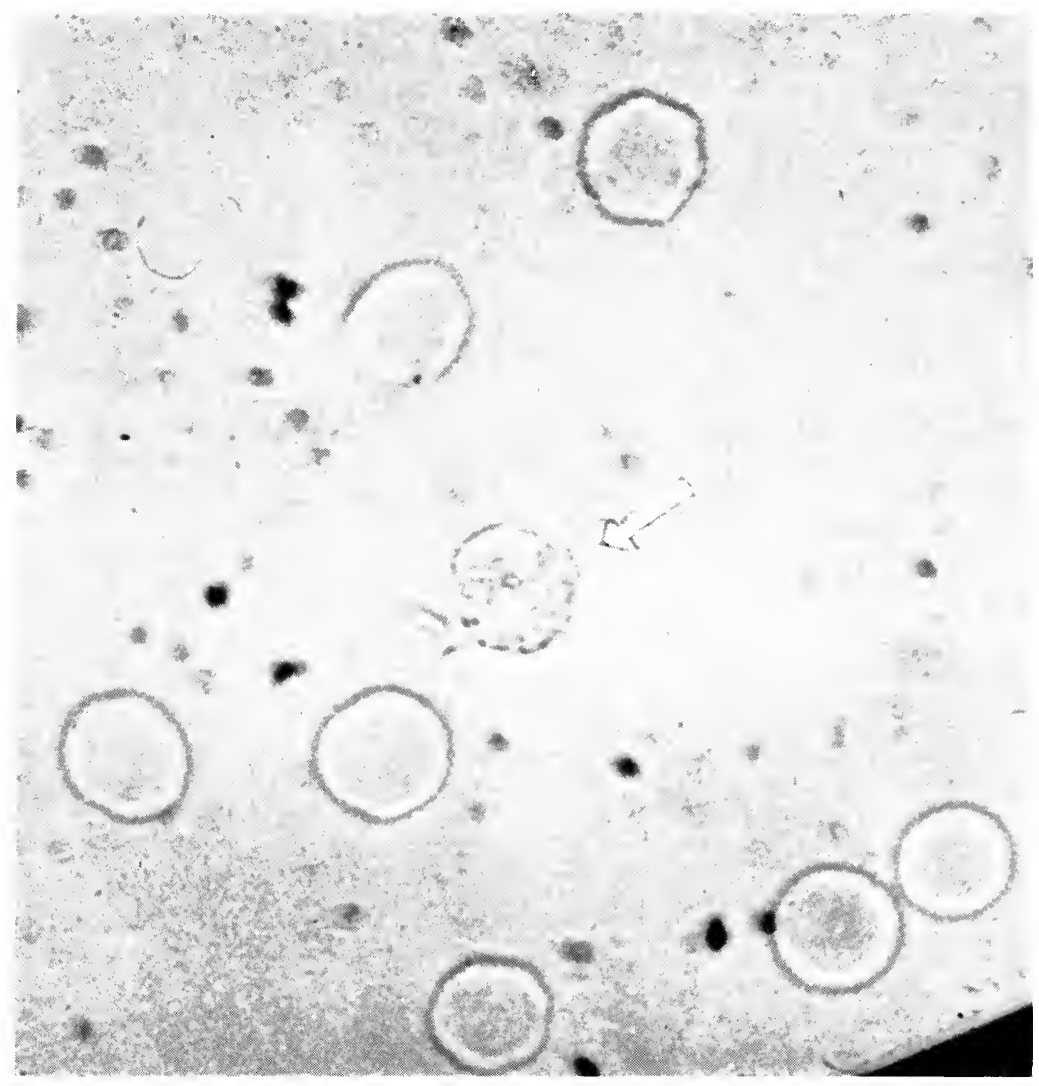

A Germ-denotring Cell

SPEAKER [deseribing the aetirities of the eell marked by the arrou]: White blood cells called leucocytes squeeze through the capillary walls and surround the bacteria. The white blood cells are aided by larger cells of similar nature. Here the microscope shows us how one of these larger cells engulfs foreign particles. This is called a phagocyte-or devouring cell.-Body Defenses against Disease. 
films an intelligent understanding of the film as a medium of instruction. As was pointed out earlier, this appreciation involves recognition of the technical elements of the sound film (such as the different types of photography, for example); the function of the film in the learning process-what it can do and what it cannot do; and how its use compares with that of other instructional materials such as textbooks, pictures, and laboratory apparatus. This background of appreciation is vital as a basis upon which to build creative teaching procedures with the sound film.

Another goal toward which teachers should be working is a knowledge of the fundamental principles underlying the effective use of the sound film. Planning the use of the film, introducing it in a dynamic learning situation, following up the film showing, carrying on associated learning activities, repeating the use of the film when and as often as neededthese phases of the general technique of teaching with films are basic. Every teacher should be familiar with their general application to the instructional procedure he utilizes.

A third outcome is the knowledge of specific film-teaching methods which have proved effective. Each teacher should approach the problem of acquiring this knowledge in terms of the subject or grade he teaches. He should know the specific purposes or teaching situations in which the sound film may be most advantageously employed. Furthermore, he should be equipped with a working knowledge of techniques for achieving such purposes-ways and means of adjusting films to pupil needs, of introducing the use of the film, and the like. It is not expected that a teacher is to be limited by what other teachers have done; rather, when he knows the variety of techniques others have used, special adaptations of these methods-or entirely new methodswill occur to him more readily.

A fourth outcome is a habit of creative experimentation with film-teaching methods and procedures. The interesting variation possible in the classroom situation from day to day 
suggests a similar breadth to the uses and special applications which may be originated with a device as stimulating and versatile as the sound film. Teachers should be encouraged to plan new methods-trying them out, discarding those which are not productive, and retaining those which have yielded a rich return in pupil interest and achievement. It would be impossible to overemphasize the importance of this aspect of the training program. A school in which teachers enjoy working with sound films because of freedom to experiment with new ways of adapting the medium to their classroom activities and projects will be characterized by a high level of skill in the use of the sound film. It should be pointed out, also, that such experimentation and thoughtful planning for the use of these materials of instruction will have a corresponding effect in improving the teacher's efficiency in all other aspects of his work.

A fifth outcome is a knowledge of the available films in the local library and their application to the subjects taught in the local courses of study. With continued use of films circulated from the central library, the teacher would in time learn to know their content rather thoroughly; however, it is preferable to analyze them, at the very outset, in terms of the courses of study. A teacher of elementary science, for example, will find it advantageous to know for what topics in the units he undertakes with his pupils there are pertinent films in the library. Along with the knowledge of the films should go familiarity with the handbooks, manuals, or printed units of instruction which may accompany the films in the library.

\section{AN IN-SERVICE TRAINING COURSE}

Probably the most effective way to get off to a good start in developing film-teaching ability is to participate in a special training course. Such a course, including both the theory of film teaching and its practical application as demonstrated in the classroom, has the advantage of focusing 
the teacher's attention from the beginning upon proper techniques of use. It is obviously superior to the trial-anderror method by which even the good teacher could attain skill only gradually. It is much faster and more stimulating than the "infiltration" method of working with individuals in supervisory conferences, which at the best requires considerable time to reach every teacher.

Some objection may be advanced to adding still another load to the teacher's overcrowded schedule. The answer to this is that professional growth requires contacts with new techniques and new organizations of subject matter. The teacher who is content to plod along without refreshing his point of view occasionally with new perspectives is in danger of professional stagnation. Alert teachers are continually upon the outlook for opportunities to develop their grasp of educational principles and to improve the efficiency of their classroom methods. Professional growth is a matter of vital concern to every individual who has to do with the education of boys and girls.

For many school systems the easiest way of providing this type of teacher training is to arrange for an extension course from a nearby teachers' college. The extension course not only tends to insure capable instruction but has the added advantage of helping teachers in their plans for further professional study. However, in some localities it may be impossible to secure from the university or teachers' college an instructor who is a specialist in audio-visual methods of instruction. In such cases it is desirable to enlist the services of an expert field worker - the director of visual education in a neighboring school system, or a superintendent or principal who has studied and experimented extensively with the use of films. It is of the utmost importance that the instructor's competence should be evident in his knowledge of the curriculum, grasp of instructional problems, and familiarity with the application of audio-visual devices in specific areas of learning. 


\section{0\% HOW TO USE THE EDUCATIONAL SOUND FILM}

A variation of the extension-course plan may be utilized in small school systems. It has been found practical to encourage some member of the local staff-the superintendent, a principal, or an outstanding teacher-to pursue graduate study during the summer, qualifying him to guide a faculty study project in the local system. Although this expedient is not as desirable as the special course, it has the merit of stimulating local professional study which otherwise might not be undertaken. Even in the larger school systems it will be worth while for as many teachers and principals as possible to extend their professional training by taking summersession work in the utilization of films and other materials of instruction. ${ }^{2}$ This gives the local staff a nucleus of individuals who may be of service to the other teachers in planning their use of films and acquiring skill in film teaching.

The local in-service training course may also be undertaken on a smaller scale as a faculty study project, especially where the use of sound films is being organized in a single school building. The content and objectives of the course would be the same, the only difference being that the project would logically be directed by the principal. He would have the advantage of close contact with experimental film units developed in the classrooms of the building, as part of his routine of supervision. Another variation of the training course would be to initiate the project as a departmental activity, as in the science department. This plan has merit when the beginning use of films is to be concentrated in a single department, with film use extended to other departments as the local film library is enlarged.

The course may be organized to meet once every two

${ }^{2}$ Some teacher-training institutions, such as Boston University, New York University, and Teachers College of Columbia University, schedule courses in audio-visual instruction at hours which permit teachers in service to enrol during the academic year. Those who live within the radius of campus attendance will find it profitable to investigate the type of course offered and the opportunities for graduate study in combination with developing solutions to the local problems of film use. 
weeks, for a two-hour session in the afternoon at the close of school. Many school systems have scheduled such extension courses for a semester. In some schools the class may take the place of the regular faculty meeting, with routine business transacted at the opening of the period. Some groups of teachers may prefer to meet one afternoon every week for a shorter length of time.

A. SUGGESTED CONTENT FOR THE TRAINING COURSE

The purpose of this preliminary training is essentially that of helping the teacher to develop a basis for later growth upon his own initiative. The content selected, therefore, should stress broad educational principles rather than the oiling of a projector or sources of still pictures on Asia. Such details have their place, but they are subordinate to the knowledge of basic teaching techniques. The topics considered should deal with the educational implications of audio-visual devices, presented in terms of the subject matter with which the teacher is most familiar.

The following outline for the content of the course includes the minimum essentials; it may be altered or expanded as desired to fit the local situation. Although it has been limited for the most part to teaching with sound films, it may be readily enlarged to include the consideration of all types of audio-visual teaching aids, since the principles involved are similar. It should be noted that the outline follows closely the concepts which have previously been stressed as fundamental to the effective use of the film medium in teaching.

I. Appreciation of the sound film as an instructional aid (this understanding orients the whole study of sound-film use)

A. Characteristics of the educational sound film

1. Functions of the sound film in the learning process

2. Educational purposes of various cinematographic techniques

B. Complementary relationship to other instructional aids

1. Classification of other types of aids

2. Special functions and advantages of each type

3. Ways of integrating the use of other devices with that of the film 


\section{HOW TO USE THE EDUCATIONAL SOUND FILM}

C. Application of the sound film to various subject-matter fields

1. Illustrations from films of specialized uses to which the film may be put in different subjects

II. Standards for educational sound films

One of the most important problems in connection with the use of materials of instruction is that of proper selection. Teachers should learn how to judge the probable effectiveness of a particular film for the topic, unit, or activity for which they happen to be planning. Practice in rating will equip teachers with skill in determining the educational worth and the specific applications of films. The standards given below may be made the point of departure in formulating a local check-list for rating.

A. How to rate sound films

1. Become familiar with standards for evaluation

2. Study accompanying printed supplementary materials

3. View the films twice before rating

4. Secure group judgment

B. Suggestive list of standards for the educational sound film

1. Instructional value of the film subject matter

2. Appropriateness of the depicted material for the sound-film medium

3. Unity of development

4. Accuracy of the presentation

5. Thoroughness of the exposition

6. Ease of understanding

7. Technical excellence of the photography and the sound recording

8. Artistic value

9. Adaptability to specific grade levels

III. Integrating sound films with courses of study

This step is part of the important curriculum-making process of selecting materials of instruction and writing them into the work of the classroom at appropriate points. Even though the local film library may already have been established, each teacher should know in detail how the films tie in with the work he is teaching.

A. Advantages

1. The contribution of each film subject to the curriculum has been thoroughly explored

2. Potential uses are indicated in terms of the objectives of the courses of study or units

3. The use of the film tends to be planned rather than merely incidental 
4. The application of specific films to designated topics is preserved for future use

B. Method of writing sound films into courses of study

1. Analyze each film in terms of $(a)$ objectives, $(b)$ subject-matter topics, and $(c)$ grade placement

2. Select points in the course of study where the particular film makes a contribution

3. Indicate the contribution, with suggestions for the use of the film in that connection ${ }^{3}$

IV. Techniques of teaching with sound films

A. Planning the use of the sound film

1. Planning the unit of instruction or project

2. Selecting the appropriate film

3. Studying its content and the teacher's manual

4. Setting up the purposes which each showing of the film is expected to accomplish

B. Introducing each showing of the film

1. Explaining difficult concepts or technical details

2. Connecting the film presentation with the student's past experience

3. Giving the student a perspective for observing the film

C. Guiding learning activities after the film showing

1. Purposes of the discussion following the showing

2. Initiating related learning activities

3. When and how often to repeat the showing

V. Operation of $16-\mathrm{mm}$. sound-film equipment

Although in many school systems special operators may be provided or student operators trained, it is highly desirable that teachers have an understanding of the mechanical aspects of projecting films in the classroom. ${ }^{4}$

${ }^{3}$ It is desirable to point out to teachers that keeping a record of outstanding units or projects in which the sound film was used will facilitate the addition of valuable suggestions when the course of study is revised.

${ }^{4}$ Many training courses in visual education have tended to stress the physical and mechanical aspects. Projectors and screens, since they could be seen and manipulated, appealed to teachers and instructor alike. There is no question of their importance, but the educational aspect of the use of the film overshadows the mechanical. Teachers should, of course, become competent in operation, where such skill is necessary, or acquainted with techniques for conserving the time of the class, where a special operator is provided. But the essential part of the teacher's task, in connection with the use of instructional materials, is making sure that they serve the learning needs of the students to the best advantage. 
A. Units of a 16-mm. sound-film projector

1. Projector, amplifier, and loudspeaker

B. Preparing a classroom for projection

1. Proper selection for acoustic qualities

2. Provision of darkening facilities and electric outlets

3. Type of power supply needed

4. Lenses and picture sizes

5. Placement of the screen, projector, and loudspeaker

C. Techniques of operating a $16-\mathrm{mm}$. sound-film projector

1. Threading the film

2. Controlling the volume

3. Care of the equipment

4. Care and repair of sound film

B. TEACHING THE TRAINING COURSE

The method of instruction for the training course should be the laboratory-demonstration-discussion type, an approach which is ideally adapted to the nature and functions of the devices being studied. Few classes present such rich and varied opportunities to vitalize the learning through the use of objective materials of instruction. Films should be brought into the classroom, evaluated, considered in terms of child interests, analyzed for their contributions to specific units of work. Indeed, an instructor who endeavored to present the concepts of film teaching mainly through lectures would be denying the utility of that which he is explaining.

Almost every phase of the course lends itself to practical exercises and demonstration. In discussing the relationship between the film and other instructional devices direct comparisons may be made, first by a film showing and then by demonstration of the other illustrative aids. As a part of the study of the standards which should govern the educational sound film, practice in rating films is essential. The integration of audio-visual materials with the courses of study suggests actual curriculum-making along this line. Techniques of film teaching may be studied through demonstration lessons, the preparation of film-lesson plans, and the like. The physical and mechanical aspects of projection, especially 

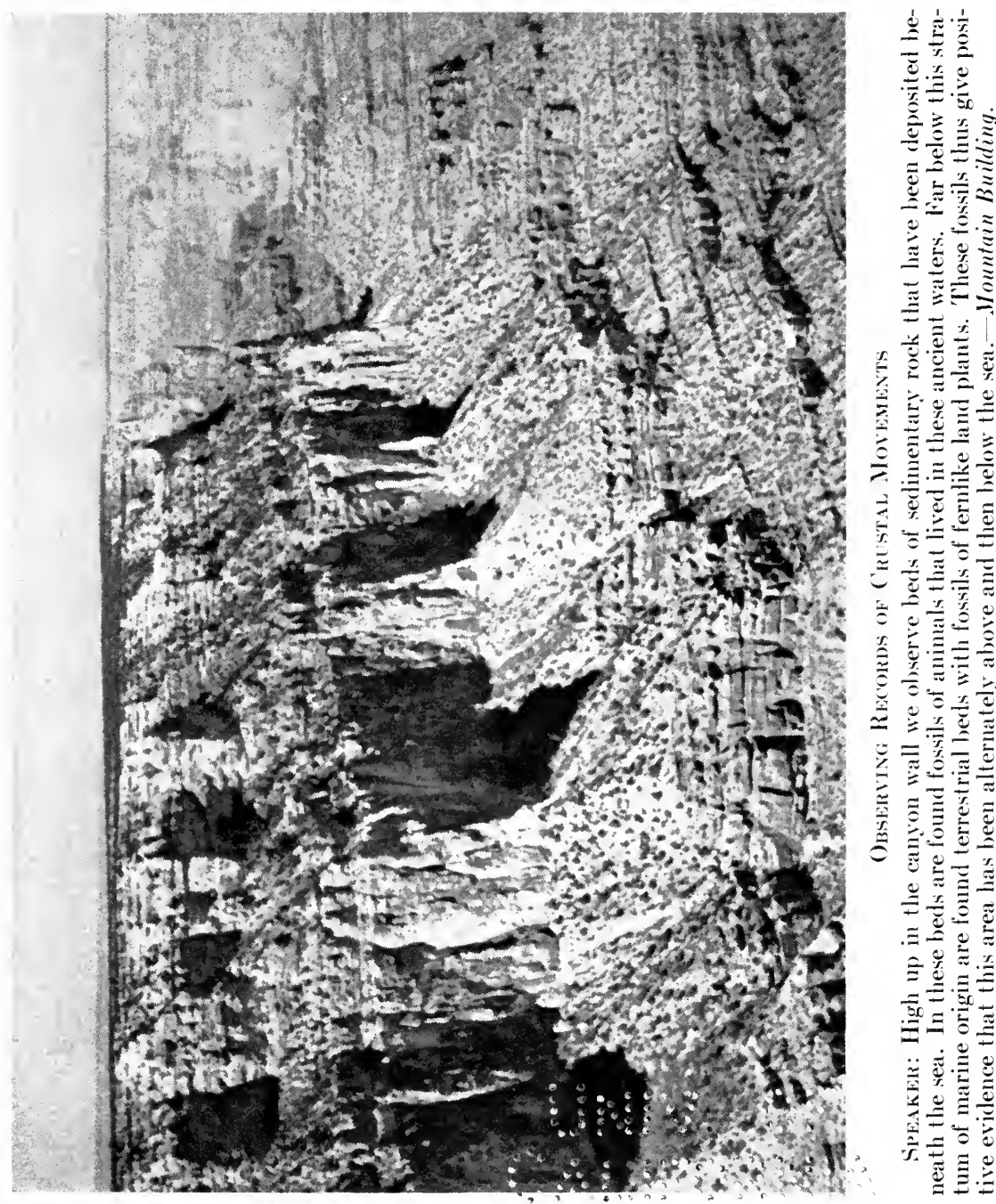


$$
\begin{aligned}
& \vdots \vdots \quad \text { a }
\end{aligned}
$$

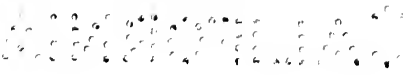


those dealing with equipment, are almost entirely demonstrable through first-hand contact and practice. The equipment which has been purchased for use in the local system should be brought into the class, explained, and practice periods scheduled for teachers to acquire skill in operating it.

In making use of the film medium itself to train teachers in the effective use of sound films, several types of films may be employed. There is the subject-matter film which will be utilized by the teacher in the classroom. It will be advantageous to study at least one unit in which such a film is employed; the subject matter should be that which is comparatively unfamiliar to most of the group, such as that represented in the film Mountain Building. Studying a film which, although of general interest, is comparatively new to most of the teachers will enable them to approximate the pupil's situation as he undertakes the study of units, topics, or projects in which films are utilized.

Another type of film which will be of assistance to the teachers is that which has been prepared especially for such training purposes. An example of this type is the picture Teaching with Sound Films, ${ }^{5}$ which presents illustrations of the teaching purposes for which the educational sound film may be employed and specific techniques for achieving those purposes. Thus the film will serve as a standardized demonstration which may be repeated and discussed as often as desired. As an interesting variation, this film might be compared with actual demonstrations of film teaching held for the class.

\section{RELATED TRAINING ACTIVITIES}

The practical application of the theories developed in the training class may be made through experimental film lessons initiated by individual teachers and discussed before the group. Since the outcome is to be a skill, or rather a group of specialized teaching skills, it follows that teachers should have ample opportunity to practice those skills in the regular

${ }^{5}$ Prepared by the research staff of Erpi Picture Consultants, Inc. 
course of their teaching. Each member of the group might first develop a plan for a film lesson, to be criticized before the group. In succeeding stages of the course individual members of the group could report on the effectiveness of the planning as it worked out in actual film teaching-methods they devised to introduce a specific film, to guide the subsequent discussion, and to carry on related learning activities. Of particular importance to the teacher at this stage will be his own analysis of the strength or weakness of the techniques he followed. He should be encouraged to form the habit of planning each use of the film, to create approaches which seem promising, and to evaluate their effectiveness in terms of basic principles. Supervised practice in film teaching, as a laboratory feature of the course, will do much to strengthen the teachers' skill.

Some school systems may find it feasible to co-ordinate the study of audio-visual materials of instruction with the revision or extension of the curriculum. For example, if a new course of study in elementary science were to be prepared, one of the important tasks would be the selection of instructional materials to be suggested in the syllabus for the use of teacher and pupils. It would be quite appropriate to study at the same time the application of sound films in connection with the units outlined by the course of study. Not only would the course of study be enriched, but teachers would be considering instructional materials in terms of the new units and objectives with which they are to deal. In one school system where this plan was tried out the inauguration of a course of study in elementary science was greatly facilitated through planning the integration of appropriate film subjects.

\section{REFERENCE MATERIALS}

Teachers and principals will find it helpful to have convenient access to a library ${ }^{6}$ of references dealing with audio-

${ }^{6}$ The following references are suggested as part of a minimum library:

Frederick L. Devereux and others, The Educational Talking Picture (rev. ed.) (Chicago: University of Chicago Press, 1935).

V. C. Arnspiger, Measuring the Effectiveness of Sound Pictures As Teaching Aids 
visual instruction. Essential books, monographs, and pamphlets may be located as a unit library in each school. These references might include the following:

1. Studies of types of instructional materials and their selection for specific teaching situations

2. Studies evaluating the effectiveness of the sound film

3. Monographs describing programs of audio-visual instruction

4. Superior courses of study illustrating the integration of materials of instruction

5. Reports dealing with film-teaching techniques

6. Outstanding film-lesson plans developed locally and made available in mimeographed form

7. Syllabi for training in visual instruction

8. Periodicals in visual instruction

9. Film catalogues and lists of sources

10. Teacher's manuals accompanying the films in the local film library

\section{SPECIAL TRAINING FOR PRINCIPALS}

Principals as well as teachers will profit by intensive study of the various aspects of audio-visual instruction. Their contacts with the film program are both administrative and supervisory. For the latter it is important that they participate in the same preliminary training as the teachers, as a foundation for their supervisory service in assisting the teachers to plan film uses and to evaluate the worth of filmteaching techniques. The principal's function as a supervisor is not that of operating the projector for teachers timid about mechanical things; he should be an educational consultant upon whom the teacher relies for perspective and suggestions regarding instructional problems and methods.

(New York: Bureau of Publications, Teachers College, Columbia University 1933).

A. V. Dorris, Visual Instruction in the Public Schools (Boston: Ginn \& Co., 1929).

Aids to Teaching in the Elementary School: Thirteenth Yearbook, Department of Elementary School Principals, N.E.A. (1934).

Materials of Instruction: Eighth Yearbook, Department of Supervisors and Directors of Instruction of the N.E.A. (New York: Bureau of Publications, Teachers College, Columbia University, 1935).

Cline M. Koon, The Art of Teaching by Radio, Bull. 4 (Washington: U.S. Office of Education, 1933). 
The efficient administration of the film program, in so far as it devolves upon the principals, may be developed through a series of conferences, in which the principals meet with the superintendent or the individual directing the program to map out desirable routines, or to suggest modifications of the administrative procedure which seem desirable.

A list of topics which might be discussed at the principals' meetings would include such administrative problems as the following:

1. Method of insuring the proper operation of the equipment.

2. The arrangements for requisitioning and distributing films

3. Records and reports of film use required from teachers

4. Techniques of film teaching and its supervision

5. Course-of-study changes involving instructional materials

6. Evaluation of films in local use

\section{SUPERVISION OF FILM TEACHING}

Supervision is probably the most important means of insuring the development of film-teaching skill. 'The initial basic training serves to give teachers a background of knowledge and understanding of the film medium, but supervision guides them as they grow in the ability to utilize the film in the classroom. Intelligent, sympathetic criticisms and suggestions, given by supervisors who have a keen appreciation of the part which audio-visual materials of instruction may play in the attainment of objectives and in the mastery of subject matter, will stimulate teachers to creative use of all the devices at their command. On the other hand, a supervisor who is either uninterested or unaware of the possibilities inherent in the working tools of the classroom may eventually dampen any enthusiasm which the teacher might generate.

The supervisor should be a person able to lead, to detect omissions and faulty methods, and to suggest desirable changes in approach and technique. This means that the individual supervising should know more about film teaching than the teacher, should have a background of appreciation into which instructional materials and devices have been 
oriented with respect to the whole process of teaching. Furthermore, the supervisor must know what instructional materials may be secured-the sound films in the local film library, for example-so that he may be of assistance to the teacher in planning units and projects. The supervisor's familiarity with the films available must go beyond the mere knowledge of titles and appropriate grade levels; he should know specific sections of the films, especially in connection with topics in the courses of study.

The supervisor visiting a classroom where the sound film is being utilized must consider the procedure of the film presentation in the light of the organization planned for the entire unit. Furthermore, the use of this instructional material is an integral part of the other teaching activities of the period, not to be disassociated in the supervisor's analysis. For example, the way in which a teacher employs a film on vocational guidance to develop the concepts leading to intelligent choice of an occupation is a functional part of the teaching technique for the entire lesson or series of lessons.

It should be emphasized that the criticism of film-teaching methods, like that of any other teaching activity, must be made in terms of the purposes which the teacher has planned as the guide for the day's lesson. To illustrate, a casual observer might criticize the showing of only part of the film during the lesson, or object to a lack of discussion following the showing. But such techniques might be perfectly valid in terms of the purposes for the lesson-in the first case, the teacher might be concentrating in a repeated showing upon one important theme developed in a sequence of the film; in the second case, the showing might be a review, coming at the end of a series of lessons in which the film has been presented several times, and shown finally to crystallize the thinking which has taken place.

The supervisor's conference with the teacher after the film lesson may be devoted to the consideration of such specific points as the following: 


\section{HOW TO USE THE EDUCATIONAL SOUND FILM}

1. How did the use of the film contribute to the attainment of the purposes of the day's lesson?

2. How had the students been prepared for the showing? In what ways was the use of the film meeting learning needs and interests? Had the students been prepared to understand difficult new words or unfamiliar photographic devices?

3. How well did the discussion after the film showing uncover interest leads to activities or study?

4. Was the use of the sound film well integrated with other learning activities proceeding in the class? Did the teacher make full use of film impressions in guiding the discussion after the showing?

5. Was the particular film used the best one which could have been selected for the purpose? Would another film have been better suited to the class, or for the presentation of the subject matter under discussion?

6. Did the use of the film contribute something unique or time saving? Could the same purpose have been better served through the use of some other device-a field trip, a textbook assignment, an experiment?

7. How well was the mechanical part of the film showing handled? Was the picture clear? The room well ventilated? Projection managed with a minimum of time consumed?

8. Is the film being utilized to stimulate creative expression in writing, speaking, and art work?

9. Are there centers of interest on the fringe of the unit or of the lesson taught which might profitably be developed for individual students?

10. Should there be another showing of the same film? If so, when, and for what specific purposes?

The supervisor should encourage the publication, even if only in mimeographed form, of outstanding lessons which his teachers have developed. Such recognition of professional excellence not only encourages the creative teacher, but helps to bring others up to a higher level of skill, by suggesting film uses and procedures which might not have occurred to them. Another stimulating device is to issue periodically a mimeographed bulletin which may become a "Handbook of Film Teaching Methods."7 This may be issued as a monthly bulle-

${ }^{7}$ An illustration of this device is the Handbook for the Use of Visual Aids, printed in periodic revisions for the schools in Pittsburgh, Pa. The manual lists guiding principles for the use of visual aids, directions for ordering and returning materials, and a complete catalogue of the materials available. 


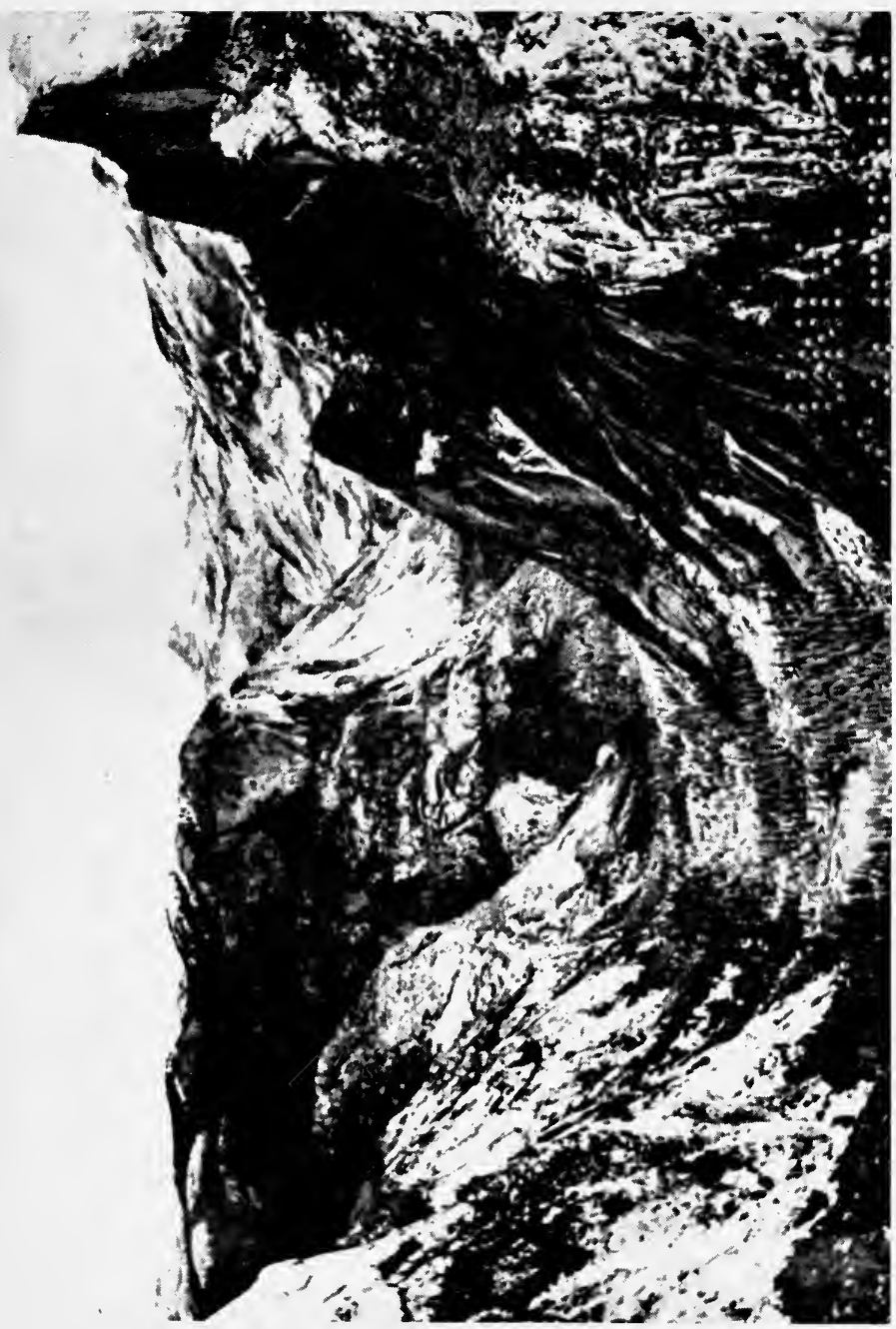

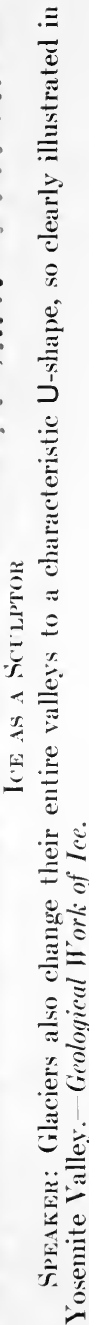




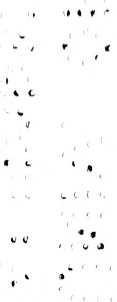


tin, to be bound at the end of the school year, or prepared as one section of the catalogue of materials in the local library of audio-visual aids. In either case, this body of information should be an evolving accumulation of procedures and applications of the film in local instruction, paralleling the rise in the general level of teaching skill with films.

\section{SUMMARY}

The suggestions given here for helping the teacher gain confidence and skill in the use of the sound film include a preliminary training course of the in-service type; graduate study in audio-visual instruction problems and techniques at teacher-training institutions; experimental film units developed in the classroom; demonstration lessons illustrating film-teaching methods; the establishment of unit libraries on audio-visual instruction in each school; the creation of a local handbook on film-teaching methods, perhaps issued at first in the form of bulletins; the publication of superior units and projects created by the local staff; the enrichment of courses of study through the addition of tested materials of instruction; and a program of supervision. These ways of assisting the teacher are not novel; many of them have long been standard practice in school systems with outstanding departments of visual instruction. Any school beginning the use of sound films may select the training devices which seem most promising and co-ordinate them in a definite program of professional growth.

No local faculty need hesitate to undertake such a program because of unfamiliarity with visual aids. It has been emphasized throughout this discussion that it is not the device itself that is important, but the use made of the device in helping boys and girls to learn. Acquiring skill in the use of materials of instruction does not necessarily require a visualinstruction department; it simply requires interested individuals, alert to participate in any organized effort which promises to increase their competence as teachers. 


\section{CHAP'TER VI}

\section{MECHANICAL AND ROU'TINE ASPECTS OF SOUND-FILM USE}

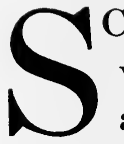

CHOOLS interested in developing programs of audiovisual instruction will find it profitable to devote time and thought at the outset to the minor mechanical arrangements which play such a large part in facilitating or hindering the teacher's use of films in the classroom. Selecting satisfactory projection equipment and providing for its operation and maintenance, adapting classrooms for projection, developing a convenient system for distributing films, establishing adequate facilities for storing and repairing films, and maintaining a simple, but complete, record of film use-these are problems which if unsolved will discourage consistent use of the films. From the teacher's standpoint the value derived from a film may be overshadowed by difficulties encountered in presenting it in the classroom. Details such as a proper darkening of the room, or the prompt replacement of projector lamps, tend to assume unduly large proportions. Perhaps this is because physical needs can be seen and therefore readily appreciated; perhaps it is because so often the lack of carefully planned provisions for showing films has been allowed to defeat the teacher's efforts to make use of available films. The experience of those school systems where successful visual education programs are operating indicates that thorough planning and adequate budgetary support can eliminate mechanical difficulties. It is the purpose here to assist the planning of those who are beginning the use of sound films by presenting practical suggestions which are the outgrowth of studies in this field. Those interested in a more comprehensive discussion of the physical and 
mechanical aspects of film usage are referred to other volumes on audio-visual instruction. ${ }^{1}$

\section{THE SELECTION OF A SOUND-FILM PROJECTOR}

Sound-reproducing equipment in the $16-\mathrm{mm}$. size represents a remarkable recent technological achievement. A few years ago the reproduction of $16-\mathrm{mm}$. talking pictures, with the sound coming from the film itself, was only a vision. Pioneering attempts proved its possibility; rapidly various refinements have been made until now the $16-\mathrm{mm}$. sound film, from the mechanical as well as the educational standpoint, is an efficient classroom device.

Some schools considering the purchase of an equipment hesitate between the 16-mm. type and the larger size, the $35 \mathrm{~mm}$. The choice, assuming that the difference in cost is not a factor, depends entirely upon the purposes to be served. For large auditoriums in which entertainment programs are to be given, the $35-\mathrm{mm}$. equipment is most desirable. On the other hand, a program of instruction centered in the classrooms requires the $16-\mathrm{mm}$. sound-film projector. Even auditorium instruction, where the room is not unusually large, has been successfully carried on through 16-mm. projectors. Furthermore, 35-mm. sound films cost approximately twice as much as $16-\mathrm{mm}$. sound films. The portability, efficiency, and lower cost of the $16-\mathrm{mm}$. sound-film projector have made it exceptionally suitable for classroom use.

The selection of $16-\mathrm{mm}$. sound-film equipment should be controlled by specifications and standards similar to those which have been developed for the purchase of other school equipment and supplies. The practices of analyzing equipment in terms of specifications, and holding competitive tryouts, take the guesswork out of buying. When there is a choice between two or three projectors, the ultimate consideration is the performance which the machine is expected to give. Among the factors to be studied are the following:

${ }^{1}$ See Devereux, The Educational Talking Picture, chaps. viii, xi, and xii; and A. V. Dorris, Visual Instruction in the Public Schools (Boston: Ginn \& Co., 1929). 


\section{HOW TO USE THE EDUCATIONAL SOUND FILM}

\section{Intensity of illumination}

If the projector is to be used in auditoriums and large classrooms, the amount of illumination provided should be equal to the demand. It should be noted that the intensity of screen illumination is not governed solely by the size of the projector lamp; it depends also upon the efficiency of the optical system employed in the projector.

2. Steadiness of the pictures projected

A flickering image causes eyestrain, and hinders the students' concentration upon the subject matter being presented.

3. Safeguards against film damage

This is especially important where teachers and students are to operate the equipment. Automatic safeguards which largely eliminate the possibility of damage to films increase the life of the film many times over and protect the film-library investment.

4. Quality of sound

With good recording and favorable acoustics, the sound reproduced by the equipment should be perfectly intelligible. If the sound is not intelligible, the effectiveness of the instruction provided by the talking picture is materially lessened.

5. Ease of operation

A sound-film projector should not only be easy to operate but it should look easy to operate. Teachers should be able to master the necessary skills readily, without the need for technical knowledge or special mechanical aptitude. The operating controls must be conveniently accessible. It should be possible to unpack the equipment and get it ready for projection quickly.

6. Portability

The equipment should be light enough so that it may be easily carried from classroom to classroom and from building to building.

7. Durability

The quality of materials used and the general sturdiness of construction should be such that with reasonable care freedom from breakdown is assured.

8. Accessibility of repair service

For the prompt repair of any breakage or difficulties it is highly important that efficient repair service, by a trained representative of the equipment manufacturer, should be immediately available. Complete utilization of the projector and films is possible only where scheduled use is planned; interruptions in the program due to the equipment getting out of order seriously limit the teacher's use.

9. Accessories

Many 16-mm. sound-film projectors have special appliances which extend their usefulness. Among these are the phonograph jack, to 


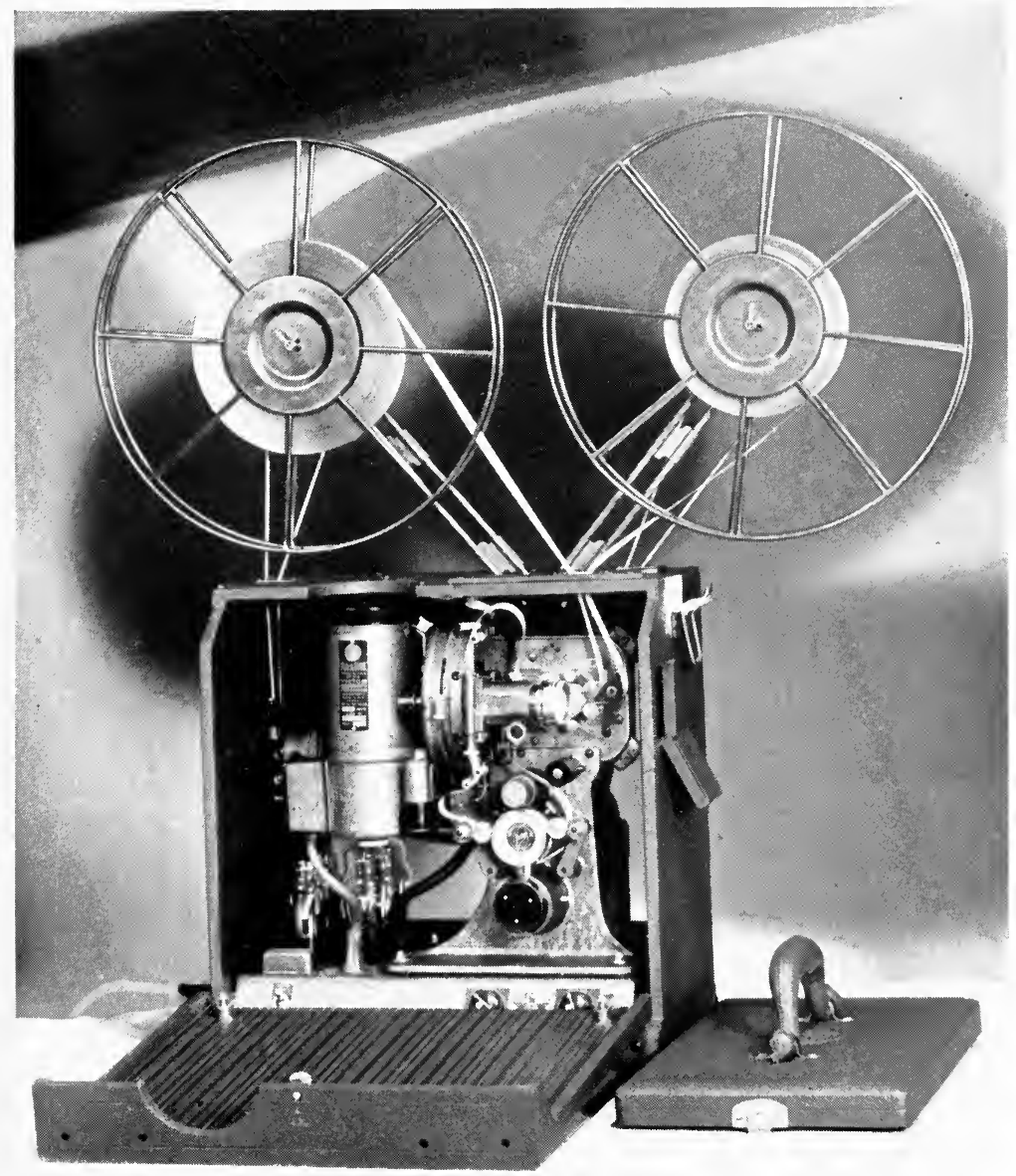

C'ourtesy Victor Inimatograph C'orporation

16-Mm. Solnd-Film EquipMent-Type $A$ 


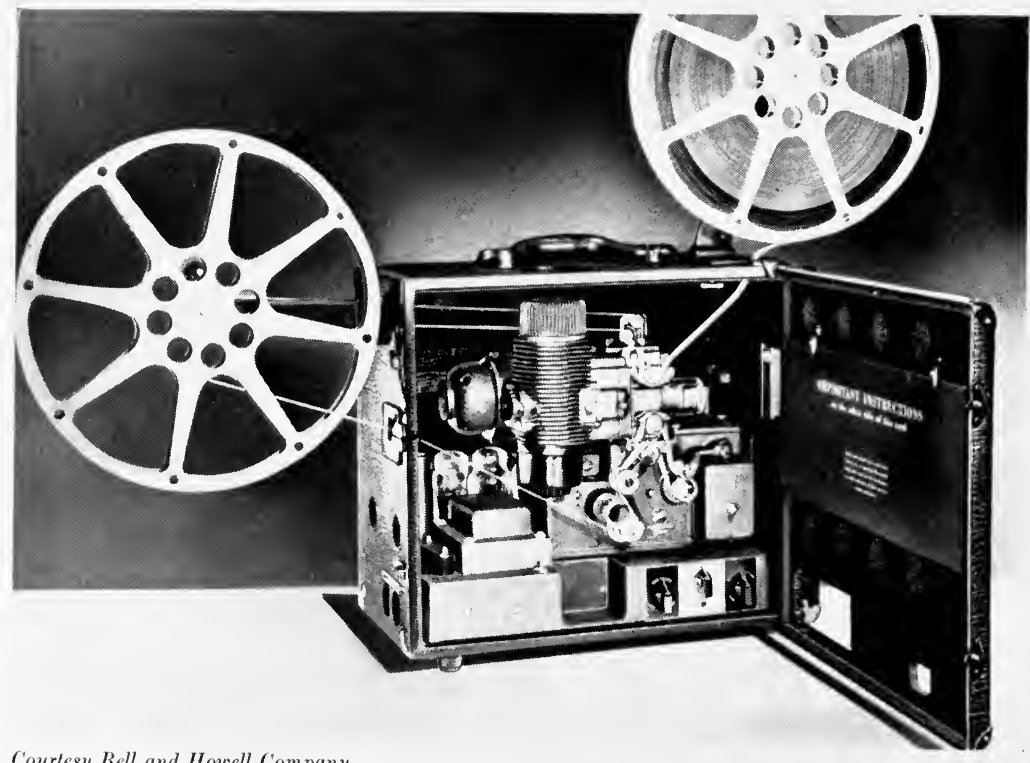

Courtesy Bell and Houell C'ompany

16-Mm. Sound-Film Equipuent-Type B 
permit the use of the amplifier with an electrically operated turntable; the microphone jack, into which the leads from a portable microphone may be plugged; and the single-frame projection device. If such accessories are to be utilized, they should be demonstrated so that their efficiency may be judged.

10. Cost

This factor is relative, that is, a matter of determining on the basis of the other standards, the desired degree of excellence required locally of an equipment.

Many schools will wish to use the $16-\mathrm{mm}$. equipment in small auditoriums as well as in the classrooms. Where this is the case, the projector selected should be capable of providing a satisfactory picture in the auditorium and sufficient sound volume without distortion. Some models now on the market are intended for classroom use only. The safest plan is to test the model under consideration both in the classroom and in the auditorium.

When the kind of projector has been settled, the next question for many school systems is that of determining how many machines are to be purchased. There can be no exact formula for the solution of this problem. The best plan, of course, is to have a projector for each school building, where films are being used continuously. But a projector is serving its purpose only when films are being shown; there is no point in installing an equipment in a building for four or five showings a week, to remain idle the rest of the time. The determining factor, if maximum utilization is to be secured, is the probable number of showings required. Therefore a school system which is beginning a program of talking-picture use may find it desirable to circulate an equipment among a group of three or four buildings, until the demand from individual schools has reached the point at which a projector is needed for each building.

THE OPERATION AND MAINTENANCE OF EQUIPMENT

One of the first considerations in planning the use of talking pictures is the matter of providing operation service. Who 
should operate the machine-teachers, principals, supervisors, students, custodians, or a special technician? How are these individuals to be trained in the mechanics of projection? These are questions of policy to be decided according to local personnel conditions and the extent to which films are to be utilized in the schools.

In the first place, most teachers can learn to operate a 16-mm. sound-film projector. ${ }^{2}$ From the standpoint of operation the machine is not much more complicated than the stereopticon or silent-film projector. Current models have been refined to the point where their operation is like that of a silent-film projector to which radio controls have been added. Given competent instruction and sufficient opportunity to practice, any teacher or older student can quickly acquire the necessary skill to manage classroom showings. Certainly these equipments, with their automatic safeguards, are no more complex than the electric sewing machine appears to the average man!

The simplicity of the $16-\mathrm{mm}$. sound-film reproducing equipment is evident in the description of operation techniques for a typical 16-mm. sound-film projector. To place the machine in operation the projector-amplifier unit, in its carrying case, is set on a table or stand at the proper distance from the screen. The power wire is uncoiled and connected from the projector to a nearby electrical outlet. The loudspeaker unit, with the front and back lids removed, is placed in the best acoustic position at the front of the room, near the screen. The speech cord from the amplifier is plugged into the loudspeaker. After the arms holding the reel of film and the take-up reel are mounted in place on the outside of the

${ }^{2}$ A rural teacher, after five months' experience with one of these equipments, commented upon its serviceability and ease of operation: "The particular machine in our county was really remarkable. It was circulated among twelve different schools with at least twelve different operators. For a machine to come through such a battle of personalities intact speaks very well for its manufacturer. The machine is easily operated. After threading it once or twice, and getting the film properly focused and framed, it becomes a small task to get a new reel in place." 
projector case, the reel is threaded as in a silent-film projector except for the additional loops around the sound-channel mechanism below the aperture. In the meantime the amplifier switch has been turned on to permit the tubes to warm up, as in a radio. With the projector lamp turned on, the projector motor is started, the picture focused on the screen, and the showing begins. At the end of the projection a power rewind may be utilized to replace the film on the original reel, ready for the next user. Oiling is a simple matter, the points receiving oil being marked for quick location. The entire equipment can be packed up for transportation in three or four minutes. ${ }^{3}$ An illustrated manual of operation accompanies the machine, with large threading diagrams conveniently accessible for reference on the projector case door.

Many school systems introducing the use of talking pictures decide to have the teachers handle all the operation. No difficulty has been found in training them to become sufficiently adept to manage classroom projections. Science teachers particularly have demonstrated an aptitude for this work, perhaps because of their constant use of laboratory apparatus. In certain schools groups of older students selected from Grades IX to XII have become skilful operators.

It should be pointed out, however, that there is a decided difference between the minimum skill required for the successful showing of one reel and the competence which provides showings over an extended period without damage to films or equipment. For example, incorrect threading of a film may not be at all noticeable during the first showing; the resulting sprocket punctures will appear to mar the screen picture during subsequent showings. Faulty adjustments may be made on the sound controls which have no immediate effect but tend to deteriorate tubes and photoelectric cells rapidly. Furthermore, a teacher who receives the projector for a single period in his classroom may or may not oil it. In

${ }^{3}$ For a detailed description of typical $16-\mathrm{mm}$. sound-film equipments see Devereux, op. cit., pp. 196-99. 
this respect the sound-film reproducer is like an automobile; there is more to successful operation over a period of time than the mere ability to drive without bumping into other cars! No matter who is selected to operate the projector, there should be a program of thorough training-training which does not cease the first time the novice gets through a showing successfully. The local representative of the equipment manufacturer is usually quite ready to co-operate in teaching the operation and care of the machine, especially since proper techniques of projection and maintenance lessen the number of service calls he will be required to make.

Some school systems will have a sufficiently extended program of film use, even at the outset, to justify the services of a special technician responsible for the operation, transportation, and maintenance of equipment and films. When there is a continuous demand for projection service throughout the school day, it is more economical to pay the salary of a special operator rather than to consume the more valuable time of teachers, principals, or supervisors. Furthermore, the special operator may help to solve the problem of film distribution and maintenance. It is easier and quicker for one person to become thoroughly adept in all aspects of the physical handling of films and equipment than it is to develop even minimum operating skill in a large group of teachers. For many schools the solution may be to utilize teacher and student operators during the initial stages of the film program; a special operator may be employed when the demand for film service becomes continuous.

In a large city-school system all the operation of the projector was managed by a member of the utility staff, temporarily released from his regular duties. He transported the equipment from building to building, according to a schedule based on the requisitions which had been received. It should be noted that the plan of having a special operator insured greater flexibility of use; on some days he visited as many as three different buildings, showing from three to six films in 
each. He used a light delivery truck belonging to the school maintenance department.

One school system in which the director of visual instruction had familiarized teachers with the operation of $16-\mathrm{mm}$. silent-film projectors secured a sound equipment similar to the silent projectors standard in the system. The techniques of operating the new equipment were explained and demonstrated at a general meeting; in addition, the director and the clerk provided special "lessons" and practice sessions for teachers either at the individual schools or at the department office.

In another school system it was decided that all teachers making use of the sound films should learn to operate the equipment. By the close of the school year at least three teachers in each of the eleven elementary schools were competent operators and could instruct others. In this school system numerous film previews at the outset provided practice periods for teachers to become skilful in operating the projector. In addition, operation procedures were discussed at the principals' meetings, and the science supervisor assisted teachers with the mechanics of projection where necessary.

High-school students, with practice and supervision, become quite proficient in running the $16-\mathrm{mm}$. sound-film projector. In one junior high school the head of the science department was thoroughly familiar with the operation of the silent $16-\mathrm{mm}$. projector, and, in addition, was quite competent in mechanical details. Consequently he quickly acquired a thorough knowledge of the sound-film equipment and immediately trained four eighth-grade boys to serve as assistant operators. Their work must be judged successful since not only were showings made on schedule and without interruption but almost no damage was done to the films over a five months' period. The instructor stated: “The machine is operated with ease by either teacher or pupil operators. In the five months of continuous service, the 
machine, operated by at least seven different persons under all kinds of conditions, has been free from any kind of breakdown except the natural wearing out of the lamps."

Where one equipment is being utilized in a large number of schools, as in a county-school system, the problem of operation must be given adequate consideration if the film library is to be preserved from damage. If only one equipment is available and travel distances are fairly short, it may be advantageous to employ a special operator, who will take the machine and films to the various schools on requisition, manage the showings, and keep both films and projector in good repair. Such a plan would be feasible at least in the beginning stages of the county program of film use. When the demands for the films in the various schools become greater than one operator can manage, some of the iarger school systems of the county may prefer to purchase equipments for their own use, drawing upon the county office only for films. Each community purchasing an equipment could very readily provide thorough training for the teachers who were to use it. This would allow the traveling operator to devote his attention to the smaller schools in the more remote sections of the county.

Two operation problems deserve discussion. One has to do with electrical power. In many districts the power supply differs from the 110-volt, 50-60-cycle type of alternating current which is most common. Some equipment manufacturers supply models especially adapted for use with the 2550-cycle type of alternating current. Where the power supply fluctuates, introducing an inexpensive line current resistor in the extension cord to the projector will eliminate the danger of burning out projector lamps through excessively high voltages. Some rural communities have their own power plant, producing direct current. In these cases the use of a converter is necessary. Equipment manufacturers supply information as to the type of converter required for their projectors. For rural schools which lack any source of electrical 


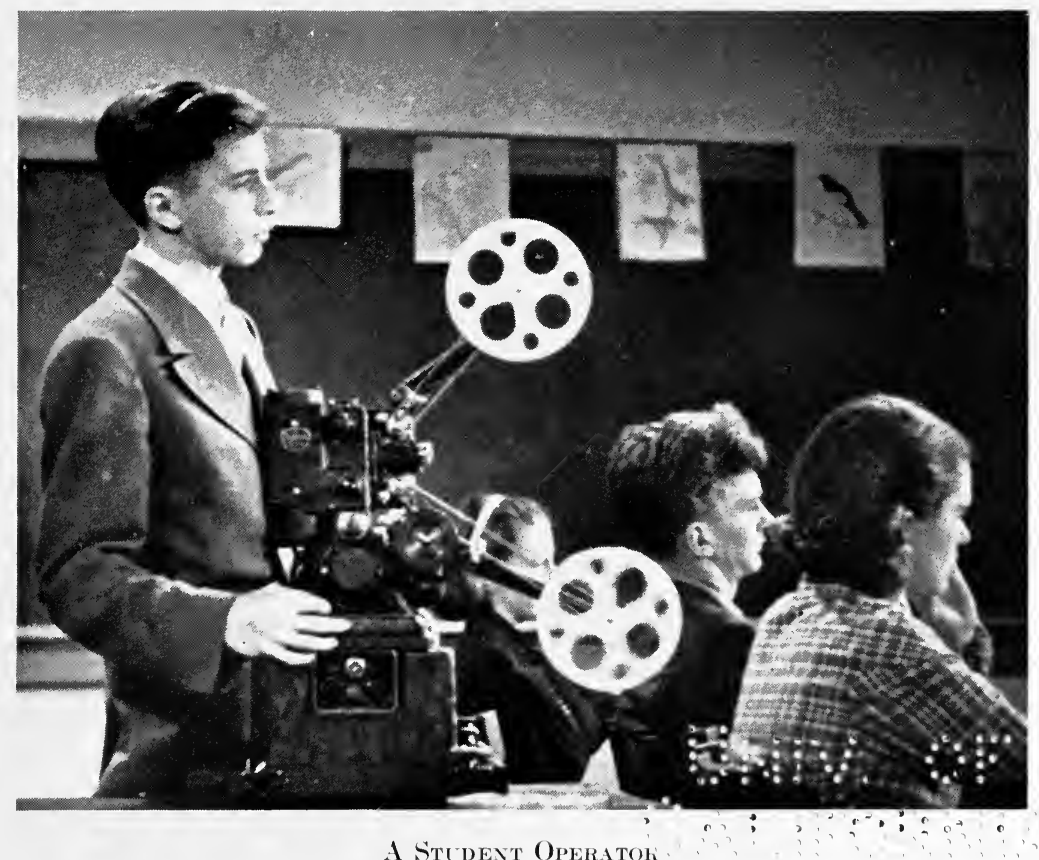

A Stroent Operatok

In many high schools utilizing sound films, students have become proficient operators of the $16-\mathrm{mm}$. sound-film projector. This scene is from Teaching with Sound Films. 


$$
\begin{array}{cc}
\cdots \\
\therefore
\end{array}
$$


power, a light truck may be equipped with dynamo and converter, or a portable generator with engine secured. This equipment is particularly valuable where there is a large number of schools in a rural area lacking electrical power.

Another problem in some schools is that of securing operators' licenses. Some states require individuals who are to operate $16-\mathrm{mm}$. sound-film projectors to pass an examination and pay a fee, before the license is granted. Both state and local regulations regarding the operation of motion pictures should be investigated when the use of films is initiated.

The maintenance of $16-\mathrm{mm}$. sound-film projection equipment usually presents no difficulty if operators are reasonably skilful and if the machine is oiled and cleaned regularly. Damage has resulted from excessive oiling as well as from lack of oiling; the best plan is to have a regular schedule for lubrication, posted at some convenient place. Responsibility for oiling, cleaning, and minor adjustments should be assigned to one individual - the special operator, a teacher, or a clerk. It is advantageous to have someone in the system who is competent to make minor repairs; this frequently saves time and insures continuous use of the equipment. Definite provisions for prompt service should be made with the manufacturer's representative when the machine is purchased.

CLASSROOM ADAPTATION FOR SOUND-FILM PROJECTION

The systematic use of sound films requires convenient arrangements for projection in the classrooms. Standard classrooms, as a rule, are readily adaptable for this purpose. However, classroom facilities for the showing of films are inadequate in most school systems; surprisingly enough, this is true even in some schools where the use of slides and silent films has otherwise been encouraged. The chief sources of difficulty usually are the lack of opaque shades, or curtains, and conveniently located electrical outlets. This condition suggests one reason why the older visual aids requiring pro- 


\section{HOW TO USE THE EDUCATIONAL SOUND FILM}

jection have not come into more extensive use. When the teacher has to go to extraordinary trouble with improvised curtains and temporary extensions, it is not unreasonable that after several experiences he should conclude that the expenditure of time and effort is unjustified by the educational return.

In a study which undertook to discover the problems incident to the local use of educational sound films, it was found that the majority of the participating schools had to contrive special arrangements to permit satisfactory projection in the classrooms. A few illustrations are given here. These ingenious makeshifts are unnecessary in a school which begins its permanent program by making the small expenditure for opaque shades and other equipment.

Difficulty was encountered in adapting classrooms for projection. The necessary physical provisions have been made in only a few of the classrooms in our school system. The method of covering windows with improvised materials was utilized to a great extent, although in many instances the rooms were not sufficiently darkened for excellent visibility. Another difficulty which arose was that of unsatisfactory ventilation because of these awkward preparations.

We had much difficulty showing the films during the day. The auditorium was practically unusable, having fourteen large windows with only light-colored shades. In the undarkened classrooms successful showings were given after considerable experimentation with the placement of the projector.

The laboratory was selected as the room to be used for showing pictures. It is 33 feet by 25 feet, with seven windows. There were light-colored blinds at the windows so it was necessary to put up dark blinds. The building was searched and about ten dark green, discarded blinds were found. As they were too short to cover the windows completely, several were cut to the required lengths and by means of thumb tacks put over the gaps.

A large white curtain found in the building was mounted against the southern wall for use as a screen. The laboratory is furnished with tables and chairs. When everything was pushed aside, the chairs could be rearranged in such a way that sixty children could be seated.

The machine was mounted on a table in the rear of room next to a cop- 
per covered chemistry table. By touching this table and the machine at the same time, one operator acted as a conducting body, much to her sorrow.

In striking contrast is the efficient adaptation made in the science auditorium of a small college where sound films were to be utilized in a new survey course. Special attention had been given to preparing this room for the ready projection of sound films. Opaque shades of excellent quality covered the windows. The acoustically treated ceiling insured satisfactory reproduction of sound. Other facilities included the following:

A large beaded rolled screen was mounted on the wall on the back of the sliding blackboards. After some experimentation the loudspeaker was mounted at a height of about 6 feet on the front wall near the blackboards. The projector was operated from the booth, a throw of about 50 feet. A large work table in the booth held the sound film projector and an opaque projector mounted in position at another vent. Lights are controlled from the main floor at one of the entrances to the room.

\section{A. SUGGESTED CLASSROOM EQUIPMENT FOR PROJECTION ${ }^{4}$}

In many school buildings it may not be considered desirable or feasible to equip and set aside a room especially for the utilization of audio-visual materials. Ideally, where no special room has been set aside for projection it would be most advantageous to have every classroom equipped so that films could be exhibited readily. This, however, would entail too great an expenditure. At least one classroom, and as many more as the proposed use of films requires, should be especially adapted for auxiliary use as a projection room. ${ }^{5}$ The expense of preparing several classrooms for film projection is comparatively slight. In a twenty-room elementary school, three classrooms equipped for this purpose-one for the primary grades, one for the intermediate grades, and one

${ }^{4}$ Much of the material in this section is adapted from an article by the author, published in the School Executice, February, 1936, pp. 215-17 and 236.

${ }^{5}$ Fig. 1, on p. 126, illustrates the planning of a modern classroom in which provision has been made for the ready use of motion pictures. 


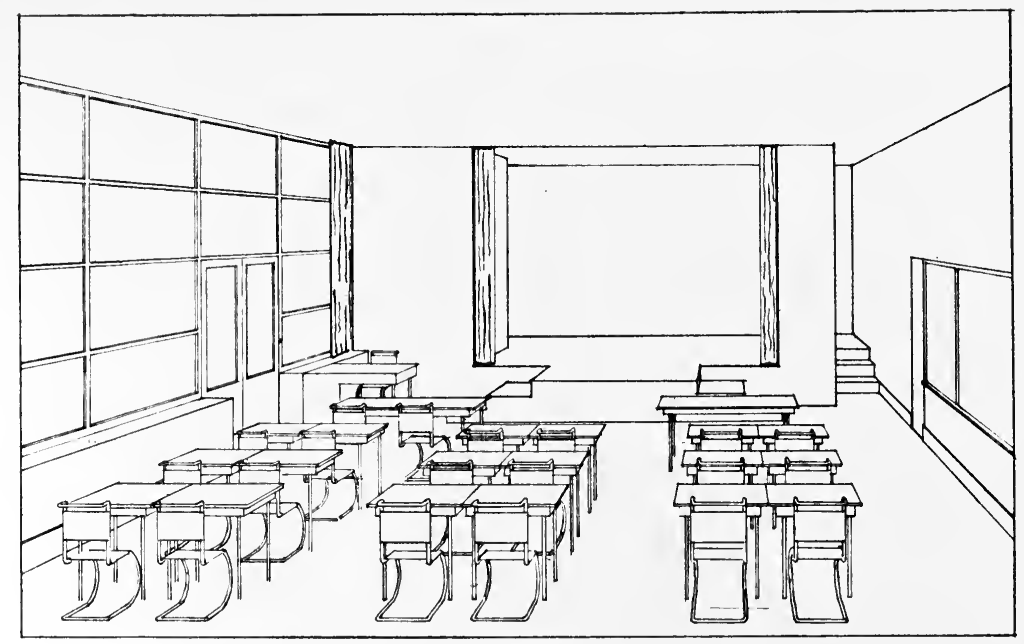

$\begin{array}{lllllllllll}\mathbf{P} & \mathbf{S} & \mathbf{l} & \mathbf{S} & \mathbf{P} & \mathbf{W} & \mathbf{C} & \mathbf{T} & \mathbf{I} & \mathbf{V} & \mathbf{E}\end{array}$

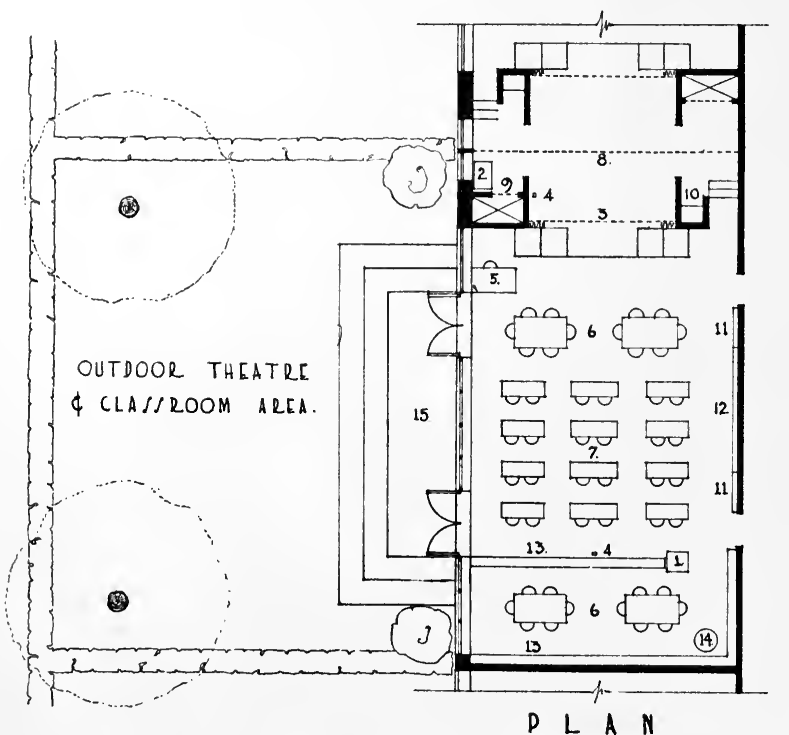

L E $G$ G E N

1. MOTION DICTURE DROJECTOI

2 MOTION DICTURE LOUDSDEA

3. MOTION DICTURE SCREEN

4 ELECTRIC OUTLET

5. TEACHER'S DESK

6 WORK TABLES

7 STUDENT TABLES

8. SOUNDPROOF CURTAIN

9 WARDROBE

10 SINK

11 BULLETIN BOARD

12 BLACKBOARD

I3 BOOKCASES

14 SUSDENDED GLOBE

15 OUTDOOR STAQE

SCALE.

Harrison \& Fouilhoux, Architects; N. L. Engelhardt, Educational Adviser

FIG. 1.-Proposed English classroom showing general equipment and motion picture facilities 
for the seventh and eighth grades-would effectively solve the problem of convenient projection space. This arrangement would, of course, necessitate a shift of classes during the periods scheduled for projection.

The essentials in equipping a standard classroom for the showing of educational sound films are: (1) darkening facilities; (2) a convenient electrical power supply; (3) reasonably good acoustics. The requirements for electric outlets are exactly the same with sound equipment as with silent projectors. An electric outlet should be installed in the rear of the room, conveniently accessible to the projector. It is also desirable that a switch controlling the room lighting be located near the projector.

Opaque shades or curtains are necessary. For a bank of large windows it may be more economical to instal opaque draw-curtains of some durable material such as canvas. The shades should fit tightly at the top, sides, and bottom.

The standard classroom usually possesses satisfactory acoustic qualities. Some classrooms, however, have a maximum of hard reflecting surface, such as a concrete floor, or a ceiling shaped so as to produce excessive reverberation. Under these conditions, if another choice of classroom cannot be made, an acoustic engineer will be able to suggest remedies.

The equipment of the room should include a portable screen or a screen permanently mounted at the front of the room. Where the sound film projector is to be utilized in a number of classrooms in the building, it will be advantageous to construct a portable projector stand, which will also serve as a storage cabinet for the equipment when it is not in use.

\section{B. A SPECIALLY EQUIPPED AUdIO-VISUAL STUdio}

The minor changes which have been suggested for adapting a classroom for the showing of sound films usually provide satisfactory projection facilities. However, when a new building is being planned or existing buildings are to be remodeled, consideration may be given to the construction of a 
studio planned and equipped especially for the use of audiovisual aids. The provision of a classroom theater will facilitate the use of educational films by insuring perfect reproduction of sound and picture, a minimum of time spent in preparing for projection, and freedom from disturbances for nearby classes.

The studio may be planned definitely for multiple use. For example, it may be utilized as a small auditorium for dramatic and musical activities. It might also be constructed as a small auditorium for platoon school work, where the use of films would be an integral part of the auditorium programs. With the increasing number of adult education classes it could be used profitably for evening group discussions and for filmcentered general-culture courses for the men and women of the community.

Figure 2 shows a floor plan for a classroom theater in a small elementary-school building. It involves major structural changes in an unused classroom located immediately adjacent to the central entrance on the first floor.

Inside partitions are planned along one side and at the rear. This creates an inside room, which eliminates the problem of excluding light and permits better control of acoustic conditions. A second entrance from the corridor is provided, both doors to be of soundproof construction.

The lighting of the studio is to be concealed in a metal trough which encircles the walls just below the ceiling. An outlet is provided at the front of the room. At a suitable height in the front wall there is a recessed loudspeaker which may be used both for sound-picture projection and for radio. The speech cord from the loudspeaker to the projector unit in the rear is laid in conduit. The roll screen is suspended by metal brackets from the ceiling. The lighting switches are located at the side entrance and at the operator's stand in the booth.

The space in the rear is a projection booth with projection equipment, a re-wind bench, and a steel cabinet for films. 


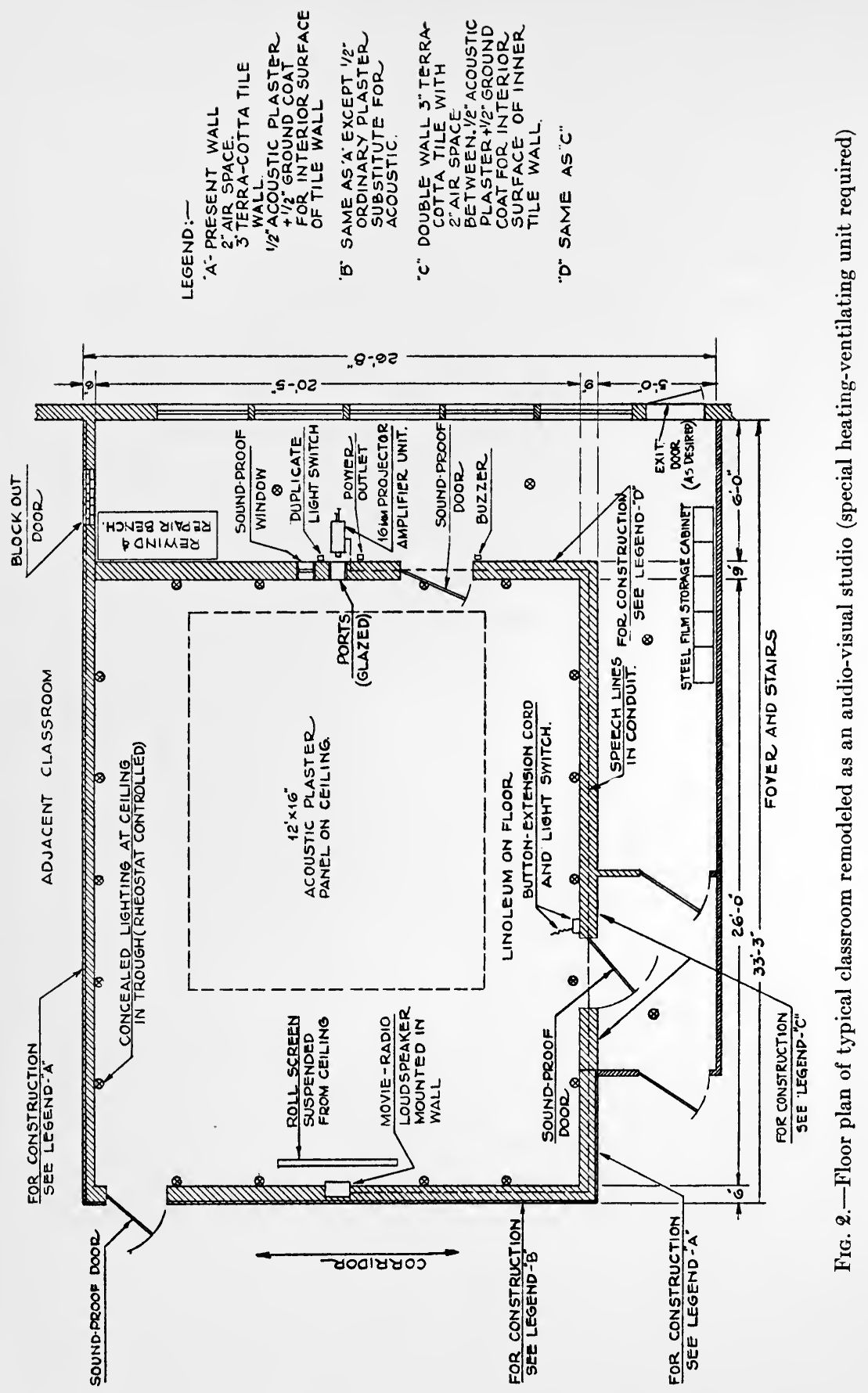


The wall which separates the studio from the projection booth is provided with a soundproof door, two ports for motion-picture projection, and a soundproof window for the operator's use. The 16-mm. sound equipment is mounted on a movable stand with an outlet conveniently located near by. Within the studio there is a button and cord connected to a buzzer beside the operator's stand which enables the teacher to signal the operator to begin projection and to adjust the volume of sound.

It will be noted that a special heating-ventilating unit is indicated for the studio. This feature is important. Provision should be made not only for complete control of temperature and humidity but also for the prevention of noise transmission through the ventilation system. In view of the special function of this room, air-conditioning equipment would be especially desirable. Plans for the heating and ventilating system should be checked by acoustic engineers.

An effective method of soundproofing the walls of this studio, considering existing construction, would be the installation of a 3-inch hollow terra-cotta tile wall to be spaced 2 inches from the two existing walls, together with the construction of a double wall of this same thickness of material, with a 2 -inch air space between, for the two individual walls to be added under this plan. ${ }^{6}$ In the event that interfering noise is transmitted through the floor above this room, it will also be necessary to provide a suspended plaster ceiling with an intervening air space of not less than 6 inches. It is further recommended that the three doors, indicated as leading directly to the studio, be of soundproof construction.

Assuming an average attendance of approximately fortyfive auditors and the probable installation of the plain wooden type of seats, the following method of interior acoustic treatment is suggested: The application of $\frac{1}{2}$-inch Sabinite Acoustical Plaster to the full area of the rear wall

${ }^{6}$ The recommendations for acoustic treatment were prepared by C. C. Potwin, of the Electrical Research Products, Inc. 
surface and to the full area of both side wall surfaces, extending down from the ceiling to approximately a 5-foot wainscot line. This treatment is to be applied to the interior surface of the tile walls adjacent to the studio. It will be necessary to apply at least a $\frac{1}{2}$-inch ground coat before the application of the $\frac{1}{2}$-inch thickness of acoustic plaster. The area below the 5 -foot wainscot line may be finished in ordinary plaster or a wood wainscot, as desired. The front wall surface (wall containing loudspeaker) should be finished in ordinary plaster. In addition, there should be a panel of acoustic plaster of dimensions approximately 16 feet for the length by 12 feet for the width, to be centered within the rear two-thirds of the ceiling surface.

The following suggestions summarize the factors to be considered in equipping a room which permits the best reproduction of sound films and other audio-visual devices under desirable educational conditions. ${ }^{7}$

\section{STANDARDS FOR THE AUDIO-VISUAL STUDIO}

Central locations.--If a number of classes is to be served by a room specially prepared for the use of talking pictures, a central location is desirable. Where the building has been planned in departmental units, it may be feasible to have one room in each suite or unit equipped for this purpose. If the building is small enough so that one projection room is adequate, the talking-picture studio should be conveniently located with respect to every other classroom.

Maximum utilization.-If the use of talking pictures in the school has reached the point where the studio is in constant demand for projection, no other adaptations will be necessary. In many buildings, however, it will be found necessary at certain times to utilize this room for other purposes, such as a science lecture-room, music-room, or community-discussion center. A careful study of all possible uses should be made when the room is designed.

${ }^{7} \mathrm{~A}$ third type of audio-visual studio is described by Devereux, op. cit., pp. 170-75. 
Seating arrangements.--In planning the audio-visual studio consideration must be given to the age of the students which it is expected to accommodate. Where the studio is to serve students in Grades I-VIII, the seats should be of the movable type. Small folding chairs should be available for the use of the primary-grade children. When the room is not being used by primary-grade children, these seats may be folded and stored in one corner of the room or in an adjacent closet.

For the older children movable chairs with tablet arms are desirable. The provision of tablet arms will permit taking notes, copying blackboard material, and filling out examination blanks.

One type of audio-visual studio has the tiered-floor construction with banks of auditorium-type seats. This arrangement permits accommodation of a maximum number of students, although it somewhat limits multiple use of the space.

Darkening facilities.-For the use of all types of audiovisual instructional aids which require a darkened room for projection purposes, facilities should be available for quickly and effectively darkening the room. If strong light is allowed to enter, the definition of the screen image is blurred and the educational value of the picture lessened. This condition also imposes considerable eyestrain, which naturally results in loss of interest and attention.

The most frequently used devices for darkening projection rooms are opaque shades or opaque draw-curtains. The materials used should be durable and tested for their resistance to the passage of light. The problem of excluding light from the sides and bottom of the window is sometimes solved by the provision of wide slots, in which the curtain or shade travels. Another device is the system of electrically actuated opaque shades, which may be drawn by the pressure of the control button.

The problem of excluding light on warm days when the windows must be kept open and the shades blow in and out is closely allied to the problem of providing adequate ventila- 
tion facilities. If the studio is an inside room with no windows, darkening facilities are, of course, unnecessary, and a special heating and ventilating unit can be installed for this one room.

Special equipment.-In addition to the projection equipment, the audio-visual studio will be provided with a screen, a suitable table for the projector-amplifier, and a stand or wall mount for the loudspeaker.

Either the incased portable or the permanently mounted screen may be used. In general, the screen may be of the nonperforated type and should be of a single piece or, if of more than one piece, the seam should be placed horizontally so as to permit easy rolling.

The over-all length of the permanently mounted screen should be equal to, or greater than, its width so that when it is pulled down for use, the center of the picture will be approximately one-half the ceiling height from the floor. For example, in a classroom 12 feet high with a picture $4 \frac{1}{2}$ feet by 6 feet approximately, the screen should be 6 feet square and the center of a $4 \frac{1}{2}$-foot picture should be 6 feet from the floor.

A stand for the projector unit is necessary. One excellent school-built model is about 20 inches wide, 3 feet long, and 3 feet high. Mounted on small rubber-tired wheels, it can be moved readily into position or out of the way, as required. It has a shelf for holding about six reels of $16-\mathrm{mm}$. film, and a compartment for storing the two units of the $16-\mathrm{mm}$. sound-reproducing equipment. This storage space is provided with doors, so that the whole equipment may be inclosed when not in use. The projector stand another school built is about 18 inches square and 4 feet high, mounted on casters, with shelving provided for films. Another type is the metal-tubing stand with a top which may be tilted for various projection angles.

Some blackboard space should be included, preferably on 
the right-hand wall. Storage cabinets for sets of slides and flat pictures, and compartments for silent projection equipment are desirable.

Wiring system.--There should be an outlet in the rear of the room, adjacent to the projector stand. It is desirable to have a permanent installation for the speech cord from the projector-amplifier to the loudspeaker in the front of the room. This wire may be laid in conduit, but should not be close to power wires. A switch controlling the room lighting may be located in the rear of the studio close to the projector stand, so that the operator may turn off the lights when he is ready to begin projection. A refinement of the usual lighting for classrooms is a series of lights in a trough at the top of the walls, controlled by a rheostat switch, so that several degrees of illumination may be secured.

Acoustic conditions.-The acoustics of the studio should permit the satisfactory reproduction of recorded or broadcast sound, without disturbance to adjacent classes. The problem of acoustics for the audio-visual studio is concerned with two factors: (1) the proper reproduction of sound within the room and (2) the prevention of the transmission of sound to adjacent classrooms. The reproduction of sound within the room is satisfactory when there is a minimum of reverberation or disturbing echoes. To prevent the transmission of sound to adjacent classrooms, soundproof doors and baffles in the ventilating ducts may be installed.

Heating and ventilating.-The heating and ventilating system of the studio should be such that comfortable conditions are maintained. Although the central heating-ventilating system in some cases may prove entirely satisfactory for the audio-visual studio, it will be preferable to instal a special unit for this room to prevent the transmission of interfering sound to other classrooms and to provide proper ventilation in warm weather. 


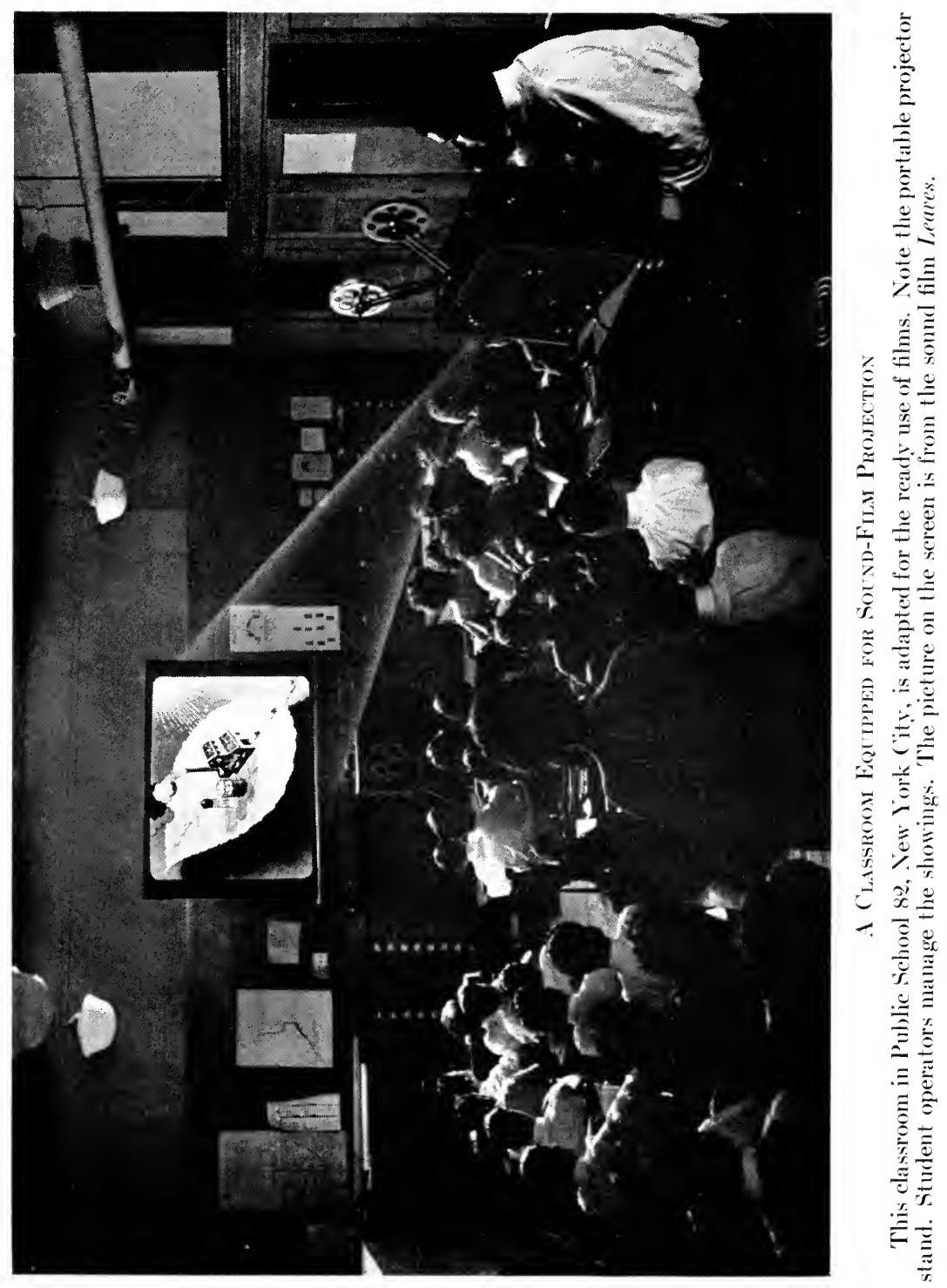





\section{DEVELOPING A SYSTEM OF DISTRIBUTING FILMS AND EQUIPMENT}

A central film library from which films may be distributed to the various buildings is usually preferred to the practice of maintaining a unit library in each school. ${ }^{8}$ The method of circulating films should enable the teacher to obtain, exactly when needed and as often as needed, the films he wishes to use for a particular unit. An inflexible schedule which does not permit drawing upon the local film library for materials as the need arises defeats one of the major goals of the film program-that of introducing the use of the talking picture at the point or time when it will be of greatest instructional value.

From the administrative point of view, the system of film distribution should provide maximum utilization of the films which have been stocked. Accordingly, some administrators have laid out an arbitrary schedule by which films and equipment are rotated among the buildings at regular scheduled intervals. This plan insures the immediate availability of the films for classroom use at definite times; it does not guarantee, however, that the films will be used in the particular building where they are sent, or that they will be used to the best advantage. The factor of timeliness of use is too essential to be overlooked in arranging the plan for film distribution.

A better procedure is to work out a weekly or bimonthly schedule on the basis of teachers' requisitions. This plan has the advantage that only those requisitions need be approved which show that the teacher is definitely planning a wellintegrated use of the film. The teachers may familiarize themselves with the film in advance, and study the accompanying supplementary material, being assured that the picture will be available at the desired time.

${ }^{8} \mathrm{~A}$ discussion of the central distribution plan versus the individual building library is in ibid., pp. 126-27. 
A superintendent who tried the routing system reviewed its deficiencies: "If we were to attempt to use one machine in our schools, it would be best to have it handled through the superintendent's office. A school cannot utilize the machine and films to the best advantage by having one fixed time in each month at which it is available. It would be better to have it constantly available, provided requests were made some little time in advance of its use."

Assuming that all the subjects selected and purchased for the film library are integrally tied up with the local courses of study, how many prints of each film subject will be required? The number of buildings in the school system and the extent to which the program of talking picture use has advanced, combine to determine the local demand for films. In some cases one print will be found entirely adequate to meet all the requests for that particular subject, while in large school systems as many as twenty or forty prints might be required. It should be possible to determine the necessary number of prints from an analysis of the following factors: the extent to which the particular film applies to local courses (this involves also the number of grades in which it may be used); the number of classes in those subjects in the local schools; the probable frequency of showing for that film in each class; the seasonal element (the topic covered by the film may be taken up in the fall, in the spring, or introduced at any time in the year); and the expected life of a film print under local conditions of use. Extra-curricular and community uses should also be considered in determining the demand for a particular film. Moreover, for the larger school systems it is probably wise to maintain an extra set of films in the central library to meet emergency uses.

Still another factor which affects any solution of the film and equipment distribution problems is that of local transportation facilities. In many school systems a school-supply truck maintains a regular schedule of delivery to the various buildings. This service can be utilized for the films and equip- 
ment. Some cities which offer an extensive service of visual aids to the schools have found it profitable to maintain delivery-truck service by the visual instruction department itself. Where these facilities do not exist, as in the smaller school systems, films and equipment may be secured or returned by automobile.

An effective method of film distribution was followed by a school system in which the department of visual instruction maintains a scheduled service for circulating visual aids. The director describes the procedure:

The sound films and equipment became part of the Visual Education Library, subject to the same rules and regulations as all our other visual materials: motion pictures and projectors, stereopticon slides, stereographs, film-slides, maps, posters, charts, pictures, specimens, articles, exhibits, magazine articles and pamphlets.

The teachers ordered the sound pictures in any of the same three ways that they regularly order from the Visual Education Library: I suggest the films to them during a conference, or they order desired materials by filling out an addressed postal card supplied all schools, or they telephone my assistant.

The record for the circulation of the sound films could have been kept on our regular circulating cards, and for the equipment on the regular monthly record sheet for the circulation of our sixteen millimeter projectors; but I chose, for this project, to have mimeographed a separate sheet so that the record of the films and equipment would be together.

$\begin{array}{ccccc}\text { Date } & \text { Day } & \text { School } & \text { Teacher } & \text { Film } \\ \text { Dec. } 19 & \text {.......... } & \text { George Innes } & \text { Ladd } & \text { Electrostatics }\end{array}$

My secretary filled all orders and made out for each shipment the same circulating record card as we used for all material distributed from the library. The Board of Education truck, which makes deliveries to each school on Monday, Wednesday, and Friday, took the films and equipment with the other visual library material going to the schools. Because we had only one sound picture equipment it is obvious that only one school could use it at a time. Therefore, I made arrangements with the business administrator, as I have done on other occasions, for the truck to make as many special trips as my secretary would ask for so the films could be used whenever a teacher needed them.

A combination of distribution methods, devised to provide flexibility of use, was followed in a medium-sized school sys- 
tem where one sound-film projector and twenty sound films were being utilized by eleven elementary schools.

The library of films was centrally located at the Assistant Superintendent's office. A school messenger service operating from this central office every Monday, Wednesday, and Friday provided one means of transporting the equipment from school to school. This transportation service did not satisfy the demand and it was necessary for principals and the Supervisor of Elementary Science to transport the equipment from time to time. Toward the close of the experiment the equipment gravitated to the Supervisor of Elementary Science, who transported it from school to school in an effort to get it used as much as possible in connection with her work in science. This was logical because of the science subject-matter covered by the film library and also because she was in contact with every school at frequent regularly scheduled intervals. She was thoroughly informed about the operation and maintenance of the equipment, as well as the content of the films.

The secretary to the Assistant Superintendent maintained a definite record of films and manuals as well as a schedule of dates for the equipment. A sample of the record form follows:

From: Assistant Superintendent's Office

Date: February 13

To: Roosevelt School

No. Reels
$1 \ldots \ldots \ldots$ The String Choir
$1 \ldots \ldots$ Thass Choir

$\begin{array}{ccc}\begin{array}{c}\text { Manuals } \\ \text { Sent }\end{array} & \begin{array}{c}\text { Reels } \\ \text { Ret'd }\end{array} & \begin{array}{c}\text { Manuals } \\ \text { Ret'd }\end{array} \\ \text { Yes } & \mathbf{X} & \mathbf{X} \\ \text { Yes } & \text { X } & \text { X } \\ & \text { Operated by: Mr. BAKER } \\ & \text { Filled by: G. P. H. }\end{array}$

This form was made out in duplicate, one copy sent with the films and equipment and one copy retained as a permanent record in the Assistant Superintendent's office.

When the use of films is being developed within a single school, as in the case of a small one-building public school system, a private school, or a college, the circulation of films and equipment reduces itself to a very simple, informal routine. The limited number of teachers involved may even make it possible for the individual instructor to withdraw a film without advance notice. Sometimes the only complicating factor is that of securing the use of the classroom which has been equipped for motion-picture projection, but even this difficulty may be obviated by installing opaque shades, 
an electrical outlet, and a screen in several classrooms. Convenient access to the film library in the building, however, does not eliminate the need for keeping records of film used.

A simple system of circulating films was devised in a large platoon school:

The films and manuals were kept in a room on the auditorium floor under the supervision of the assistant principal, who kept records of the films being used and made exchanges of films with the teachers when necessary.

The teachers indicated at the beginning the list of films they wished and the order in which they wanted to use them. After a teacher had utilized the film of her first choice, she sent it to the assistant principal's office. By this time the teacher's second or third choice had already been used by other teachers. We have very little difficulty in circulating the films.

In summary, it may be repeated that encouraging the use of talking pictures in a school system calls for making the materials available in classrooms on the basis of instructional needs rather than time allotment per building. Scheduling the distribution of films from requisitions provides a flexible system which may readily be adjusted to keep pace with increasing demand from the teaching staff. In some large buildings where a fairly continuous use of certain films is attained, it may be found desirable to experiment with the allocation of unit film libraries as an alternative to the central library. If the central-depository plan is retained, every effort should be made to increase the efficiency of the requisition and delivery system, so that there will be a maximum of use for each film and a minimum of delay in getting materials to and from the classroom.

\section{STORAGE AND CARE OF FILMS}

The storage and care of $16-\mathrm{mm}$. sound films present no new problem to those who have been accustomed to the handling of $16-\mathrm{mm}$. silent films. Visual education departments have evolved excellent methods and space arrangements for controlling this aspect of motion-picture use. In the experimental project film storage was managed without 
difficulty, inasmuch as the film library of twenty reels occupied a space only 8 inches by 20 inches. A shelf in a supply closet, or a section of a bookcase in an office, was adequate. One school kept its films in a steel supply cabinet. In the county school system all the reels were placed in a small wooden box which accompanied the equipment, so that the complete library was available wherever the equipment was sent.

For convenience, certain standard practices regarding the maintenance of school films are reviewed here.

The storage space for films should be conveniently located, and kept reasonably cool. Where there are only a few reels to be distributed, the clerk or secretary may keep them in a steel filing cabinet in the office. In the case of a large film library a space similar to that used for other school supplies should be provided, and equipped with shelving or racks for the film cans. Each rack will be labeled with the title of the film it holds. Hot, dry rooms tend to make the films brittle; simple precautions for guarding against this condition may be taken. Any state or local fire regulations affecting the storage of films must also be considered.

Where one individual is responsible for maintaining films in good condition, it is desirable not to have the teacher rewind them when he has finished with them. When they are returned to the central library, they may be checked for damage as they are being re-wound. This insures that every print sent out on requisition will be in good condition. A rewind bench and a film-splicing outfit are necessary for inspection and repairs. Repairing a 16-mm. sound film is as simple as repairing a silent film; the only difference is that the splicing outfit has only one set of sprocket teeth, because of the sound track at the other edge of the film. It is economical in some cases to return damaged films to the producer, to have new sections inserted. ${ }^{9}$

\footnotetext{
${ }^{9}$ The damaged film is returned to the laboratory and the torn section replaced at a cost of about five cents a foot.
} 
A record of the film library should be maintained. A convenient system is to enter each film print purchased in a cardindex file, one card for a print. Data to be recorded are the title, date of purchase, producer, special code number, and repairs made. The code number will correspond to the identifying number inked on the film. A similar record may be devised for keeping track of the circulation of each film. 


\section{APPENDIX I}

\section{OUTLINE OF A TYPICAL UNIT TAUGHT WITH A SOUND FILM}

\section{UNIT: "WORK OF RUNNING WATER"1}

This unit was carried on by a group of sixth-grade classes, meeting periodically in the auditorium. The teacher in charge of the unit undertook the presentation of subject matter and built the general framework of each lesson. Subsequent activities were guided by the various classroom teachers. From the account outlined here it can readily be seen that the task of teaching a class of several hundred boys and girls, even with occasional showings of the sound film, called for detailed planning to hold the attention of the group. Visitors to this class were impressed by the teacher's skill in telescoping a large-group situation into what was apparently the classroom routine.

Notice the frequent use of sequences of the film. There was no loss of interest from repeated showings. It was in this class that one boy remarked “"The screen should be eroded by this time!" after seeing the erosional action of water depicted so often.

\section{LESSON 1}

A. OBJECTIVES

I. Generalizations to be developed

1. Value of this work in connection with study of surface in geography

2. Stimulate interest in the beauty and value of the work of running water

II. Specific objectives

1. Meaning of erosion

2. Stream erosion and its effects. Formation of:
a) Rivers
d) Canyons
b) Glens
e) Waterfalls

c) Ravines

\section{B. PREPARATION}

Introduced unit by means of questions on foregoing objectives. Asked children to be prepared with answers to the following questions written on the blackboard:

${ }^{1}$ Developed by Miss Kathryn McCarthy, sixth-grade teacher in Public School 170, Brooklyn, N.Y. 
1. Meaning of erosion

2. The tools nature uses to erode the land

3. In high land what are the steep valleys cut into the land called?

4. Some well-known places are mentioned at the end of the film-enjoy them and be able to tell what they were and where they are

$$
\text { C. PRESENTATION OF THE FILM }
$$

Entire film was shown as an overview to study of the unit.

\section{ORGANIZATION}

Questions on preparation were answered by individual pupils. Other questions on film were asked:

1. What effect does the speed of the water have on the power to erode the land?

2. What do we mean by the source of a river?

3. Name two ways in which a river gets its supply of water.

4. In which kind of country will a river be steepest?

5. Therefore, in which kind will you find canyons or waterfalls?

6. Name one canyon in the Rocky Mountain Region.

7. Small falls in early part of picture were-Glenn Falls.

8. What were the large falls at the end of the picture? Ask questions about Niagara Falls.

\section{E. APPLICATION}

1. Children wrote short compositions on the general topic of the "Work of Running Water," also "Grand Canyon" and "Eroding Land."

2. Start collecting pictures of rivers in mountainous countries, canyons, and water falls. Start a scrapbook of these pictures.

3. Integrate this topic with the poem "America" by Henry Van Dyke.

I love thine inland seas,

Thy groves of giant trees

Thy rolling plains

Thy rivers' mighty sweep

Thy mystic canyons deep

Thy mountains wild and steep

All thy domains!

\section{LESSON 2}

\section{General objectives}

\section{A. OBJECTIVES}

1. Re-establish facts taught in previous lesson and correct any erroneous impressions children might have 


\section{HOW TO USE THE EDUCATIONAL SOUND FILM}

2. Stimulate interest in unusual land formations

3. Provoke discussion of these formations

II. Specific objectives

1. Questions on previous lesson

2. Potholes-the work of boulders

3. Mushroom forms-Garden of the Gods

B. PREPARATION

Some compositions on erosion written by pupils of $6 \mathrm{~A}$ and $6 \mathrm{~B}$ classes read to the whole group.

Drill cards containing questions on the previous lesson were given to volunteers. These pupils came to the platform, read the questions, and asked for answers from other pupils in the group. Pupils were told if they were at all doubtful of answers to watch carefully the next showing of the film.

On the blackboard was written the word "pothole" and pupils were told to watch for these and be able to explain their formation, also to watch for odd-shaped rocks left in the country where soft rock wore away and left the hard rock standing. They were to be able to name these and to tell where some are found.

\section{PRESENTATION}

In this showing only the first part of the film was given. The machine was turned off just before the topic "Stream Deposits" appeared.

\section{ORGANIZATION}

1. Questions given in preparation were asked of children and answered.

2. Discussion of the mushroom forms was taken next. The Garden of the Gods in Colorado was used as an illustration of these forms.

3. Which rock wears away faster, soft or hard?

4. Then which kind of rock are these forms?

5. Pupils were told the following facts:

A river has three stages just like people: 1. youth, 2. mature or full grown, 3. old age. In youth, a river has not cut its valley and flows from high to low land just as the land slopes.

Question: Therefore, what will you find in this kind or river? (Waterfalls and rapids)

Question: What shape will its canyon be? (A V-or U-shaped valley)

\section{E. APPLICATION}

1. Continue collecting pictures on canyons, mushroom forms, etc.

2. Pupils in the classroom began working on the project of a canyon. 


\section{LESSON 3}

A. AIM

I. General objectives

1. Work of erosion on the plains

2. Stream deposits

3. Flood plains and deltas

II. Specific objectives

1. In badland region water from gullies in sandy soil deposits sand when it reaches low, flat places. This stream builds with the materials worn away elsewhere

2. New land made by these stream deposits

3. Effect of vegetation on erosion of land

4. Present dust storms in middle west

\section{B. PREPARATION}

A river has three stages. They correspond to the three ages of people. We have studied the first stage. It is like you people. What is that? (Youth)

Today we study a river in the full-grown stage. Put on blackboard these facts obtained by questioning pupils:

1. Youth-waterfalls, gorges, canyons, V-shaped valley

2. Fully grown-rapids instead of falls, U-shaped valley. Why? (Because more land has been eroded)

Our new work today begins with the weird shapes formed by the water rushing over the land and forming deep gullies. Be able to tell where this is done. (Desert regions and bad lands of Dakota.) In what kind of soil does the water cut a valley quickly? (Sandy soil.) As it spreads over level land, note carefully what happens. The title "Stream Deposits" will be given. Be able to tell what it means and name two kinds of stream deposits.

\section{PRESEntation}

1. First part of film given silently. Scenes 1-31. Teacher using pointer on screen asked questions reviewing Lessons 1 and 2. Children answered as a group. "What do we call these holes?" (Potholes)

2. Sound film for new lesson

Begin at Scene 32: "On plains frequent downpours drench the soil." Film turned off at Scene 52.

"Rain washes and streams eat away unprotected land ruining it for cultivation." 


\section{HOW TO USE THE EDUCATIONAL SOUND FILM}

\section{ORGANIZATION}

Questions in preparation answered:

1. How does a river get its water in plains? (Showers and storms)

2. When land gets lower and flat, what happens to the speed of the river? (It is slowed)

3. Can it carry as much soil? (No)

4. Then what happens? (The stream deposits its soil forming "stream deposits"')

5. Where is the soil deposited? (On the side of the stream and at its mouth)

6. Where are deltas usually formed? (At the mouth of a river)

7. When a river overflows its banks and deposits the soil over the land, what is this called? (Flood plains)

8. What river in the United States has a fine delta and very large flood plains? (Mississippi)

9. The upper part of this river is an excellent example of a full-grown river.

10. Why did the flood plains appear whiter in the picture? (Not overgrown by vegetation)

11. Are they fertile? (Yes)

12. In what part of our country have we many of these fertile flood plains? (Great Central Plains)

13. Name the important industry carried on here? (Farming)

14. Name some crops? (Wheat, corn, cotton)

15. How does vegetation stop erosion of the lands? (Roots spread and protect the ground)

We have an interesting fact now in the papers showing the necessity of water and the erosion of land due to the lack of vegetation.

"The Dust Storms in the Middle West." The drought last summer destroyed the crops, causing a loss of one billion dollars. This means that the land was left unprotected by vegetation. The March winds are now sweeping up the dust and whirling it about, destroying crops for this year and endangering lives. Story told of "Shroud of Mud." People in Kansas City went to bed wrapped in sheets which they had moistened in water. The purpose of this was to help them breathe. The dust is so heavy that it stings the body and affects the breathing. They awoke in the morning to find themselves covered with mud. The dust had settled on the wet sheets and dried there.

\section{E. APPLICATION}

6A: Composition on "Flood Plains."

6B: Composition on "Deltas." 


\section{LESSON 4}

I. General objectives

A. OBJECTIVES

1. Complete study of stream deposits

II. Specific objectives

1. Review deltas and flood plains

2. Explain meandering streams-the meaning of the word, cause of meandering, and how they straighten themselves

\section{B. PREPARATION}

Today we will take rivers in the "old stage." Waterfalls and rapids have disappeared. The river in the film is a good example. (Lower Mississippi.) We will begin the film today with stream deposits. The first part will be a review of last week's work. Listen carefully and be able to answer questions on this. Watch out for this word, "Meandering." (Written on blackboard.) What does this word mean? Answers obtained from children. (Wind in and out.) Be able to answer these questions at the end of the film.

1. Does the current flow more swiftly around the outside or inside of the curve?

2. What happened to the banks?

3. How did it straighten itself?

\section{PResentation}

First part of film, Scenes 1-30, not shown. Begin at Scene 31 and on to the end of film, "Stream Deposits."

\section{ORganization}

The following questions given (review):

1. When lands get lower and flat, what happens to the speed of the river? (It is slowed)

2. Can it carry as much soil? (No)

3. Then what happens? (The stream deposits its soil, forming stream deposits)

4. Where is the soil deposited? (At the side of the stream and at its mouth)

5. What are the names of these two stream deposits? (Deltas and flood plains)

6. Where do we find each of these? (Deltas at the mouth of rivers and flood plains along the banks of rivers)

7. Are flood plains fertile? (Yes) 


\section{HOW TO USE THE EDUCATIONAL SOUND FILM}

New work-answers to questions 1-3, preparation.

1. Current flows more quickly around outside of curve

2. The banks cave in

3. River straightens itself by taking new course across the narrowest part. (Large charts in colored chalk were used to explain in simpler form the formation and correction of "Meandering Streams")

a) Slight meandering

b) Increased meandering

c) Thin wall broken down and channel straightened

4. As stream flows through straight channel, deposits are made along its banks, blocking the ends of the horseshoe channel. The crooked horseshoe channel is now closed up and is a lake called "Ox-Bow" Lake

a) Does this lake get water from the river? (No)

b) Is it shallow? (Yes)

c) What gradually happens to it? (Dries up)

d) What is formed? (Swamps, but gradually the land dries and forms good fertile soil)

e) When the land is level, does the river cut fast? (No)

f) When the slope of the land is steep? (Yes)

g) The man in the film told us that nature sometimes uplifts the surface of the earth after it has been worn flat; what happens then? (River begins to erode land again and form canyons)

In the Grand Canyon we see how the land is worn down, then uplifted and the work begins all over again. This has been going on for thousands of years.

E. APplication

Write a composition on "Meandering Streams." See if you can make diagrams to illustrate them.

\section{LESSON 5}

A. OBJECTIVES

I. General objectives

Arouse spirit of competition in pupils by reading some compositions on different parts of the work taught. Organize facts learned in previous lessons.

II. Specific objectives

1. Teach how falls are formed

2. Explain formation of Niagara Falls 


\section{B. PREPARATION}

Compositions on the following topics read:

Erosion

Pot holes and mushroom forms

Stream deposits

Deltas and flood plains

Meandering streams

How meandering streams straighten themselves

Grand Canyon

\section{PREsentation}

1. At the end of the film what natural wonder of the United States did we see? (Niagara Falls)

9. Where are these Falls? (In Niagara River)

3. Where is the Niagara River? (Between New York State and Canada)

Large diagrams on cardboard done in colored chalk were used to teach the following facts:

\section{Diagram 1}

Limestone-hard rock

Sandstone and shale-soft rock

Upper layer of rock is limestone. As the soft rock wears away by the action of the Falls, the upper hard layer, having no support, breaks down. Its pieces, as they break off, serve as tools of erosion to wear away more land. (Pupils questioned on these facts.)

\section{Diagram 2}

Between what two lakes is Niagara Falls?

Originally the Falls were at Lewiston

What happens to the rock as the tremendous force of the water flows over the Falls? (Wears away)

What do the stones in the River below the Falls cause? (Rapids)

The Falls wear away about five feet each year. They have worn back seven miles from Lewiston to Niagara. From this it has been concluded the Falls are at least 7,000 years old

\section{ORGANIZATION}

Outline on blackboard these facts with pupils:

1. Two kinds of work done by running water-erosion and stream deposits

2. Work of erosion in soil-deserts Work of erosion in rock-canyons

3. Stream deposits-deltas and flood plains 


\section{HOW TO USE THE EDUCATIONAL SOUND FILM}

4. Diagrams of meandering streams used to teach last week were used this week to review. (Pupils showed very good knowledge of this subject by their intelligent explanations)

5. Ages of rivers

a) Youth. (Waterfalls, V-shaped valley, small gorges and canyons)

Example: Mountain branches of Missouri River

b) Matured or full grown. (Rapids, U-shaped valleys, large canyons like Grand Canyon, flood plains, and deltas)

c) Old age. (Waterfalls and rapids have disappeared, meandering oxbow lakes, level land, large deltas, and flood plains)

Example: Lower part of the Mississippi River

E. APPLICATION

Classes to complete booklets on "The Work of Running Water." 


\title{
APPENDIX II
}

\section{THE INTEGRATION OF SOUND FILMS WITH ELEMENTARY-SCHOOL SCIENCE}

\author{
By Melvin Brodshaug, Ph.D. \\ Research Associate, Erpi Picture Consultants, Inc.
}

Research studies in science education have been reported in increasing numbers during recent years. Every phase of the problem has been subjected to most intensive study, particularly the curriculum and methods of instruction. A summary of these studies, except for the most recent ones, is to be found in the two volumes by Curtis. ${ }^{1}$ Arnspiger $^{2}$ and Rulon ${ }^{3}$ have reported the most comprehensive evaluations of sound films as aids in teaching science.

The National Society for the Study of Education recently devoted a yearbook $^{4}$ to the problem of science education on all school levels. The general philosophy and guiding principles suggested by this yearbook are reflected throughout this proposed course.

\section{BACKGROUND OF SCIENCE-FILM COURSE FOR \\ GRADES IV, V, AND VI}

Since 1929 Erpi Picture Consultants, Incorporated, has carried on extensive research in elementary-school science education. This field was selected for extensive investigation as a result of the preference indicated by hundreds of educators.

First, a study was made of present practice and present thought, with respect to the objectives and the content of elementary-school science as revealed in courses of study and in the literature on science education.

${ }^{1}$ Francis D. Curtis, Digest of Investigations in the Teaching of Science in the Elementary and Secondary Schools (Philadelphia: P. Blakiston's Son \& Co., 1926); A Second Digest of Investigations in the Teaching of Science (Philadelphia: P. Blakiston's Son \& Co., 1931).

${ }^{2}$ V. C. Arnspiger, Measuring the Effectiveness of Sound Pictures as a Teaching Aid (New York: Bureau of Publications, Teachers College, Columbia University, 1933).

${ }^{3}$ Phillip J. Rulon, The Sound Motion Picture in Science Teaching (Cambridge: Harvard University Press, 1933).

${ }^{4}$ National Society for the Study of Education, 31st Yearbook, Part I, A Program for Teaching Science (Bloomington, Ill.: Public School Publishing Co., 1932). 


\section{HOW TO USE THE EDUCATIONAL SOUND FILM}

More than fifteen hundred courses of study were examined, from which eighty-nine were analyzed in detail. ${ }^{5}$

On the basis of this preliminary research, certain broad topics were selected as suitable units of instruction in science for grades IV, V, and VI. These units were selected on the basis of two groups of criteria. The first group of criteria considered the educational justification of the unit in a course of study. The second group considered the possibility of significant contributions by the sound film. Twenty of these units have been completed and a sound motion picture produced and released to accompany each unit.

As soon as the first few films had been completed, an extensive experiment was conducted to determine their effectiveness and contributions in classroom situations. This study also included an evaluation of various motion-picture techniques with respect to their teaching effectiveness. This study involved nine hundred and fifty pupils distributed in five cities: New York City, Schenectady, Camden, Elizabeth, and Baltimore. The results indicated that students taught with the aid of sound films achieved approximately 26 per cent more on objective tests than equivalent groups of students taught by ordinary classroom methods. A recall test administered a few weeks later indicated that the sound-film group also retained more than the non-film group. ${ }^{6}$

In addition other studies have been made on the utilization of these films and units in classroom situations in the intermediate grades. These findings have been incorporated in this course. It has been found that the use of these films enables the classroom teacher who has had very little background in science to secure results that were formerly not thought to be possible below the senior high school.

The general outline of a course in elementary science will be presented here. The details for each unit which will be suggested are available in separate handbooks, one for each unit. These comprehensive units include general and specific objectives; an overview; suggested activities and procedures such as field trips, classroom projects, scrapbooks; a broad review of the subject matter of the unit; suggestions for using the sound film; a list of desirable outcomes; a comprehensive bibliography for teachers and pupils; and the description of the sound film, consisting of scene identifications and the narrative accompanying the screen images.

In selecting the content material to be presented in the sound films, several factors were considered. Since each unit is so broad and comprehensive, only a portion of it could be included in a one-reel sound film.

${ }^{5}$ Melvin Brodshaug, An Analysis of Activities and Objectives in Science for Grades 4, 5, and 6 (unpublished; New York: Erpi Picture Consultants, Inc.).

${ }^{6}$ Arnspiger, op. cit. 
For this reason, only those topics that seemed most significant for elementary science were incorporated in the film. Special emphasis was given in the film to those processes in nature that the pupils would be unable to observe with comprehension because of their complexity, their relative slowness, their relative speed, their inaccessibility, or their untimely occurrence. The economy of time and money made possible by sound-film presentation were other factors considered in selecting topics for the film. The topics or sequences were then fitted into a complete film continuity.

It is not intended that this outlined course should become a fixed program of instruction in elementary-school science. Rather, a committee of teachers should constantly be at work revising and supplementing the program to the end that it may more nearly meet the needs and interests of the pupils, and co-ordinate with the local environment as regards industries, geographical features, and distribution of plant and animal life.

The suggested course is so prepared that even teachers with little or no preliminary training in science content and methods of science teaching can carry on effective work in this field. However, it is desirable that teachers secure a background of information in science instruction on the intermediate level.

\section{OBJECTIVES FOR THE COURSE}

Science objectives are today thought of as being the same for all school levels, except in the more advanced college courses that lead to specialization or professional pursuits. This means that the objectives in science are the same for a liberal education from the kindergarten through the college. These objectives aim primarily at appreciation and understanding of natural laws, phenomena, and broad generalizations. The skills receive less emphasis in science instruction than they did a few years ago. Since the objectives in science are identical on all school levels, the extent to which they can be attained depends upon the grade level or the maturity of the learner. In other words, the outcomes that can be expected on the elementary level must fall considerably below the outcomes that should be expected on the high-school level.

It is suggested that the instruction in this course be developed around the following generalizations, which may serve as major objectives. These generalizations, or objectives, may, of course, be modified in the light of local conditions and special pupil needs.

1. Many animals and plants must struggle with other plants or animals (struggle for existence) for space to live in and for food. This results in a balance (balance in nature) among the many life-forms.

2. Many plants and animals, because of certain characteristics, have become better fitted (survival of the fittest) to continue to live.

3. Changes in the physical surroundings, such as temperature, moisture, 


\section{HOW TO USE THE EDUCATIONAL SOUND FILM}

or food supply, may result in changes in plants or animals (adaptation) that make them more able to live under the new conditions.

4. Man, because of his intelligence and consequent inventions, has wilfully or unconsciously influenced the number and distribution of plants and animals. By a knowledge of natural laws, man has modified or changed (breeding and culture) the characteristics of many plants and animals.

5. There is a very close interrelation (unity in nature) between man, plants and animals, and their physical surroundings.

6. The laws of nature are always the same; they never change (inviolability of natural laws), and every occurrence or activity has a cause and effect.

7. The energy manifested in ail forms of life-activities came originally from the sun. The energy from the sun is transformed in the green leaves of plants (photosynthesis) into food. Green plants are directly or indirectly the source of all food, and naturally, if there were no sunlight, there could be no plant or animal life.

8. The world presents a vast array of plants and animals varying greatly in their forms, habits, life-histories, and the degree to which their various parts have special functions. But still all these forms represent a continuous chain (tree of life) from the simplest to the most complex.

9. Reproduction is a life-process whereby a plant or animal is able to continue its own kind (propagation of the species). The method of reproduction varies with the type of plant or animal.

10. There are persistent forces that are at all times tending to reduce all land (gradation) to sea level.

11. Certain parts of the earth's surface are constantly being elevated by folding and fracturing (diastrophism) of the earth's crust, and by the outflow of lava.

12. Energy in a state of constant change of form (conservation of energy) is the basis of all physical and biological activity.

\section{OUTLINE OF STUDY UNITS}

Each of the units suggested in this course is accompanied by an educational sound film specifically produced for the unit, and thoroughly integrated with it. Likewise, the units themselves have a natural sequence and are integrated with each other. They are summarized below, listed in sequential order by grades. After having studied the units of instruction, the local committee on intermediate-grade science will be in a position to rearrange the order, modify the units of study, and expand the materials of instruction as desired. 
SUGGESTED SCIENCE UNITS FOR THE INTERMEDIATE GRADES

\begin{tabular}{|c|c|c|c|}
\hline Season & Grade IV & Grade V & Grade VI \\
\hline Fall. & $\begin{array}{l}\text { Butterflies } \\
\text { Seed Dispersal } \\
\text { Animals of the Zoo }\end{array}$ & $\begin{array}{l}\text { Beetles } \\
\text { Mushroom and Other } \\
\text { Fungi } \\
\text { How Nature Protects } \\
\text { Animals } \\
\text { The Earth and Its } \\
\text { Rocky Crust }\end{array}$ & $\begin{array}{l}\text { Flowers: Parts and } \\
\quad \text { Functions } \\
\text { Parasitic Flowering } \\
\text { Plants } \\
\text { Aquatic Insects } \\
\text { Microscopic Pond Life } \\
\text { Reactions in Plants } \\
\text { and Animals }\end{array}$ \\
\hline Spring . & $\begin{array}{l}\text { Growth of Plants } \\
\text { Animals of Beach } \\
\quad \text { and Sea } \\
\text { Amphibians } \\
\text { Moths } \\
\text { Spiders }\end{array}$ & $\begin{array}{l}\text { The Forces That Wear } \\
\text { Away the Land } \\
\text { Animal Life } \\
\text { Green Leaves as Food } \\
\text { Factories } \\
\text { Flies }\end{array}$ & $\begin{array}{l}\text { The Work of Running } \\
\text { Water } \\
\text { Roots of Plants } \\
\text { Aphids and Their Rela- } \\
\text { tives } \\
\text { Carnivorous Plants }\end{array}$ \\
\hline
\end{tabular}

\section{GRADE IV (AUTUMN)}

Unit 1. Butterflies ${ }^{7}$ (film title, Butterfies)

The study of butterflies should be pursued either in early autumn or late spring. Interest should be maintained throughout the year so as to secure first-hand knowledge regarding the entire life-history of this insect. The sound film gives the complete life-history together with interesting activities of two common butterflies, the swallow-tail butterfly and the cabbage butterfly. The unit, however, treats of a great number of butterflies common to the United States. It is suggested that only those be considered that are to be found in the immediate vicinity of the community. Generalizations suggested for emphasis:

Struggle for Existence

Balance in Nature

Propagation of the Species ${ }^{8}$

${ }^{7}$ As stated previously, there is a unit of instruction, or teacher's handbook, already prepared for each of the proposed units.

${ }^{8}$ See pp. 153-54. 


\section{HOW TO USE THE EDUCATIONAL SOUND FILM}

\section{Unit 2. Seed Dispersal (film title, Seed Dispersal)}

The study of seed dispersal is most desirable in the autumn when this phenomenon can be observed in nature. The sound film that accompanies this unit presents a wide variety of methods by which seeds are scattered. Many seeds are carried by the wind, either as a result of a parachute arrangement on the seed, or by wings. Others attach themselves by means of hooks or spikes to the fur of animals. Most seeds have some device by which they are attracted to the most favorable environment for germination. The film concludes with a brief treatment of the germination of seeds. Generalizations suggested for emphasis:

Propagation of the Species

Survival of the Fittest

\section{Unit 3. Animals of the Zoo (film title, Animals of the Zoo)}

The unit, which may be studied at any time of the year, is most opportune during the visit of the circus or during the winter when the season is less suitable for other units. Both the unit and the film treat primarily of large mammals from all parts of the world. Although the unit suggests integrating the study with the zoo, it may in some localities be desirable to develop the unit around the circus. Carefully selected still photographs and slides will contribute much to this unit. The film portrays the following animals in their characteristic activities: Siberian tiger, Tasmanian wolf-dog, eland, giraffe, bison, hippopotamus, rhinoceros, gorilla, chimpanzee, lemur, sea lion, black bear, and polar bear. Generalizations suggested for emphasis:

Adaptation

Tree of Life

\section{GRADE IV (SPRING)}

\section{Unit 4. Growth of Plants (film title, Plant Growth)}

This unit surveys living plants-their growth, reproduction, and adaptation. The film portrays the life-history of a pea plant from the first sprouting of the seed through its growth, blossom stage, pollination, development of seed, and, finally, the dispersal of the seed to start a new generation. Generalization suggested for emphasis:

Unity in Nature

\section{Unit 5. Invertebrate Animals of Beach and Sea (film title, Beach and Sea Animals)}

The unit of instruction considers three groups of beach and sea animals from the standpoint of reproduction, protection, methods of locomotion, and other habits and activities. Three groups are the echinoderms, including sea urchin, sea cucumber, starfish, and brittle star; the mollusks, in- 
cluding snail, slug, whelk, oyster, clam, mussel, scallop; and the crustaceans, including crab, crayfish, shrimp, wood-lice, sand-hopper, waterflea, and barnacle. About a dozen of the more important of these beach and sea animals are presented in the sound film Beach and Sea Animals in typical activities as locomotion and feeding. Generalizations suggested for emphasis:

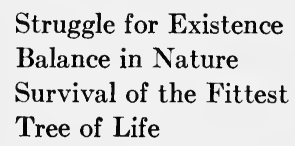

\section{Unit 6. Amphibians (film title, The Frog)}

The unit is devoted to the more common species of frogs, toads, and salamanders. The sound film, however, presents the complete life-history of the common frog, from the jelly-like mass of eggs to the mature frog. Consideration is given to its growth, its change from a water animal to a land animal, and its peculiar methods of locomotion and feeding. Generalizations suggested for emphasis:

Propagation of the Species

Struggle for Existence

Adaptation

Uniт 7. Мотнs (film title, Moths)

The study of moths should be closely integrated with the unit on butterflies. If butterflies are studied in the fall, chief emphasis in the study of moths should be placed on their form and nature during the winter, the emerging of the adult in spring, and the laying of eggs. The sound film treats comprehensively the life-stories of two common moths-a giant silk moth, and the white-marked tussock moth. Generalization suggested for emphasis:

Inviolability of Natural Laws

\section{Unit 8. Spiders (film title, Spiders)}

In the study of spiders on the fourth-grade level, the chief emphasis should be devoted to the study of the web, its construction, form, and function. In the sound film Spiders, four types of webs are portrayed, together with the habits and characteristics of the spiders that weave these webs. These spiders are the garden spider (which builds an orb web), the nursery-web spider, the trap-door spider, and the funnel-web spider. Generalizations suggested for emphasis:

Struggle for Existence

Balance in Nature 


\section{GRADE V (AUTUMN)}

\section{Unit 1. Beetles (film title, Beetles)}

The sound film reveals three common beetles: the tiger beetle, the Japanese beetle, and the ladybird beetle. The Japanese beetle is now a serious menace in all the central Atlantic states and is rapidly spreading into the surrounding states. The unit on beetles describes the life-history and economic importance of several common beetles, and the peculiar habits and features of many of them. Among those included are the ladybird beetle, tiger beetle, Colorado potato beetle, Japanese beetle, sacred scarab beetle, firefly, pea-weevil, bean-weevil, May beetle, rose beetle, carrion beetle, dytiscus beetle, and whirligig beetle. Generalizations suggested for emphasis:

\section{Breeding and Culture}

Photosynthesis

Balance in Nature

\section{Unit 2. Mushrooms and Other Fungi \\ (film title, Fungus Plants)}

It is usually desirable to study fungus plants during the early autumn. The unit of instruction on mushrooms and other fungi gives consideration to the life-history of these parasitic plants and compares them to other plants with respect to food sources, reproduction, and structure. Some attention is given to the economic importance of fungus plants, their value to man, and also their danger. The mushrooms featured are field, shaggy-mane, ink-cap, and deadly amanita. The other fungi discussed are puffballs, morels, shelf-fungi, molds, rusts, smuts, mildews, lichens, and a few miscellaneous plant diseases. The sound film that accompanies the unit portrays, by microscopic and stop-motion photography, the growth and structure of several fungi. Animation contributes to an explanation of their method of reproduction. Generalizations suggested for emphasis:

Propagation of the Species

Tree of Life

\section{Unit 3. How Nature Protects Animals (film title, How Nature Protects Animals)}

The unit of instruction considers the several methods of protection that can be found in the animal kingdom. Chief emphasis is devoted to protective coloration, which is illustrated among birds, fishes, amphibians, reptiles, moths, and insects. The other methods of protection explained are: armor, keen senses, mimicry, agility, arms, odor, migration, homes, and hibernation. The sound film presents the following animals as they exhibit their protective devices-rabbit, raccoon, giraffe, tiger, lion, zebra, 
horse, goat, kangaroo, echidna, magpie, warbler, woodpecker, tree creeper, shear-water, water hen, pheasant, grouse, chameleon, hawkmoth caterpillar. Generalizations suggested for emphasis:

Survival of the Fittest

Adaptation

\section{Unit 4. The Earth's Rocky Crust ${ }^{9}$ (film title, The Earth's Rocky Crust)}

The film and the unit are well integrated. Both consider the earth in relation to the universe; the formation of the earth's crust by the action of volcanoes; sedimentation; earth movements that result in earthquakes; and ways in which rocks are broken up to form soil. Generalization suggested for emphasis:

Diastrophism

Unit 5. The Forces That Wear Away the Land ${ }^{10}$

(film title, The Wearing Away of the Land)

The unit and the film consider the chemical decomposition of rocks; the rock or soil formations responsible for springs and wells; the nature of underground caves; the work of glaciers, the wind, and the ocean in wearing away the earth's crust. Generalization suggested for emphasis:

Inviolability of Natural Laws

Gradation

Unit 6. Animals and Their Functions ${ }^{11}$

(film title, Animal Life)

The unit and the sound film present a survey of several widely different types of animal forms, including sponges, coelenterates, echinoderms, worms, mollusks, crustaceans, insects, and vertebrates (fishes, amphibians, reptiles, birds, and mammals). Some attention is also devoted to the physiology of animal life. Generalization suggested for emphasis:

Tree of Life

\section{Unit 7. Leaves of Plants (film title, Leaves)}

The unit on leaves of plants includes a consideration of several forms of leaves, their relation to the plant itself, and their specific function - that of manufacturing food. Extensive use is made of animation to explain the process of photosynthesis. Generalizations suggested for emphasis:

Photosynthesis

Conservation of Energy

${ }^{9}$ This film is one of the "Harvard University Natural Science Series." The unit of instruction is found in Philip J. Rulon, The Earth and Its Life (Cambridge: Harvard University Press, 1932), chap. i.
in Ibid., chap. ii.
${ }^{11}$ Ibid., chap. v. 
Unit 8. Flies (film title, The House Fly)

The sound film portrays the life-story of the common house fly, with special emphasis on the relationship of the house fly to health and hygiene. The unit in addition takes up other members of the two-winged (diptera) group of insects. Generalization suggested for emphasis:

Unity in Nature

\section{GRADE VI (AUTUMN)}

\section{Unit 1. Flowers: Parts and Functions (film title, Flowers at Work)}

The unit of instruction on flowers surveys various types of flowers, their importance to the plant, their methods of pollination and fertilization, together with unusual devices and methods in achieving pollination and fertilization. The sound film utilizes animated drawings to contribute to an explanation of these processes. The flowers revealed in the film include the snowdrop, spider wort, monkshood, snapdragon, poor man's orchid, lupin, meadow sage, cornflower, daisy, dandelion, globe thistle, carline thistle, and the everlasting. Generalizations suggested for emphasis:

Propagation of the Species

Adaptation

\section{Unit 2. Parasitic Flowering Plants (film title, The Dodder)}

During the study of this unit, comparison should be made with a typical green plant, such as the pea plant in the unit "Growth of Plants," to note the major differences. The unit of instruction includes a consideration of several plants that are parasitic (without green leaves), but that do have flowers. Among these plants are: the dodder, beechdrop, pinedrop, pinesap, mistletoe, and Indian pipe. The sound film, however, treats exclusively (hence comprehensively) of the dodder, which is probably the most prevalent of this group of plants. Time-lapse photography is employed throughout to show the growth movements. Generalizations suggested for emphasis:

Struggle for Existence

Adaptation

Unit 3. Aquatic Insects (film title, Pond Insects)

The unit on aquatic insects describes the life-story, the peculiar habits of reproduction, locomotion, struggle for existence, and the method of securing food, of those insects that spend their larval, and sometimes their pupal stage, in ponds or marshes. The unit includes consideration of the May-fly, dragon fly, diving beetle, whirligig beetle, back swimmer, water 
scavenger beetle, giant water bug, water strider, water scorpion, mosquito, crane fly, midge, caddis fly, and stone fly. The sound film treats specifically three common water insects-the water beetle, the May-fly, and the dragon fly. Generalization suggested for emphasis:

Adaptation

Unit 4. Microscopic Pond Life (film title, Tiny Water Animals)

This unit gives major consideration to the one-celled organisms that are to be found in fresh-water ponds or stagnant marshes. The sound film surveys many of these organisms, such as rotifers, protozoa, chilodon, nematode, swan animalcule, stentor, volvox, paramecium, amoeba, and desmid. Because of their small size all of these are shown by microcinematography. Many of the scenes are remarkable in their pictorial quality. There are possibilities of excellent integration with the unit on aquatic insects. Generalizations suggested for emphasis:

Tree of Life

Propagation of the Species.

Unit 5. Stimulus and Reaction in Living Organisms ${ }^{12}$ (film title, Reactions in Plants and Animals)

The unit and the sound film are closely integrated. The film presents a demonstration of the irritability of protoplasm, the nature of this reaction, and types of reactions, such as geotropism, phototropism, stereotropism, and several other higher forms. Generalization suggested for emphasis:

Inviolability of Natural Laws

\section{GRADE VI (SPRING)}

Unit 6. Water and ITS WORK ${ }^{13}$ (film title, The Work of Running Water)

The unit and the film, which is one of the "Harvard University Natural Science Series," are closely integrated. The film shows vividly the action and power of running water, and its ability to erode stream beds. Some of the geological forms resulting from the water action, such as river valleys, deltas, floods, are presented. Special attention is given to soil and its conservation. Generalization suggested for emphasis:

Gradation

\section{Unit 7. Roots of Plants (film title, Roots of Plants)}

The unit and the sound film explain the various forms of roots and their several functions in respect to the rest of the plant: anchoring the plant,

${ }^{12}$ Ibid., chap. viii.

${ }^{13}$ Ibid., chap. iii. 
and absorbing water and minerals. A short demonstration in the film, involving both an experiment and animation, explains the process of osmosis. Generalization suggested for emphasis:

Tree of Life

Unit 8. Aphids and Their Relatives

(film title, Aphids)

The unit and the educational sound film explain in detail the complete life-story of aphids. Microscopic photography is employed almost throughout the entire film. Both the unit and the film reveal the economic significance of this group of insects in destroying plants and crops. Methods of controlling the insect are demonstrated in the film and discussed in the unit. Generalizations suggested for emphasis:

Breeding and Culture

Unity in Nature

Unit 9. Carnivorous Plants (film title, Plant Traps)

Two types of carnivorous or insectivorous plants-the sundew and pitcher plants-are discussed in the unit and shown in the sound film. The value of this unit lies in the fact that it reveals a most unusual form of adaptation in the vegetable kingdom. Generalization suggested for emphasis:

Adaptation

\section{OPTIONAL UNITS}

If a somewhat broader scope is desired in this course, or if a greater number of units is desired, the following units are suggested. Illustrative materials in motion pictures, slides, and specimens should be used whenever possible.

Unit 1. Birds.-The study of birds should center around their economic significance, nesting habits, food habits, mating, rearing of young, migration, and identification of local birds. Colored slides and pictures will be found helpful.

Unit 2. Fish.-A unit on fish may include a study of the process of reproduction, food habits in connection with the balance in nature, and identification of local fresh-water fish and food fish sold in local markets.

Unit 3.-Magnets and Electricity.-The subject of electricity must, of course, be limited to elementary principles on this level. Experiments may be undertaken with magnets, frictional electricity, dry cells, door bells, and small motors. Some attention may be given to the dangers of defective wiring.

Unit 4.-Fire.-A unit on fire on the elementary level may include a brief historical review of methods of producing fire, what happens chemi- 
cally when wood, oil, or coal burns, the principles and use of fire extinguishers, and dangers of spontaneous combustion.

Unit 5. The Heavenly Bodies.-It is possible to give many of the elementary facts and laws of astronomy even on the elementary level. Consider the sun, moon, stars, constellations, planets, meteors, from the standpoint of their nature, their movements, and their distribution in space.

Unit 6. Light.-On the elementary level the study of light may be centered around sources of light, transmission of light, use of lenses and prisms and the basis of colors, in relation to light waves.

Unit 7. Sound.-The elementary study of sound may include a survey of sound sources, musical instruments, the nature of sound, and speed of sound in air.

\section{SUGGESTED PROCEDURE IN TEACHING THIS COURSE}

Each of the units of instruction and the films briefly described in the preceding section is related in some way to one or more of the other units. All the plant units are more or less closely integrated. In introducing new units the teacher may take advantage of the interest developed in previous units. If the study of butterflies precedes the study of moths, the nature of the four-stage metamorphosis will already be well known. The time may therefore be devoted to other aspects of the unit. But even more important is the integration of all the units so as to achieve the major objectives of the course.

Before beginning any unit of instruction, the teacher should become thoroughly familiar with the subject-matter content. An understanding both of the concepts involved and of their application in the world of nature will enable the teacher to develop in the pupils a driving interest in the unit at the very start. The teacher may introduce the units by displaying specimens in the classroom, by reading or relating some interesting story, and by screening the accompanying film, following it immediately by a discussion period.

The handbook for each unit suggests a number of activities that may be pursued. In the bibliographies, readings suitable for the pupils are listed.

The teacher should understand, and should make clear to the pupils, certain motion-picture techniques that are used extensively in this series of films, such as microphotography, animation, slow-motion photography, and time-lapse photography. The explanation of these techniques should be adapted to the level of understanding possessed by the pupils.

Microphotography. - The motion-picture camera is attached to a microscope. Objects that are invisible to the eye can thus be made to appear large on the screen. 
Animation (the technique used in making movie cartoons).-Animated scenes are obtained by photographing a series of drawings.

Slow-motion.-Ordinarily the motion-picture camera photographs, and projector screens, twenty-four frames or individual pictures every second. If the camera is speeded up to photograph forty-eight or seventy-two pictures every second, and if the resulting film is then screened at the regular twenty-four frames per second, the action will appear to be slower than the action of the original object. In other words, what the camera recorded in one second may be lengthened to two, three, or even more seconds on the screen depending upon the camera speed used.

Time-lapse (also called "stop-motion").-The opposite of slow-motion. Instead of taking twenty-four pictures or frames per second, the camera may be slowed down to photograph sixteen, twelve, or even one a second. In fact, if the action is very slow, such as the growth of a plant, a frame or picture may be taken every minute, or even at five-, ten-, and fifteenminute intervals. A picture every minute makes the action $1440(24 \times 60)$ times slower than the normal action. When a film made in this way is projected on the screen at twenty-four frames per second, the action occurs faster than in real life.

The teacher should by all means permit the pupils to see a strip of a motion-picture film so that they may secure some notion of how motion pictures operate. The pupils may study the difference between consecutive frames.

The film should be screened a second time after the unit is well under way and when the pupils have developed a greater background. The second showing will add considerably to the pupils' understanding of the concepts thay have been studying, and will suggest new problems for investigation.

Shown a third time as one of the culminating activities of the unit, the film will draw together and crystallize as an integrated whole the various concepts and ideas that the pupils have established in the study.

\section{SUGGESTED FACILITIES}

Though not essential, it is desirable that a special room in the elementary school be set aside and planned specifically for science instruction. The following furniture, equipment, and features should be secured (the starred [*] items are indispensable in this course):

Movable tables and chairs

*Much bulletin-board space

*One slab of blackboard

Storage cabinets

Filing cabinets

*Book shelves or cases
*Access to a 16-mm. sound projector

${ }^{*}$ Motion-picture screen $(4 \times 6)$

*Access to the twenty-five educational motion pictures

*The "Units of Instruction" accompanying the foregoing films 
*Display cases

Storeroom

*Sun window or alcove

Insect-catching net

Reference books for the teacher

*Science books for the pupils

Good artificial illumination

Electric outlet for the projector

*Opaque window shades
*Window flower boxes

Running water

Gas outlet

Large aquarium

*Battery jars

*Terrarium

Animal cages

Microscope

${ }^{*}$ Hand lenses

In addition, a variety of supplies will be required, such as drawing paper, paints, brushes, crayons, wire screening, soil, sand, etc.

There are several courses of study for science in grades IV, V, and VI with which the teacher should become familiar, particularly those used in Pittsburgh, Denver, St. Louis, and Horace Mann School, Columbia University.

The following books will be found to contain valuable reference material for the teacher:

Arnspiger, V. C. Measuring the Effectiveness of Sound Pictures as a Teaching Aid. New York: Bureau of Publications, Teachers College, Columbia University, 1933.

Brodshaug, Melvin. An Analysis of Activities and Objectives in Science for Grades 4, 5, and 6. (Unpublished.) New York: Erpi Picture Consultants, Inc.

Comstock, Anna Botsford. Handbook of Nature Study. Ithaca: Comstock Publishing Co., 1929.

Curtis, Francis D. Digest of Investigations in the Teaching of Science in the Elementary and Secondary Schools. Philadelphia: P. Blakiston's Son \& Co., 1926.

- A Second Digest of Investigations in the Teaching of Science. Philadelphia: P. Blakiston's Son \& Co., 1931.

Craig, Gerald S. Certain Techniques Used in Developing a Course of Study in Science for the Horace Mann Elementary School. New York: Bureau of Publications, Teachers College, Columbia University, 1927.

Downing, ElLiotr R. Our Living World. New York: Longmans, Green \& Co., 1930.

Lutz, Frank E. Fieldbook of Insects. New York: G. P. Putnam's Sons, 1930.

Morrison, Henry C. Practice of Teaching in the Secondary School, chap. xi. Chicago: University of Chicago Press, 1931.

National Society for the Study of Education, 31st Yearbook, Part I. A Program for Teaching Science. Bloomington, Illinois: Public School Publishing Co., 1932.

Rulon, Philuip J. The Sound Motion Picture in Science Teaching. Cambridge: Harvard University Press, 1933.

- The Earth and Its Life. Cambridge: Harvard University Press, 1932. Chapter One.

Transeau, Edgar N. General Botany. Yonkers-on-Hudson: World Book Co., 1929. 


\section{SUGGESTIONS FOR THE PUPILS' BOOK SHELF}

Duncan, F. Martin and L. T. “Wonders of Insect Life." New York: Oxford University Press.

The following individual booklets are available in this series: Butterfies and Moths; Bees, Wasps and Ants; Beetles and Flies; In Pond and Stream; Some Curious Insects; Spiders and Scorpions.

. "Wonders of Plant Life." New York: Oxford University Press.

The following individual booklets are available in this series: The Story of Plants; Plants and Their Children; Land and Water Plants; Plant Traps and Decoys; Some Curious Plants; Plant Friends and Foes.

. "Wonders of the Sea." New York: Oxford University Press.

The following individual booklets are available in this series: Wonders of the Shore; The Lobster and His Relations; The Star-Fish and His Relations; Dwellers in the Rock-Pools; Life in the Deep Sea.

Craig, Gerald S., and others. Pathways in Science (Books III, IV, V, and VI). New York: Ginn \& Co., 1932.

Nida, William L. and Stella H. Science Readers (Books IV, V, and VI). New York: D. C. Heath \& Co., 1926.

Payne, E. G., Barrows, H. R., and Schmerber, L. J. Elementary Science Readers (Books I, II, III, and IV). Boston: Benj. H. Sanborn \& Co., 1930.

Patterson, Alice Jean. Nature Study and Health Education (Fourth, Fifth, and Sixth Years). Normal, Illinois: McKnight \& McKnight, 1927.

Persing, Ellis C., and others. Elementary Science by Grades (Books III, IV, V, and VI). New York: D. Appleton and Co., 1929.

In addition, much science material will be found in suitable encyclopedias, such as The World Book, Compton's Pictured Encyclopedia, and The Book of Knowledge. Other reference books are listed in the handbooks for the individual units. 


\section{INDEX}

Ability level, adjusting film use to, 45 Acoustic problems, 127

Acoustic treatment, 125, 130-31, 134

Activities after film use, 19, 21-23, 30, 33-36, 64-69

Adaptation to environment, unit, 55

Adapting film to pupil interests and abilities

fitting film to grade level, 46-47

relating film to other school experiences, 48

utilizing the environment, $\mathbf{4 7 - 4 8}$

Adapting film showing

interrupted showings, 56-57

questions during showing, 57-58

showing part of film, 60-61

silent projection, pupil comments, 5960

silent projection, teacher comments, 58-59

Adjustments to projector, 123

Administration

film program, 9-10, 73-88

films, study of, 77-78

Administrative organization, film program (chart), 87

Adult education, possible use of films for, 40,128

Aids to learning, classified, 2

Aids to Teaching in the Elementary School, 109

Air conditioning, 130

Animal Life, 48

Animals of the Zoo, 15-16, 21-23, 48, $53,55,58,67-68,70,91$

Animated drawings and diagrams, 4

Aphids, 64-65, 92

Appreciation of film medium, 99

Arnspiger, V. C., 3, 108

Art of Teaching by Radio, The, 109

Art work, 26, 31, 58, 68

Assembly, use of films in, 16-17, 33-38, 57

Assignments, before film showing, 50-51 At the Zoo, 23
Attention-directing devices, 4

Audio-visual aids

catalogues of, 93

classified, 76

effective use of, 75

integration with courses of study, 106-7

inventory, 88

selection and integration with curriculum, 88-94

survey of, 76

teacher's skill with, 77

Audio-visual instruction

course in, 100-108

program of, 75

references on, 108-9

Audio-visual instruction program administration, 77-79

committee for studying, 78-79

described, 10, 74-75

large school system, 78-80, 85-88

organizing the services for the, $83-88$

procedures (chart), 80

small school system, 84-85

use of existing staff, 83-84

Audio-visual studio, 127-34

plan, 129

Auditorium

sound-film equipment for, 115,117

use of films in, 13, 17-23, 50, 52-53, 70-71

use for instruction, 94-95

Balance in Nature, unit, 27

Beach and Sea Animals, unit, 47, 52, 67-68, 91

Bees, unit, 25-26

"Better Films" group, use of films in, 41

Biology teacher, 84

Blackboard, use of, 13, 17, 20, 22, 51, $52,62,63$

Board of education, 79

Booth, motion picture, 125, 128

Borrowing films, 90

Boston University, 102

Brass Choir, 26, 51, 53

Butterflies, 68 


\section{HOW TO USE THE EDUCATIONAL SOUND FILM}

Camera angles, 4

Care of films, 140

Catalogue, audio-visual aids, 93

Ceilings, acoustically treated, 125

Central film library, 84

Choosing Your Vocation, 37, 51

Cinematographic techniques, types of, 4

Circulation of equipment, 120, 122

Circus Fun, 23

Classroom Pets, unit, 48

Classroom plan, 126

Classroom projects, 54,55

Classroom, working tools of, 1-2

Classrooms

adaptations for projection, 123-34

equipped for projection, required number, 125-26

sound-film equipment for, 115,117

Club programs, use of films in, 32-33

Collections, 68

College, use of films in, 18, 28, 32, 47, 125

Community project, $47-48$

Community use of films, 40-41

Composition, the sound film as an aid to, $22,24,25,30,51,68$

Continuity of thought, in sound film, 3-4

Converter, 122, 123

County school system, traveling operator, 122

Course of study

analysis of, 10, 75-76

initiating new, 38

Course of study committees, 91

Crawford, E. W., 97

Curriculum, films integrated with, 4-5, 73-74, 91-93

Curriculum revision, 108

Curriculum specialist, 85, 87

Curtains, 123, 127, 132

Damaged film, replacement of, 140

Damrosch radio concerts, 26

Delivery service, 87

Demonstration lessons, 106-7

Department of audio-visual instruction, $83,85-88$

Department of visual instruction, 80, 97, 137,139
Departmental study, film use, 102

Development of Transportation, The, 8, 29-30, 45, 68

Devereux, Frederick L., 4, 83, 108, 115, 131

Diagrams, use of, 52

Direct current, 122-23

Director Guides Teachers in Use of Visual Aids, 97

Director, part-time, 85

Director of visual instruction, 80, 91, 97-98

Discussion

after film showing, 31, 61-64, 69

before film showing, 48

purpose of, 61-62

references to the film in, 62

stopping projection for, 57

types of, 62-63

Distribution of films, $10,78,84,137-39$

Dorris, A. V., 109

Dramatization, 21-23, 52-53, 67

Drill cards, 20

Dynamo, 123

Earth's Rocky Crust, The, 27, 89

Educational methods, film production, 5

Educational Screen, The, $\mathbf{9 7}$

Educational sound film

activities, related, 19, 21-23

administration, co-ordinated with, 74

appreciation of, 103, 104

assembly programs, use in, 33-38

club programs, use in, 32-33

flexibility of use, 11-12

functions of, $5-8$

initiating courses of study, 38

integrating with curriculum, 4-5, 28, 91-93, 104-5

nature of, $3-5$

other materials of instruction, relation to, 7, 103

parent-teacher association, use in, 40-41

planning use of, 12-15

previewing, 27, 50, 81-82, 89-91

principles of use, 99

projection, facilities for, 123-34

purposes for use of

direct instruction, 19-23

enriching a unit, 24-27

initiating a unit, 16-19

objectives, illustrated, 15-16 
Educational sound film-continued purposes for use of-continued organization of subject matter, as illustration of, 26-27

review, 29-31, 62 survey, orientation, $18,19,27-29$ rating, 104 repeating film showings, $31,43-44,47$, $50,60,65,69$

research in, 3

selection, 25, 88-91, 94

special projects, use in, 32-33

standards for, $4-5,88,104$

study of, 3, 9, 98-100, 103-9

teachers' relation to, $8-9,11-12,38$

teacher-training project, $38-40$

techniques of film use

adapting the film showing, 56-61

adjusting film to pupil interests and ability, 44-49

introducing film showing, 49-56

teaching activities after showing, 61-69

Educational Talking Picture, The, 4, 83, 108,115

Educational versus entertainment films, 70

Eighth Yearbook of the Department of Supervisors and Directors of Instruction, 2

Electrical outlets, 123, 127, 130, 134

Electrical power supply, 122

Electrostatics, 17-18, 30, 36, 59, 67, 92

Elementary school, use of films in, 15$17,18-27,30-36,45-48,51-55$, 57-71, 90

Elementary-science course of study, 9192, 95, 108

Elf Band, The, $\mathbf{3 4}$

Energy and Its Transformations, 68

Englewood Junior High School, 81

English, use of films for, 24-25

Entertainment films, 37

Environment, used in developing interests, 47-48, 51

Equipment, minimum standard, 93-94

Equipment, sound-film

circulation of, 117, 135-39

maintenance, 87, 119-20, 122-23

operation of, 117-23

required number of, 117

selection, standards for, 116-17

16-mm. compared to $35-\mathrm{mm}$., 115
Erosion, unit, 89

Erpi Picture Consultants, Inc., 107

Errors in film use, 46, 70-72

Evansville, Indiana, 85

Evening social hour, use of films in, 3738

Exhibits, in connection with film use, 30-31, 37-38

Experimentation with film uses, 99-100, 102

Experiments, in film units, 30-31, 54, 68,69

Extension course, 101

Extra-curricular projects, 75-76

Faculty study project, 102, 103

Field trips, 54-55

Film analysis, illustration of, 89

Film catalogues, 81-82

Film content, leading questions on, 50

Film curriculum committee, 84-85, 91

Film damage, 119, 121

Film distribution, 10, 78, 84, 137-39

Film guide, 90, 93

Film interpretation, written by pupils, 59-60

Film-lesson plans, making, 106, 108

Film-lesson procedure, types of, 42

Film library, 81, 88, 100, 135-39

Film manual, use of, 36, 69, 71

Film previews by teachers, 121

Film program

illustrations of, 79-95

large school system, 79-80, 85-88

nature of, 10

planning the, 79-83

single school, 80-83

small school system, $80,84,85$

stages of, 79

Film requisitions, 90, 135-37, 139

Film-reviewing committee, 90

Film re-wind bench, 140

Film schedule, 135

Film-splicing outfit, 140

Film storage, 78

Film teaching

acquiring skill in, 8,9

adaptive use of sound film, 14-15

creative planning, 14

criteria for, 42-43 


\section{HOW TO USE THE EDUCATIONAL SOUND FILM}

Film teaching-continued

errors in, 70-72

evaluation of, 108

experimentation, $99-100$

methods, how to overcome deficiencies in, 72

practice in, 108

procedures, classified, 16

purposes, classified, 15

scope of, 98

supervised practice in, 108

supervision of, 110-13

Film unit, an integrated experience, 14

Films

budget for, 90

care of, 87,140

central library, 78

circulation of, 78

distribution of, 135-39

grade placement of, 91

integration with the curriculum, 8994

policy for purchasing, 94

previewing, 89-91

records of, 87, 141

rental of, 90

selection of, 88-91

showing of

facilities for, 10

too many films, 70

unrelated films, 70-71

at wrong time, 71

storage of, 139-41

Flowers at Work, 19, 26, 31-32, 35-36, 54

Focusing attention upon film elements, $51-52$

Frequency of film showing, 43-44

Frog, The 18, 25, 29, 52-53, 62, 68

Fungus Plants, 19, 30-31, 36, 71, 92

Garden club activities, 32

Gardening course, use of films in connection with, 41

Generator, 123

Geography, use of films, for, 67,68

Grade level, fitting the film to, 46-47

Graduate study, 102

Graduation exercises, use of films in, 37

Handbook for the Use of Visual Aids, 112

Heating and ventilating unit, 132-34

Hobby shows, 33

How Nature Protects Animals, 26, 35$36,48,52,55,69-70,91-93$
Individual assignments, 51

Individual interests stimulated by films, 32-33

Insects, unit, 64-67

Instruction

conditions for, 73-74

developing new areas and modes of, 94-95

limitations of, 1

Instructional materials, types of, 2

Integration

films with curriculum, 4-5, 28, 91-93, 104-5

science with English, 28

Interne teacher, duties of, $\mathbf{8 4}$

Interrupted showings, 56-57

Introducing use of film

advance assignments, 50-51

dramatization, 52-53

leading questions, 50

preparatory teaching, 51-52

use of other aids, 53-54

Introduction to film, types of, 49-50

Jack and Jill in Songland, 34-35, 53, 67

Junior college, use of films in, 18, 32

Junior high school, use of films in, 13, $17-19,26,30-31,36-37,50-52,57$, $59,62-63,68$

Junior high school film program, 81-83

Kindergarten use of films, 35

Koon, Cline M., 109

Kuhlmann, W. D., 81

Large-group instruction, use of films in, $13,17-23,33,50,62-63,94-95$

Large-Group Instruction through the U'se of Visual Aids, 13

Large school system, 79, 85, 93

Learning

after film showing, 6-7

during film showing, 6

from sound films

nature of, 5-6

training for, 7-8

Learning activities in a film unit, 69 initiation of, 62

Lighting, control of, 125, 127-28, 134

Loudspeaker, 125, 128, 133-34

Lubrication, schedule for, 123 
Maintenance, 16-mm. equipment, 11920, 122-23

Manipulating the film showing, 56-61

Manual of operation, 119

Manuals, film, 36, 69, 71

Materials of instruction

classified, 2

function of, 1

selection of, 74

Materials of Instruction: Eighth Yearbook, Department of Supervisors and Directors of Instruction of the $\mathrm{Na}$ tional Education Association, 109

Measuring the Effectiveness of Sound Pictures as Teaching Aids, 3, 108

Mechanical problems, film use, 114

Microcinematography, 4, 8

Microphone, use of, 50

Micro-projector, 69

Minimum standard equipment, 93-94

Molecular Theory of Matter, 18, 26, 68

Moths, 47-48, 55-56, 92

Moths and Butterflies, unit, 47-48

Mountain Building, 107

Music, use of films in, 24, 26, 32-35, 37, $40,51,53,67$

New York University, 102

Noon-hour program, films for, 37

Normal school use of films, 26, 27

Objectives aided by film use, illustrated, $15-16$

Objects and specimens, creating interest with, 54

Oiling projectors, 119, 123

Operation of $16-\mathrm{mm}$. sound-film projectors

competence required, 119-20

description of, 118-19

operation service, 117-18

special projectionist, 120-22

teacher and student operators, 82, 119-21

training in, 119-21

Operator's licenses, 123

Oral composition, 67

Organizing an audio-visual program, problems of, 73

Organizing knowledge, use of film for, 30-31
Organizing new activities after the film showing, 67-69

Organizing services, film program, $83-88$

Original songs, composition of, 67

Our Town, 34-35

Parent-teacher meetings, 40-41

Pennsylvania State Course of Study in Science-Grades Four, Five and Six, 92

Percussion Group, The, 38

Photoplay appreciation, 95

Physics class, film use in, 31

Pictures, use of, 22-23, 30, 53, 54, 67, 68,69

Pittsburgh, Pennsylvania, 112

Planning the film program, $10,79-83$

film unit, $12,13,45$

Plant Growth, 19, 26, 31-33, 44, 54, 92

Plastic modeling, 68

Platoon school, use of films in, 19-23, $52-53,94,128,139$

Poetry, in connection with film use, 23

Pond Insects, 27

Potwin, C. C., 130

Preparatory teaching, 51-52

Preparing for film use, 12-13

Preteaching

film outline, 46

words in film, 46-47, 52

Presenting part of film, 47

Previewing of films, 27, 50, 81-82, 89-91

Previous experience, adjusting film use to, 45

Primary grades, use of films in, 15, 34$35,47-48,52-53,55-56,58,67-68$

Primary Teacher at Work, The, 38, 41

Principal, supervisory function, 109-10

Principals, activities of, 80

Principals' meetings, topics for discussion, 110

Private school, use of films in, 28, 37-38

Program, audio-visual instruction (see Audio-visual instruction program)

Program for the Utilization of Audiovisual Teaching Aids, Evansville, Indiana, 88

Projection booth, 128, 130 


\section{HOW TO USE THE EDUCATIONAL SOUND FILM}

Projection, classroom adaptation for, 123-34

Projection facilities, 81, 106

Projection room, auxiliary use, 125, 131

Projection schedule, 82

Projectionist, 87, 120-22

Projector stand, portable, 127, 130, 133

Projectors, sound-film

circulation of, 117, 135-39

maintenance, 119-20, 122-23

operation of, 105-6, 117-23

required number of, 117

16-mm. compared to $35-\mathrm{mm}$., 115

standards for selection, 116-17

Projects, use of films in, 33

Protective coloration unit, 92-93

Pupil reactions during showing, 57

Purchase of films, 90

Purposes for which sound film may be used, 15-41

Questions and answers during the showing, $\mathbf{5 7 - 5 8}$

Questions, as key to showing, 50

Rating films, 90, 104, 106

Rating forms, 88-90

Reading, 30, 48, 54-55, 68, 69

Record form, sample of, 138

Records, film-distribution, 53, 82, 93, 137-39

References, audio-visual instruction, 83, 108-9

Relating the film to other school experiences, 48

Rental of films, 36-37, 90

Repairs, equipment, 123

Repeated showings, $31,43-44,47,50$, $60,65,69$

Requisitions, films, 81-82, 137, 139

Review

after film showing, 20

discussion as, 62

Review device, criteria for, 29

Reviewing, use of films for, 29-31, 59-60

Roots of Plants, 19, 31, 92

Rulon, Phillip J., 3

Rural school, use of films in, 29-30, $37,40-41,44,70-71$

Rural schools, power supply for, 122-23
Schedule record, 81

School administrator, functions of, 7374

School Executive, 125

School program, defined, 2

School projects, use of films in, 48

School supply truck, 136

Schools, different types, use of films in colleges, 18, 28, 32, 47, 125

elementary schools, 15-17, 18-27, $30-36,45-48,51-55,57-71,90$

junior high school, 13, 17-19, 26, 30$31,36-36,50-52,57,59,62-63$, 68

large school system, 79, 85, 93

platoon school, 19-23, 52-53, 94, 128, 139

private school, $28,37-38$

rural schools, 29-30, 37, 40-41, 44, 70-71

senior high school, 24, 29-31, 47, 69 small school system, 37, 40-41, 80, $83-85,102$

teacher training institutions, 26-27, 97, 102

Science survey course, 28

Science teacher, director of film program, 81

Science, use of films for teachers of, 26-27

Screen

permanently mounted, 125, 127-28, 133

portable, 127, 133

size of, 133

Seed Dispersal, 19, 27, 31, 92

Selecting film sequences for study, 47 , 60-61

Selection of films, 10, 25, 88-91

Senior high school, use of films in, 24, 29-31, 47, 69

Service contract, 123

Shades, opaque, 123-25, 127, 132

Showing of films. See Films

Single showing, 43, 71

Slides, use of, $13,17,28,50,57,58,62-63$

Slow-motion photography, 4,8

Small-group interests, 68

Small school system, 37, 40-41, 80, 8385,102

Socialized activities after film showing, 68 
Socializing Experiences in the Elementary School, 33

Sound component, types of, 4

Sound film, comparison with earlier visual aids, 3

Sound-film program, criterion for judging, 11

Sound Motion Picture in Science Teaching, 3

Soundproofing, 130

Sound Waves and Their Sources, 19, 24, $51,68,92$

Specimens, 69

Spiders, 16-17, 56, 60, 63, 68, 92

Spiders, unit, 63-64

Staff and functions, first stages of program (chart), 86

Staff, selection of, 77-78

Standards

educational sound film, 4, 5, 88, 104

for selecting sound-film projectors, 116-17

State regulations, film use, 140

Stock clerk, 87

Storage cabinets, 127-28, 134

Storage of films, 139-41

String Choir, The, 38, 58

Student operators, 118, 119, 121-22

Student-organization activities, 37

Students' notebooks, 69

Studio

acoustic conditions of, 134

audio-visual, 127-34

booth, 128

darkening facilities for, 132-33

heating and ventilating of, 134

lighting, 128

location of, 131

multiple use, 128, 131

seating arrangements, 132

special equipment for, 133

wiring, 128, 134

Study of Verbal Accompaniments to Educational Motion Pictures, A, 3

Summarizing after reviewing films, 30

Superintendent, functions, film program, 9-10, 74, 78-79, 84

Supervision of film teaching analysis of teacher's purposes, 111 points for discussion, 111-12 publication of film lessons, 112-13 skills required, 110-11

types of service, 97-98

use of film in unit, 111

Supervisor of elementary science, 138

Survey

use of films for, 27-29

visual instruction, 76

Teacher attitudes toward film use, 12

Teacher commentaries with silent films, 58,59

Teacher introduction to film, importance of, 49

Teacher planning, illustration of, 13

Teacher-training project, $38-40$

Teachers, planning local program, 78, 97-98

Teachers College, Columbia University, 102

Teachers college, use of films in a, 18-19, 26-28, 57

Teacher's function in film use, 9

'Teachers' meeting, film use discussed, 82

Teachers, operating projectors, 118-21

Teachers, previewing films, 89-90

Teaching after film showing completing activities, 64-67

discussion, 61-64 organizing new activities, 67-69

Teaching certificate, requirement for, 97

Teaching procedures with films, classified, 42,44

Teaching with films criteria for, 42-43

nature of, 11

Teaching with Sound films, 15, 44, 107

Techniques of teaching following film showing, 61-69

Tennessee Valley Administration Project, 27

Thirteenth Yearbook of the Department of Elementary School Principals: Aids to Teaching in the Elementary School, 2

Time-lapse photography, 4,8

Tiny Water Animals, 25, 38, 69, 92

Toy band, organization of, 67

Training course, teachers, 100-108

Training program, objectives, 98-100

Training teachers, methods of, 113

Transportation, 8, 29, 38, 45, 68 


\section{HOW TO USE THE EDUCATIONAL SOUND FILM}

\author{
Transportation \\ of films, 136-37 \\ unit on, 29-30 \\ Units \\ Adaptation to Environment, 55 \\ Balance in Nature, 27 \\ Beach and Sea Animals, 47 \\ Bees, 25-26 \\ Classroom Pets, 48 \\ Erosion, 89 \\ Insects, 64-67 \\ Jack and Jill in Songland, 34-35 \\ Moths and Butterflies, 47-48 \\ Protective Coloration, 92-93 \\ Spiders, 63-64 \\ Transportation, 29-30 \\ Vocational Guidance, 60-61 \\ Wild Animals, 21-23
}

Use of the film, preparation for, 12-13

Use of partially applicable film, 24
Variation of film use, 46

Visual aids study of use of, 76 use with sound film, 53-56, 64

Visual instruction courses, 96-97

Visual instruction department, 74,80 , 81-83, 97

Visual Instruction in the Public Schools, 109,115

Vocational guidance unit, 60-61

Wearing Away of the Land, The, 27, 70

Westfall, L. H., 3

Wild Animals, unit, 21-23

Woman's club, use of films by, 41

Work of Running Water, The, 12, 19-21, 27, 52,68

"World Fair," 48

Worrell, F. M., 13, 81 


